\title{
ESTUDO TEÓRICO-EXPERIMENTAL DO COMPORTAMENTO ELASTOPLÁSTICO DE POLIURETANO DERIVADO DO ÓLEO DE MAMONA (Ricinus communis)
}

\section{Amauri Bravo Ferneda}

Tese apresentada à Escola de Engenharia de São Carlos, da Universidade de São Paulo, como parte dos requisitos para a obtenção do título de Doutor em Engenharia Mecânica.

Área de concentração: Engenharia mecânica.

Orientador Prof. Assoc. Jonas de Carvalho

São Carlos 


\section{Dedicatória}

Dedico este trabalho a toda minha família:

À minha Esposa e minha Filha; ao meu Pai, minha Mãe, minha Irmã e meu Irmão os meus sinceros agradecimentos com amor, pelo incentivo.

Obrigado por existirem. Eu nada seria se não tivesse vocês. 



\section{Agradecimentos}

Manifesto meus humildes, honestos e sinceros agradecimentos:

A DEUS por ter me concedido saúde, proteção, sapiência, paciência, paz e inspiração para percorrer todo esse caminho (sem ELE nada seria possível);

A minha família pela paciência, amor, incentivo, cumplicidade e esperança;

Ao Professor Jonas de Carvalho por me aceitar como seu aluno, pela orientação e amizade de todas as horas.

Ao Professor Benedito de Moraes Purquerio pelo incessante auxílio e amizade.

Ao Professor Gilberto Orivaldo Chierice e ao Professor Salvador Claro Neto do Instituto de Química de São Carlos da Universidade de São Paulo (Departamento de Química e Física Molecular) pela cessão do biopolímero da mamona e pelo auxílio.

Aos Professores Dirceu Spinelli e Waldek Bose Filho do Departamento de Engenharia de Materiais, Aeronáutica e Automobilística por terem posto a disposição a máquina de ensaios EMIC para a realização dos ensaios experimentais assim como pela confiança depositada na utilização das dependências do laboratório.

Ao Professor Sérgio Persival Baroncini Proença pela constante disponibilidade e auxílio no transcorrer desta pesquisa.

Ao Professor Bello por disponibilizar gentilmente o equipamento de aquisição HBM.

Ao Professor Carlos Demarqui Junior pela amizade, disposição, auxílio e orientação na operação do sistema de aquisição HBM.

Ao Técnico e Mestre Cláudio Bigode pela disposição e auxílio na preparação dos experimentos com o sistema de aquisição HBM e amizade;

Ao Professor Benedito Di Giacomo pela confiança e auxílio na utilização das dependências do Laboratório de Metrologia em todas as medições que foram necessárias.

Ao Professor Elias Hage da Universidade Federal de São Carlos (Departamento de Engenharia de Materiais) por ter cedido a máquina de ensaios INSTRON para a realização de ensaios e ao Dr. Leonardo Bresciani Canto pelo auxílio na operação da mesma.

Ao Professor Volnei Tita pela amizade, disposição e auxílio constante;

Aos Professores Neilor César dos Santos, Romeu Rony Cavalcante da Costa e Rodrigo Bresciani Canto pela grande amizade, parceria, envolvimento e tudo mais que não caiba mencionar aqui. 
Ao Professor Geraldo Dantas Silvestre Filho pela amizade e parceria nos ensaios da haste de implante de quadril.

Ao Dr. Luiz Vareda pelo grande auxílio prestado na parte experimental com strain gages.

Ao pessoal do LAMAFE: Zé Carlos, Luiz, Alessandro Fiu, Adão, Botelho por todo o auxílio na usinagem de peças, aplicadores, moldes, matrizes, medições e etc.

A todos os amigos do LTC ainda não citados, pelo excelente ambiente de trabalho que sempre proporcionaram e que sempre mantiveram: Rogério Ikegami, Henrique Monaretti, Ricardo Angélico, Cláudia Camilo, Thaís Samed, Ricardo Andrade, Cláudio Torres, Gilberto Souza, Roni Carvalho, Marcio Marques, Maria Alejandra, Cassius Riul.

Ao pessoal das secretarias: Maragno, Cristina, Maragareth, Vilma, Ana Paula e seus auxiliares por todo apoio que sempre deram e pela amizade.

A todos os amigos que formei em São Carlos nesses anos pesquisa: Zilda de Castro, Pedro Noritomi, Carlos C. Elias, Mariano MeMoreno, Rodrigo Godoy, Rodrigo Stella, Sérgio Toddy Evangelista, Ricardo Hasegawa, Reginaldo Ré, Alessandro Marques, Fabiana, Gislaine, Kellen, Luciana Montanari, Luciane Cuca, Cláudio Bigode, Fabrício Flores, Wagner Jamanta, Beth, Alexandre Malavolta, e etc, que direta ou indiretamente me auxiliaram no trabalho e na vida quando me deram a honra de sua amizade.

Ao CNPq pela bolsa de estudos que me foi concedida.

À USP por toda a estrutura de trabalho disponibilizada. 


\section{LISTA DE FIGURAS}

FIGURA 2.1 - Protótipo de prótese de quadril para fabricação em biopolímero (Silvestre Filho, 2001)

FIGURA 2.2 - Comportamento elástico linear sob carregamento e descarregamento: curva tensão(s)-deformação(e) (adaptado de McCrum et al, 1992)

FIGURA 2.3 - Comportamento visco-elástico sob carregamento: Entrada (tensão x tempo);

Saída (deformação x tempo) (McCrum et al, 1992)

FIGURA 2.4 - Comportamento elasto-plástico sob carregamento e descarregamento: curva tensão(p)-deformação(x) (Williams, 1973)....

FIGURA 2.5 - Comportamento hiperelástico sob carregamento e descarregamento: curva tensão(p)-deformação(x) (Williams, 1973)

FIGURA 2.6 - Comportamento visco-elasto-plástico sob carregamento e descarregamento:

curva tensão(p)-deformação(x) (Williams, 1973) ....

FIGURA 2.7 - Representação esquemática da deformação de um polímero em nível

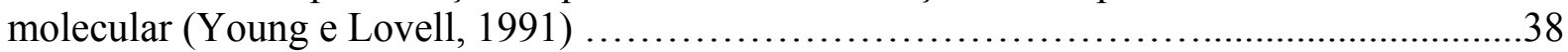

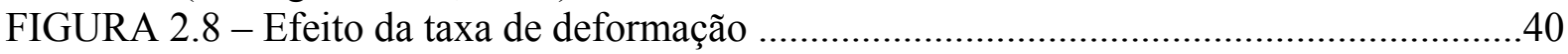

FIGURA 2.9 - Representação esquemática da resposta (R) para entrada (I) de polímeros

visco-elásticos: Fluência e Relaxação (Young e Lovell, 1991) ..............................................41

FIGURA 2.10 - O fenômeno de Recovery: (a) tensão x tempo; (b) deformação x tempo

(Williams, 1973)

FIGURA 2.11 - Superfície do Critério de Drucker-Prager: (a) no espaço das tensões

principais; (b) segundo os eixos dos invariantes de tensão (Hibbit et al., 2000) .....................42

FIGURA 2.12 - Representação geométrica do ângulo de dilatação (Hibbit et al., 2000) .......43

FIGURA 2.13 - Ensaios triaxiais: (a) compressão; (b) tração (Hibbit et al., 2000) ................44

FIGURA 2.14 - (a) Curvas tensão-deformação de ensaios triaxiais; (b) Superfície de plastificação obtida por interpolação (Hibbit et al., 2000) ....................................................4

FIGURA 2.15- Modelo de falha de Mohr-Coulomb (Hibbit et al., 2000) ...............................45

FIGURA 2.16 - Critério de Mohr-Coulomb e Drucker-Prager projetados no Plano-p (Hibbit

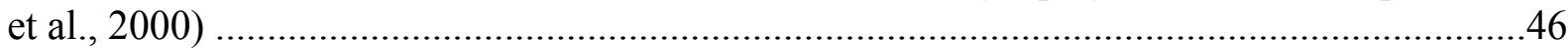

FIGURA 3.1 - moldagem em molde aberto fabricado em silicone. (a) molde de tração e (b)

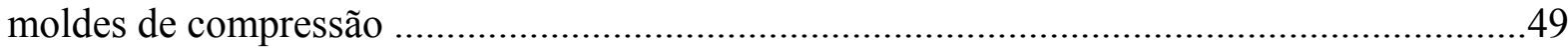

FIGURA 3.2 - Protótipo da prótese de quadril. (a) Modelo prototipado em ABS; (b) caixa de

moldagem para obtenção do molde utilizando o modelo prototipado ....................................49

FIGURA 3.3 - CPs de tração levados a um forno micro-controlado .....................................53

FIGURA 3.4 - Marcações para posicionamento nas garras $(115 \mathrm{~mm})$ e de extensômetro

(50mm ou gage length) (ASTM D638-96- Tipo I) ..............................................................54

FIGURA 3.5 - Projeto de haste de implante de quadril proposto por Silvestre Filho (2001) .55

FIGURA 3.6 - Dimensões em milímetros do CP de tração (ASTM D638-96- Tipo I) .........60

FIGURA 3.7 - Determinação do coeficiente de Poisson por: (a) extensômetros; (b) strain-

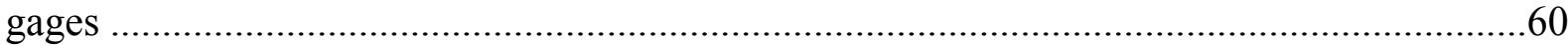

FIGURA 3.8 - Ensaios de compressão: medida de deformação através do travessão ............62

FIGURA 3.9 - Ensaios de compressão com medida de deformação através de strain gages, colados no mesmo CP, nos sentidos (a) longitudinal e (b) transversal .................................62 FIGURA 3.10 - Dispositivo para avaliar prótese de quadril: (a) configuração geral mostrando os mecanismos inferior e superior; (b) mecanismo inferior

FIGURA 3.11 - Mecanismo inferior do Dispositivo para avaliar prótese de quadril: (a)

Cilindro oco com o dispositivo bipartido e prótese acoplados; (b) gaiola em aço-liga 
FIGURA 3.12 - Parte superior do dispositivo para avaliar prótese de quadril: (a)

Componentes - pista de deslizamento e assento com rolamento; (b) Componentes montados e

já com acetábulo instalado no assento

FIGURA 3.13 - (a) Montagem do dispositivo: parte inferior e parte superior (b) Dispositivo

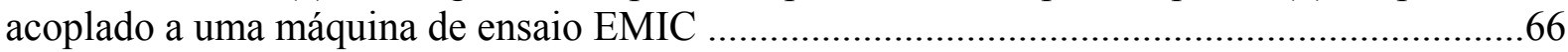

FIGURA 3.15 - Malha de 1/8 do modelo de tração ................................................................68

FIGURA 3.16 - Vinculações simulando a simetria de 1/8 do modelo de tração e imposição

dos deslocamentos

FIGURA 3.17 - Superfície do Critério de Drucker-Prager segundo os eixos dos invariantes de tensão (Hibbit et al, 2000)

FIGURA 3.18 - Geometria do modelo de compressão com eixo de simetria (unidade $=$ milímetro)

FIGURA 3.19 - Malha de $1 / 2$ da seção transversal do modelo de compressão e imposição das

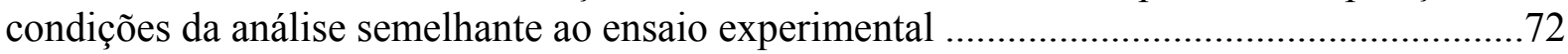

FIGURA 3.20 - Curva de encruamento de compressão estimada para o biopolímero ...........73

FIGURA 3.21 - Modelo sólido confeccionado em software de CAD segundo dimensões

especificadas em Silvestre Filho (2001) ..........................................................................74

FIGURA 3.22 - Esfera de Alumina segundo normas ASTM F370-94 e ASTM F1636-95: a)

Geometria (Wregge, 2000); b) Modelo sólido

FIGURA 3.23 - Superfícies selecionadas para interação do tipo "tie-contact": (a) na esfera de alumina e (b) na cabeça da prótese de quadril .....................................................................76

FIGURA 3.24 - Interação do tipo "tie-contact" entre a esfera de alumina e a cabeça da prótese de quadril

FIGURA 3.25 - Malha para o conjunto esfera e haste com elementos tridimensionais, do tipo

sólido, denominados C3D8R

FIGURA 3.26 - Contato entre duas superfícies utilizando a interação finite sliding (HIBBIT

et al., 2000)

FIGURA 3.27 - Possível evolução do contato entre o nó 101 e a superfície "master"

utilizando finite sliding (HIBBIT et al., 2000).

FIGURA 3.28 - Contato entre duas superfícies utilizando a interação small sliding (HIBBIT

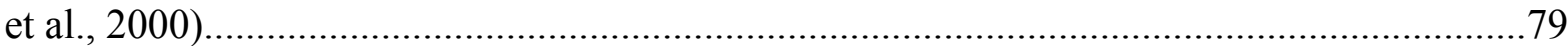

FIGURA 3.29 - As superfícies selecionadas para o acetábulo e a esfera de alumina ............79

FIGURA 3.30 - Interação acetábulo-esfera de alumina ........................................................8

FIGURA 3.31 - Modelo posicionado com inclinação de $10^{\circ}$ e carga na direção vertical.......80

FIGURA 3.32 - Modelamento do engastamento da haste no bloco de granito ........................81

FIGURA 3.33 - Posição do implante (a) no inicio da análise, indeformada e (b) no final da

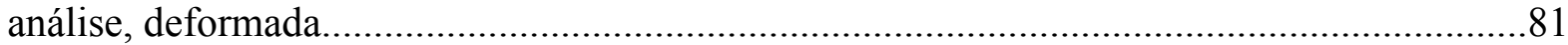

FIGURA 4.1 - Teste para um espectro de velocidades de ensaio..........................................84

FIGURA 4.2 - Curvas tensão-deformação de engenharia: ensaio monotônico de tração sob

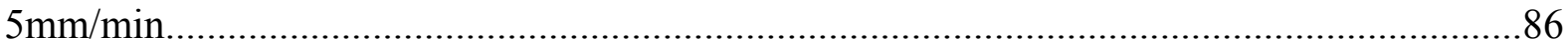

FIGURA 4.3 - Curva tensão-deformação de engenharia x verdadeira (ensaio monotônico de

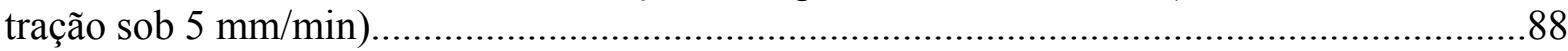

FIGURA 4.4 - Módulo de elasticidade e tensão de escoamento: ensaio monotônico de tração

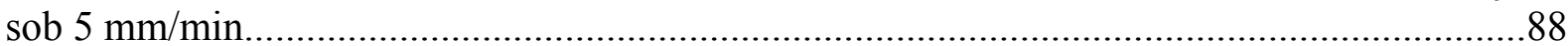

FIGURA 4.5 - Curvas tensão-deformação verdadeira: ensaio monotônico de tração sob $0,8 \mathrm{~mm} / \mathrm{min}$

FIGURA 4.6 - Módulo de elasticidade e pico de tensão: ensaio monotônico de tração sob

$0,8 \mathrm{~mm} / \mathrm{min}$

FIGURA 4.7 - Curva deformação transversal-deformação longitudinal (ensaio monotônico de tração sob 0,8 mm/min): (a) extensômetros; (b) strain-gages 
FIGURA 4.8 - Curvas carga-deslocamento com ciclos sob $0,8 \mathrm{~mm} / \mathrm{min}$ (ensaio de tração)...91 FIGURA 4.9 - Linhas de tendência de descarregamento e laço histerético.............................92

FIGURA 4.10 - Curva tensão-deformação para os dois primeiros ciclos...............................93

FIGURA 4.11 - Curva tensão-deformação para três ciclos...................................................93

FIGURA 4.12 - Curvas tensão-tempo e deformação-tempo para três ciclos...........................94

FIGURA 4.13 - Curvas tensão aplicada-tempo e deformação transversal-tempo (medida por

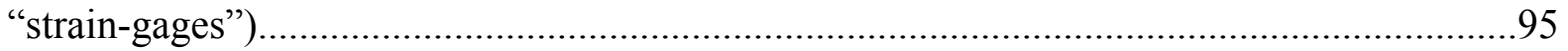

FIGURA 4.14 - Curvas tensão-deformação de engenharia: ensaio monotônico de compressão

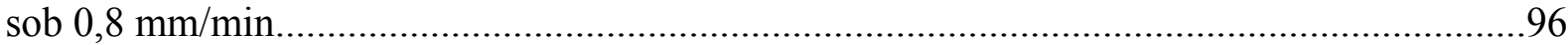

FIGURA 4.15 - (a) Aumento do diâmetro do CP de compressão (b) Curva tensão-deformação de engenharia $\mathrm{x}$ verdadeira (ensaio monotônico de compressão sob 0,8

$\mathrm{mm} / \mathrm{min})$

FIGURA 4.16 - Módulo de elasticidade e tensão de escoamento (travessão da máquina):

ensaio monotônico de compressão sob $0,8 \mathrm{~mm} / \mathrm{min}$.

FIGURA 4.17 - O corpo-de-prova é mostrado numa comparação entre ensaios com: (a)

ocorrência do embarrilamento (b) comportamento esperado. (ensaio monotônico de compressão sob $0,8 \mathrm{~mm} / \mathrm{min}$ ).

FIGURA 4.18 - Módulo de elasticidade e tensão de escoamento (strain-gage): ensaio monotônico de compressão sob $0,8 \mathrm{~mm} / \mathrm{min}$

FIGURA 4.19 - Curvas carga-deslocamento com ciclos sob $0,8 \mathrm{~mm} / \mathrm{min}$ (ensaio de compressão)

FIGURA 4.20 - Linhas de tendência de descarregamento e laço histerético sob

compressão.

FIGURA 4.21 - Curva tensão-deformação para dois ciclos.

FIGURA 4.22 - Curvas tensão-tempo e deformação-tempo para dois ciclos.

FIGURA 4.23 - Curvas tensão-tempo e deformação circunferencial-tempo (medida por straingage).

FIGURA 4.24 - Ensaio segundo a norma ISO 7206-3: posição do acetábulo no início do ensaio (a) bem como ao final do ensaio (b)

FIGURA 4.25 - Curva carga-deslocamento sob 0,8 mm/min (ISO 7206-3) ........................106

FIGURA 4.26 - Ensaio segundo a norma ISO 7206-3: Utilização de bloco de granito sintético bipartido como suporte da haste de implante de quadril..........................................................107

FIGURA 4.27 - Curva carga-deslocamento sob 0,8 mm/min (ISO 7206-3) .........................108

FIGURA 4.28 - Curvas Limite Superior e Limite Inferior para o biopolímero .....................112

FIGURA 4.29 - Curva de encruamento de tração estimada para o biopolímero $(\mathrm{w}=0,5) \ldots .113$

FIGURA 4.30 - Resultado numérico de carga-deformação de engenharia considerando o

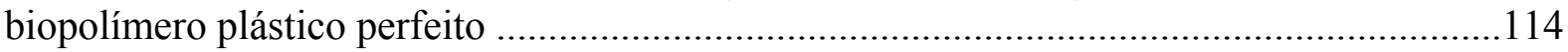

FIGURA 4.31 - Resultado numérico: "necking" difuso e "necking” localizado.....................114

FIGURA 4.32 - Resultado numérico de carga-deformação de engenharia empregando a

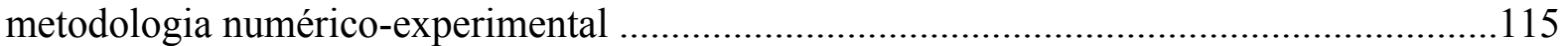

FIGURA 4.33 - Curva de encruamento de compressão estimada para o biopolímero............116

FIGURA 4.34 - Resultado numérico de carga-deformação (sob compressão).......................117

FIGURA 4.35 - Posição do implante (a) no inicio da análise, indeformada e (b) no final da

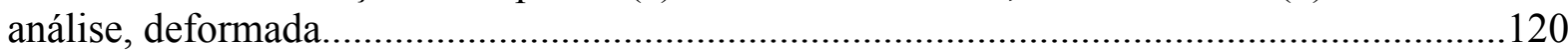

FIGURA 4.36 - Curva carga-deslocamento comparando: Modelo Plastic X Modelo de

Drucker-Prager.

FIGURA 4.37 - Superfícies da interação do tipo "tie-contact" entre a esfera de alumina e a cabeça da prótese de quadril. 
FIGURA 4.38 - Ensaio segundo a norma ISO 7206-3: (a) Ensaio Experimental; (b) Análise computacional.....

FIGURA 4.39 - Curva carga-deslocamento comparando: resultado experimental x resultado

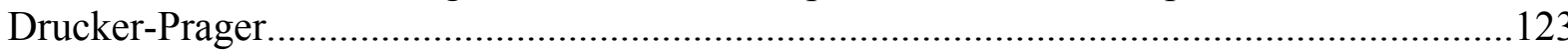
FIGURA 4.40 - Curva carga-deslocamento comparando: resultado experimental x resultado numérico. 


\section{SUMÁRIO}

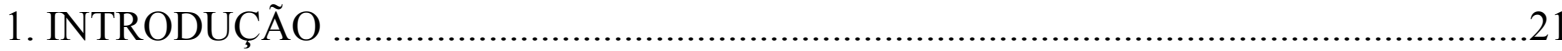

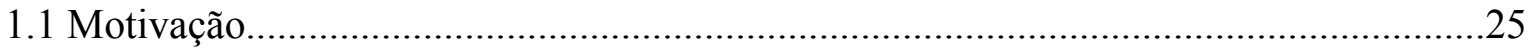

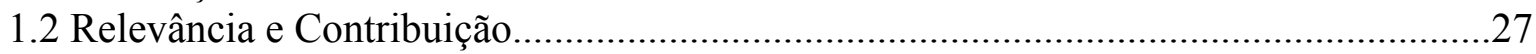

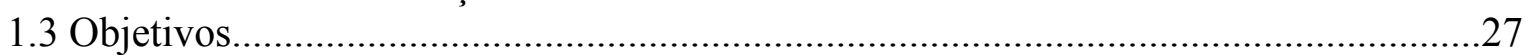

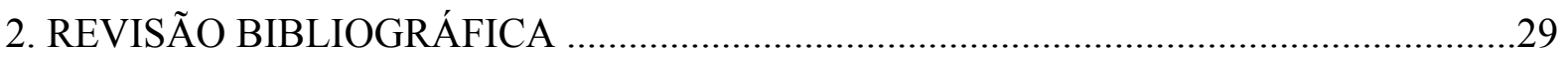

2.1 Comportamento Mecânico dos Materiais Poliméricos ..................................................33

2.1.1 Plastificação envolvendo Grandes Deformações ..............................................37

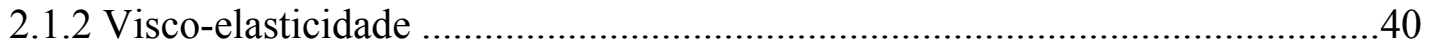

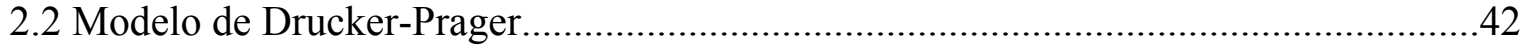

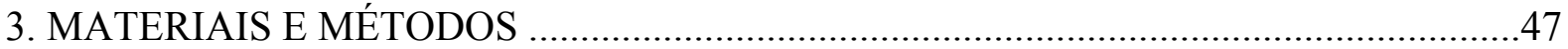

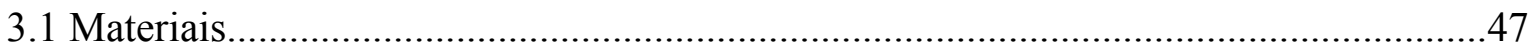

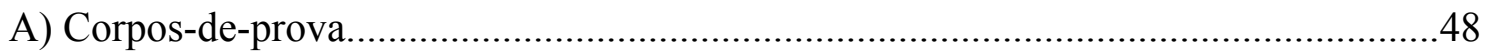

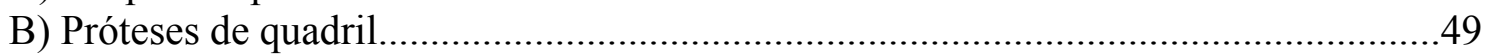

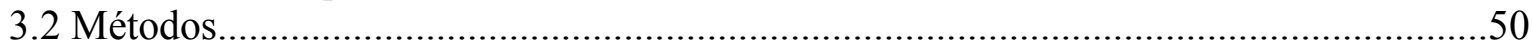

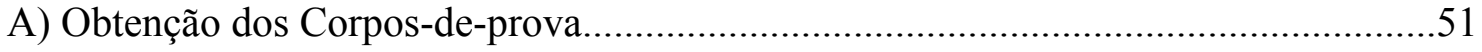

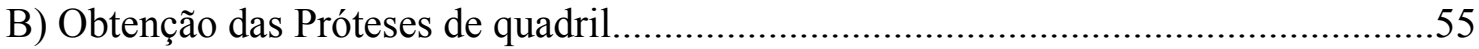

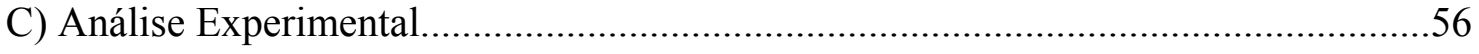

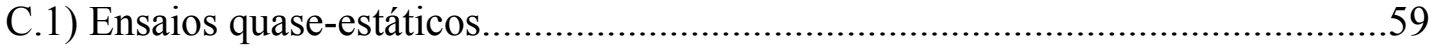

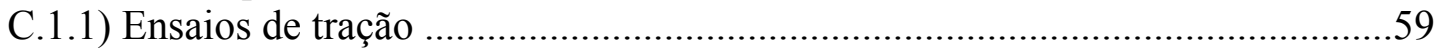

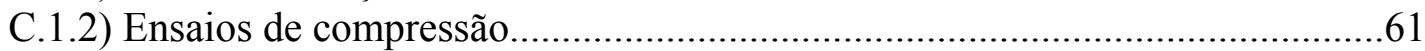

C.1.2) Ensaios da Prótese de quadril..................................................................63

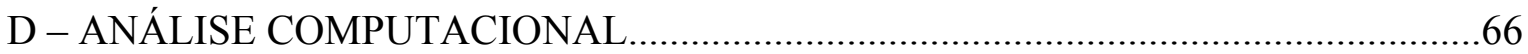

D.1) Análise Computacional para Tração............................................................67

D.2) Análise Computacional para Compressão...................................................... 71

D.3) Análise Computacional para Haste de Quadril..................................................73

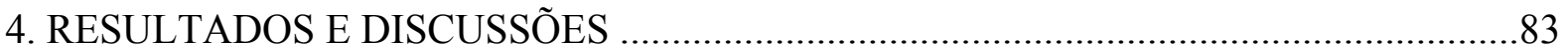

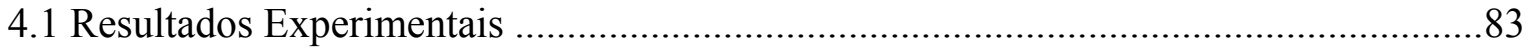

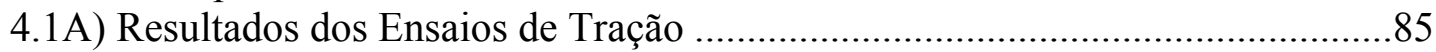

4.1B) Resultados dos Ensaios de Compressão.........................................................95

4.1C) Resultados dos Ensaios da Prótese de Quadril..............................................105

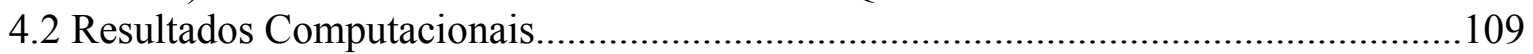

4.2A) Modelos Computacionais de Tração.........................................................109

4.2B) Modelos Computacionais de Compressão...................................................115

4.2C) Modelos Computacionais da Prótese de Quadril..........................................118

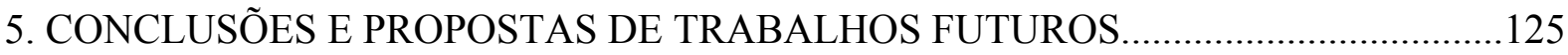

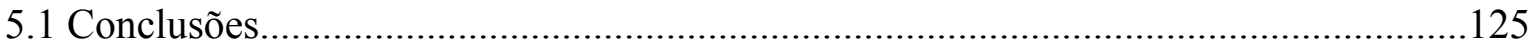

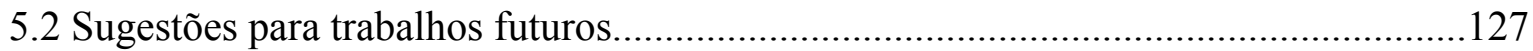

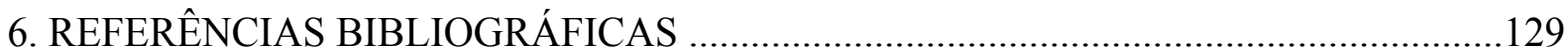


FERNEDA, A. B. (2006). Estudo Teórico-experimental do Comportamento Elastoplástico do Poliuretano Derivado do Óleo de Mamona (Ricinus Communis). 2006. 135p. Tese (Doutorado) - Escola de Engenharia de São Carlos, Universidade de São Paulo, São Carlos, 2006.

Os biopolímeros surgem como materiais alternativos no atendimento aos requisitos de desempenho que a Área Médica tem exigido para implantes ósseos. Nesse contexto o polímero poliuretano derivado de óleo de mamona (Ricinus communis) tem obtido lugar de destaque. Mesmo assim, esse material, considerado um biopolímero regenerador ósseo, ainda necessita de investigação mecânica consistente para uma aplicação de forma confiável. No entanto, há uma grande dificuldade em se prever o comportamento mecânico das estruturas fabricadas por biopolímeros. Diante desse fato, o presente projeto de pesquisa visa através de ensaios experimentais em amostras padronizadas para ensaios de tração e compressão, bem como, ensaios normalizados para próteses de quadril, adquirir propriedades de material adequadas para a implementação dos modelos computacionais, assim como dados de comportamento mecânico sob solicitação. De posse desses dados, através do Método dos Elementos Finitos, são realizadas simulações computacionais com o objetivo de verificar a capacidade do modelo de material de Drucker-Prager representar o comportamento mecânico do biopolímero. Este modelo é aplicado inicialmente na simulação dos ensaios de tração e compressão e posteriormente nas simulações das próteses em biopolímero, onde carregamentos mais complexos estão presentes. Os resultados obtidos nas simulações são analisados e discutidos para fins de validação do uso deste modelo de material em estruturas fabricadas com o biopolímero.

Palavras-chave: Materiais Poliméricos, Comportamento Mecânico, Ensaios Quase-estáticos, Identificação de Parâmetros de Material, Simulação Computacional, Ensaios de Prótese de Quadril. 


\section{Abstract}

FERNEDA, A. B. (2006). Theoretical and experimental study of the Elastoplastic behavior of the Castor Oil Polyurethane (Ricinus Communis). 2006. 135p. Ph.D. Thesis São Carlos School of Engineering, University of São Paulo, São Carlos, 2006.

Biopolymers have been widely used as alternative materials to attend the performance requirements that medical area has demanded to bone implants. In this way, the Castor Oil Polyurethane (Ricinus communis) has taken a distinct place. Nevertheless, this material, considered bone constructive, still needs a consisting mechanical investigation for a reliable application, despite the great difficulty to predict the mechanical behavior of biopolymer structures. Face this fact, this work intends through experiments in normalized specimens for tensile and compressive tests, as well as normalized tests for hip implants, to obtain material properties and mechanical behavior data required to implement computational models of the hip prosthesis. Using the finite element method, computational simulations are carried out to verify the capability of Drucker-Prager material model to represent the biopolymer mechanical behavior. This model is first applied in tensile and compressive tests simulations, and further in prosthesis biopolymer simulations, where more complex loadings are present. The results of these simulations are analyzed and discussed in order to validate the use of this material model in biopolymers structures.

Keywords: Polymeric Materials, Mechanical Behavior, Quase-static Tests, Material Parameters Identification, Computational Analysis, Hip Prosthesis Tests. 


\section{Capítulo 1}

\section{INTRODUÇÃO}

Ao longo do último século a humanidade tem vivido contínuo processo de melhoria nas condições de vida, o que tem se refletido, em última instância, em uma expectativa de vida maior. Isso tem ocorrido, principalmente, devido a avanços tecnológicos que ganharam aplicação prática e tornaram-se acessíveis à população (Etchebehere, 1998). Em contrapartida esse envelhecimento da população mundial pode ser apontado como um dos fatores que contribuem para o aumento da demanda de cirurgias para reconstituição óssea (Wregge, 2000). A deterioração dos tecidos duros, devido principalmente à diminuição de sua densidade com o avanço da idade, tem sido a maior causa para a necessidade dos reparos (Latham \& Goswani, 2004). Wregge (2000) salienta que em muitos casos, a fratura é de tamanha gravidade que o processo de reconstituição torna-se inviável, havendo a necessidade do emprego de implantes.

A Área Médica tem exigido cada vez mais implantes ósseos que possam cumprir de maneira adequada às funções da parte substituída ou reposta. Sendo assim, a estrutura que será implantada deve ter um desempenho satisfatório, capaz de suportar as solicitações em serviço e proporcionar o mínimo de desconforto ao usuário.

Hoje em dia são utilizados metais e ligas metálicas na recuperação do indivíduo. Estes materiais suprem as necessidades exigidas para os implantes, entretanto também possuem algumas particularidades indesejáveis que podem trazer desconforto e transtornos à saúde do usuário. A busca de soluções para este tipo de ocorrência tem proporcionado a introdução dos biopolímeros, tendo estes despontados como materiais alternativos para atender as expectativas de desempenho que vêm sendo geradas. 
Nesse contexto, destaca-se o poliuretano derivado de óleo de mamona que é um biopolímero regenerador ósseo. Desde 1984, o Grupo de Química Analítica e Tecnologia de Polímeros (GQATP) do Instituto de Química de São Carlos da USP desenvolve pesquisas com poliuretanos derivados de óleo de mamona (Ricinus communis). A utilização desta poliuretana como biomaterial para reparar defeitos decorrentes de perdas ósseas bem como na produção de implantes tem sido objeto de estudo desde então.

Desta forma, pesquisadores do Laboratório de Tribologia e Compósitos da Faculdade de Engenharia Mecânica da Escola de Engenharia de São Carlos (EESC) da Universidade de São Paulo (USP) tiveram participação em trabalhos de reconstrução de mandíbulas e crânios com o citado biopolímero. As necessidades de intervenção em tais estruturas são resultado de perdas ósseas devido a acidentes ou tumores. E assim, através desta parceria foi possível adquirir familiarização com o biopolímero e notar que a utilização deste material apresentava uma grande capacidade de aplicação em estruturas ósseas.

Porém apesar de toda sua potencialidade, existe uma grande dificuldade em se prever o comportamento mecânico das estruturas fabricadas por biopolímeros, tanto naquelas que são substituídas pelas próteses como naquelas que sofrem apenas uma reposição.

Diante disso, o presente projeto de pesquisa visa através de ensaios experimentais em amostras padronizadas para ensaios de tração e compressão, bem como, ensaios experimentais normalizados para próteses de quadril, adquirir propriedades de material consistentes assim como dados de comportamento mecânico sob solicitação. De posse desses dados simulações computacionais são realizadas (via Método dos Elementos Finitos), com o objetivo de verificar a capacidade dos modelos de material implementados num pacote comercial de análise computacional, no caso o ABAQUS®, representarem com fidelidade o comportamento mecânico de estruturas fabricadas a partir do biopolímero. Para tal, num primeiro momento o modelo de material implementado é avaliado nas estruturas (amostras) 
sob tração e compressão. Posteriormente, são realizadas simulações computacionais das próteses em biopolímero a fim de verificar a validade do modelo de material para carregamentos mais complexos. Para tanto, o desenvolvimento do trabalho está estruturado da seguinte forma:

\section{- CAPÍTULO 1: INTRODUÇÃO}

Apresenta uma breve introdução do presente trabalho assim como a motivação e justificativas para a realização do mesmo e também a contribuição proporcionada.

\section{- CAPÍTULO 2: REVISÃO BIBLIOGRÁFICA}

É uma Revisão bibliográfica que apresenta aspectos históricos do biopolímero da mamona e sua relação com a aplicação na área médica. Aborda também o comportamento mecânico dos materiais poliméricos assim como aspectos de Plastificação envolvendo grandes deformações e visco-elasticidade. Apresenta também o modelo de plastificação de Drucker-Prager e o de Mohr-Coulomb.

\section{- CAPÍTULO 3: MATERIAIS E MÉTODOS}

Aborda os materiais e métodos empregados, descrevendo inicialmente que a divisão das amostras foi feita em dois grupos:

1) corpos-de-provas, ou simplesmente CPs;

2) próteses de quadril.

Detalha-se, assim, toda a metodologia de fabricação. Em seguida são descritas as condições em que os ensaios quase-estáticos foram realizados. Em alguns desses ensaios, evidencia-se o emprego de strain-gages para medir grandes deformações (até $15 \%$ ). São delineados também todos os equipamentos utilizados nos ensaios. Um novo modelo de 
dispositivo de ensaios de compressão, especialmente projetado para o desenvolvimento de testes em polímeros. Por fim, apresenta-se ainda a descrição de detalhes dos ensaios da prótese de quadril. São mostradas características de fabricação desde a confecção dos moldes até a moldagem das próteses bem como os dispositivos e todo o procedimento de ensaios.

\section{- CAPÍTULO 4: RESULTADOS E DISCUSSÕES.}

Contempla os resultados e discussões, mostrando primeiramente os resultados obtidos dos ensaios de tração. Esses ensaios estão divididos em dois grupos:

1) ensaios de tração monotônicos;

2) ensaios de tração com ciclos de carregamento-descarregamento e recarregamento.

A partir dos ensaios monotônicos é possível obter o módulo de elasticidade, a tensão de escoamento, o limite de deformação elástica e o coeficiente de Poisson. Por outro lado, os ensaios com ciclos demonstram que as linhas de tendência nos descarregamentos coincidem com a inclinação no regime elástico, além de evidenciar a presença de laços histeréticos. Posteriormente, os resultados obtidos dos ensaios de compressão são descritos. Assim como os ensaios de tração, os ensaios de compressão estão divididos em dois grupos:

1) Ensaios de compressão monotônicos;

2) Ensaios de compressão com ciclos de carregamento-descarregamento e recarregamento.

A partir dos ensaios monotônicos de compressão o módulo de elasticidade, a tensão de escoamento e o limite de deformação elástica são obtidos. Por outro lado, novamente, os ensaios com ciclos demonstram que as linhas de tendência nos descarregamentos coincidem com a inclinação no regime elástico, além de evidenciar a presença de laços histeréticos. 
Também são apresentadas simulações computacionais dos ensaios realizados de tração e compressão, que consistiu em simular o comportamento mecânico de estruturas fabricadas a partir do biopolímero sob a ação de carregamentos simples, desconsiderando os efeitos visco-elásticos. É feita a extensão das simulações computacionais para carregamentos mais complexos, utilizando para esse fim a prótese de quadril fabricada em biopolímero proposta por Silvestre Filho (2001). Dessa forma visa-se a verificação da consistência de representação do modelo de material descrito no Capítulo 2 comparando os resultados numéricos com os resultados experimentais.

\section{- CAPÍTULO 5: CONCLUSÕES.}

Apresenta conclusões oriundas do presente estudo assim como sugestões para trabalhos posteriores.

\section{MOTIVAÇÃO}

Como cada prótese é feita sob medida para cada paciente, os pesquisadores do Laboratório de Tribologia e Compósitos do Departamento de Engenharia Mecânica da Escola de Engenharia de São Carlos (EESC) da Universidade de São Paulo (USP) desenvolveram uma metodologia para a confecção das próteses que consiste das seguintes etapas:

1) Primeiramente uma tomografia do local da intervenção que vai receber o polímero é obtida;

2) A imagem, trabalhada em computador, é enviada para uma máquina de prototipagem, onde um protótipo da prótese é produzido em plástico rígido;

3) Baseado nesse protótipo é feito em seguida um molde em silicone que proporcionará a confecção da prótese em biopolímero. 
Dessa maneira, antes do paciente ir para a cirurgia, a prótese já está pronta e personalizada. A metodologia proposta otimiza o tempo de intervenção cirúrgica. Para um caso que antes demorava de 16 a 17 horas, tem-se uma redução para duas horas de duração. Ressalta-se ainda que pelo processo antigo, todas as medições e acertos da nova prótese eram feitos na própria sala de cirurgia. Além disso, o material empregado, o biopolímero da mamona, é biocompatível e assim possui mínima possibilidade de rejeição pelo organismo (Ereno, 2003).

Assim devido ao seu potencial e versatilidade, houve diversas aplicações do referido biopolímero. Dentre estas, Silvestre Filho (2001) apresentou em seu trabalho de mestrado uma versão preliminar de uma prótese de quadril fabricada a partir do biopolímero da mamona. A geometria da mesma foi especificada com base em cálculos de resistência dos materiais bem como em cadeias dimensionais para que a esta pudesse ser adequadamente implantada. Desta forma, por se tratar de uma estrutura com aplicação na área da medicina, que possui procedimento de ensaio normalizado, a referida geometria foi a selecionada como estudo de caso para o presente trabalho.

A capacidade de prever o comportamento mecânico de estruturas fabricadas a partir deste biopolímero foi, assim, o fator importante e motivador para a realização do presente trabalho. Apesar disso, não se pretende, entretanto discutir aspectos relacionados a estudos biológicos sobre tal material. O trabalho publicadado por Katti (2004), apresenta comentários sobre pontos positivos e negativos de diversos materiais para implante total de quadril assim como a tendência de pesquisas nessa área de biomateriais.

\section{RELEVÂNCIA E CONTRIBUIÇÃO}

Devido à interação do Grupo de Química Analítica e Tecnologia de Polímeros (GQATP) do Instituto de Química de São Carlos da USP com o Laboratório de Tribologia e 
Compósitos foi possível estabelecer uma parceria que tinha como meta principal, potencializar o emprego do poliuretano derivado do óleo de mamona, especialmente na reconstrução e reconstituição óssea.

Destaca-se que o biopolímero da mamona foi desenvolvido pelo Instituto de Química de São Carlos (IQSC) e o mesmo, desde o início, já se apresentava como um excelente reconstrutor ósseo. Porém, faltava a capacidade de se prever o comportamento mecânico desse material de maneira confiável.

Dessa forma, o grupo de pesquisa do Laboratório de Tribologia e Compósitos que detém conhecimento em simulação computacional através do método dos elementos finitos, buscou realizar uma pesquisa mais aprofundada acerca do biopolímero, determinando suas propriedades mecânicas e avaliando modelos de material mais consistentes.

Assim sendo, o presente trabalho visa realizar um estudo teórico-experimental deste material ao qual são atribuídas, através de estudos anteriores, características excelentes para implantes ósseos e, para que se possa realizar a previsão confiável do comportamento do mesmo quando implantado em seres humanos.

\section{OBJETIVOS}

Os objetivos do presente trabalho estão divididos da seguinte forma:

1. Realizar ensaios monotônicos normalizados de corpos-de-prova a fim de obter parâmetros de material associado ao poliuretano derivado do óleo de mamona de forma que atenda todas as necessidades do presente trabalho;

2. Realizar ensaios normalizados de haste de implante de quadril na geometria proposta por Silvestre Filho (2001), a fim de obter dados de comportamento mecânico para servir de estudo de caso e que atendam todas as necessidades do presente trabalho; 
3. Realizar simulações computacionais dos ensaios de tração e compressão a fim de avaliar a consistência do modelo de material confrontando os resultados numéricos com ensaios experimentais representativos;

4. Estender as simulações computacionais para carregamentos mais complexos, utilizando assim a prótese de quadril fabricada em biopolímero proposta por Silvestre Filho (2001);

5. Verificar a qualidade dos resultados numéricos para carregamentos complexos através de ensaios normalizados específicos para próteses de quadril.

6. Proporcionar a previsão de maneira confiável do comportamento mecânico do biopolímero derivado do óleo de mamona. 


\section{Capítulo 2}

\section{REVISÃO BIBLIOGRÁFICA}

Os esforços para encontrar substituições para reparo de ossos humanos com fraturas severas datam desde séculos atrás. Atualmente, os materiais utilizados na recuperação do indivíduo, tais como metais e ligas metálicas, suprem em parte as necessidades exigidas para os implantes. Assim como características benéficas estes materiais também possuem algumas particularidades indesejáveis que podem trazer transtornos à saúde do usuário. Alguns autores citam como exemplo de infortúnios: metalose, rigidez excessiva do material em relação ao osso, curto espaço de tempo para manutenção e substituição, etc (Latham \& Goswani, 2004; Romero, 2005). Ressalta-se ainda que o emprego de implantes compostos por materiais muito mais resistentes que os ossos do corpo faz com que a carga sobre o osso seja reduzida resultando num fenômeno chamado de bloqueio de tensão (do termo em inglês "stress shielding”). O grau de bloqueio de tensão está relacionado com a diferença de rigidez entre o osso e o material do implante. Os processos regenerativos e de remodelamento do osso são ativados diretamente pelo carregamento que estes sofrem, ou seja, ossos sujeitos a carregamentos regeneram-se enquanto que aqueles que não sofrem carregamentos atrofiam-se (Katti, 2004).

O desenvolvimento atual na Área Médica tem exigido que os implantes apresentem um elevado grau de desempenho para que possam cumprir de maneira adequada às funções da parte substituída ou reposta. Nesse sentido é imprescindível a utilização de materiais que apresentem biocompatibilidade e resistência satisfatória dentre outras características (Katti, 2004). Essa busca tem proporcionado o surgimento de materiais alternativos para confecção 
de implantes sendo notada em trabalhos científicos de alguns pesquisadores, tais como: Yildiz et al (1998), Li et al (2002), Simões et al (2000), Simões e Marques (2001), Romero (2005).

Biomaterial pode ser definido como uma substancia ou combinação de duas ou mais substâncias farmacológica inerte, de natureza natural ou sintética, utilizadas para melhorar, aumentar ou substituir, parcial ou integralmente, tecido e órgãos do corpo humano (Willians, 1987).

Neste contexto, o Grupo de Química Analítica e Tecnologia de Polímeros (GQATP) do Instituto de Química de São Carlos da USP vem desenvolvendo pesquisas com poliuretanos derivados de óleo de mamona (Ricinus communis) desde 1984.

A utilização desta poliuretana como biomaterial para reparar defeitos decorrentes de perdas ósseas bem como na produção de implantes tem sido investigada em vários trabalhos científicos, tais como: Plepis (1991), Ignácio (1995); Ohara et al. (1995); Carvalho et al. (1997); Kharmandayan (1997); Frascino (1998); Bonini (1999); Ignácio (1999); Morales (1999); Kfuri Jr (1999); Pascon (1999) e Kuhnen (2001).

Segundo Ereno (2003), o biopolímero derivado de óleo de mamona foi tanto aprovado pelo Ministério da Saúde do Brasil em 1999, como pelo FDA (Food and Drug Administration - a agência do governo norte-americano responsável pela liberação de novos alimentos e medicamentos nos Estados Unidos) em 2003.

Dentre as vantagens apresentadas por estes poliuretanos se destacam:

- A processabilidade;

- A flexibilidade de formulação;

- A possibilidade de alterar a temperatura de cura e de controlar o pico exotérmico na transição líquido-gel;

- A presença de propriedades estruturais atrativas; 
- A ausência de emissão de vapores irritantes ou tóxicos;

- Ser promotor de osteogênese;

- Ter baixo custo.

Ao longo do processo de desenvolvimento científico da poliuretana da resina da mamona, vários estudos de caso foram efetuados. Dessa forma, próteses para substituir ossos nas mandíbulas, no crânio e na face ou, ainda, como suportes na coluna cervical, no lugar dos testículos, no pênis, nos globos oculares e nas gengivas foram fabricadas utilizando esse biopolímero. O mesmo também é pesquisado na forma de fios muito finos para ser empregado em cirurgias plásticas a fim de evitar a flacidez da pele. Algumas das próteses mencionadas acima, antes de serem fabricadas foram projetadas e analisadas por pesquisadores do Laboratório de Tribologia e Compósitos da Faculdade de Engenharia Mecânica da Escola de Engenharia de São Carlos (EESC) da Universidade de São Paulo (USP).

Para tornar possível que uma prótese poder ser feita sob medida para cada paciente, tais pesquisadores desenvolveram uma metodologia para a confecção das próteses que se torna muito interessante mencionar: Primeiramente uma tomografia do local que vai receber o polímero é obtida; essa imagem, trabalhada em computador, é enviada para uma máquina de prototipagem, onde a prótese é produzida em plástico rígido; de posse desse protótipo, é feito em seguida um molde em silicone que proporcionará que numa etapa final seja confeccionada a prótese com o biopolímero. Dessa maneira, quando o paciente vai para a mesa de cirurgia, a prótese já está pronta, personalizada. Lançando mão deste procedimento, a intervenção, que demorava de 16 a 17 horas pelo método tradicional, leva, em média, duas horas. Ressalta-se ainda que pelo processo antigo, todas as medições e acertos da nova prótese eram feitos na própria sala de cirurgia, sem contar que o material utilizado nesse tipo de prótese (aço inoxidável) pode ser rejeitado pelo organismo, o que não ocorre com o biopolímero da 
mamona. Segundo Romero (2005), o aço inoxidável pode apresentar índices elevados de toxicidade, e eventual degeneração nos tecidos ao redor do implante.

Segundo Ereno (2003), o sucesso do biopolímero é explicado pela compatibilidade que ele tem com o organismo humano. Segundo Lizeti Toledo Ramalho, professora da Faculdade de Odontologia de Araraquara da Universidade Estadual Paulista (Unesp), na composição química desse material existe uma cadeia de ácidos graxos cuja estrutura molecular está presente nas gorduras existentes no corpo humano, por isso, as células não 'enxergam' este material como um corpo estranho e não o repelem (ainda em Ereno, 2003).

Investigação conduzida por Azevedo \& Hippert Jr (2002) revelou que a implantação de materiais que não são biocompatíveis pode causar vários tipos de problemas dentro do corpo humano que podem auxiliar na falha prematura dos implantes, atribuindo danos imensuráveis para os implantados assim como perdas para o investimento público.

Dessa forma, com os pesquisadores do Laboratório de Tribologia e Compósitos da Faculdade de Engenharia Mecânica da Escola de Engenharia de São Carlos (EESC) da Universidade de São Paulo (USP) inseridos no desenvolvimento de trabalhos de reconstrução óssea e implantes com o biopolímero, em 2001 uma versão preliminar de prótese de quadril fabricada biopolímero (Figura 2.1) foi apresentada em Silvestre Filho (2001). No projeto de Silvestre Filho, a geometria da prótese foi especificada com base em cálculos simples de resistência dos materiais bem como em cadeias dimensionais para que a esta pudesse ser adequadamente implantada. 


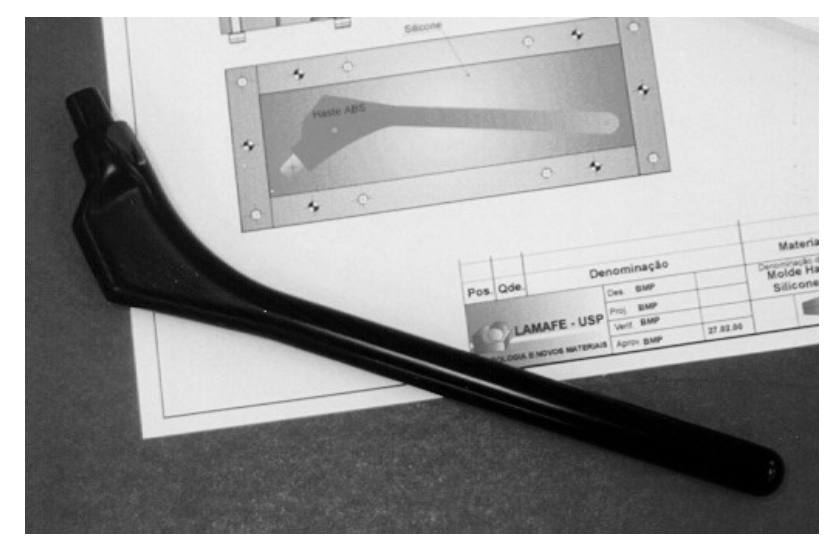

Figura 2.1 - Protótipo de prótese de quadril para fabricação em biopolímero (Silvestre Filho, 2001).

Apesar das vantagens apresentadas pelo biopolímero, há uma grande dificuldade em se prever falhas nessas estruturas, tanto naquelas que são substituídas pelas próteses de biopolímeros como naquelas que sofrem apenas uma reposição. Isso se deve ao tipo de comportamento mecânico apresentado pelos materiais poliméricos.

\section{1 - COMPORTAMENTO MECÂNICO DOS MATERIAIS POLIMÉRICOS}

De acordo com Williams (1973), o comportamento mecânico dos materiais pode ser classicamente dividido em dois grandes grupos:

- Comportamento mecânico independente do tempo (e/ou do histórico de carregamento);

- Comportamento mecânico dependente do tempo (e/ou do histórico de carregamento).

Uma das formas de identificar o tipo de análise que deve ser adotado baseia-se no ensaio de tração. Observando o comportamento do material frente a ciclos de carregamentodescarregamento e re-carregamento em função do tempo, pode-se concluir se a análise dependerá ou não do mesmo. 
Por exemplo, na Figura 2.2 é mostrado um material que possui uma resposta linear. Nota-se que o mesmo, ao sofrer um ciclo de carregamento e descarregamento, possui deformação igual a zero quando o nível de tensão for reduzido a zero. Além disso, quando aplicada uma dada tensão, é importante ressaltar, que o nível de deformação esperado é atingido quase que instantaneamente.
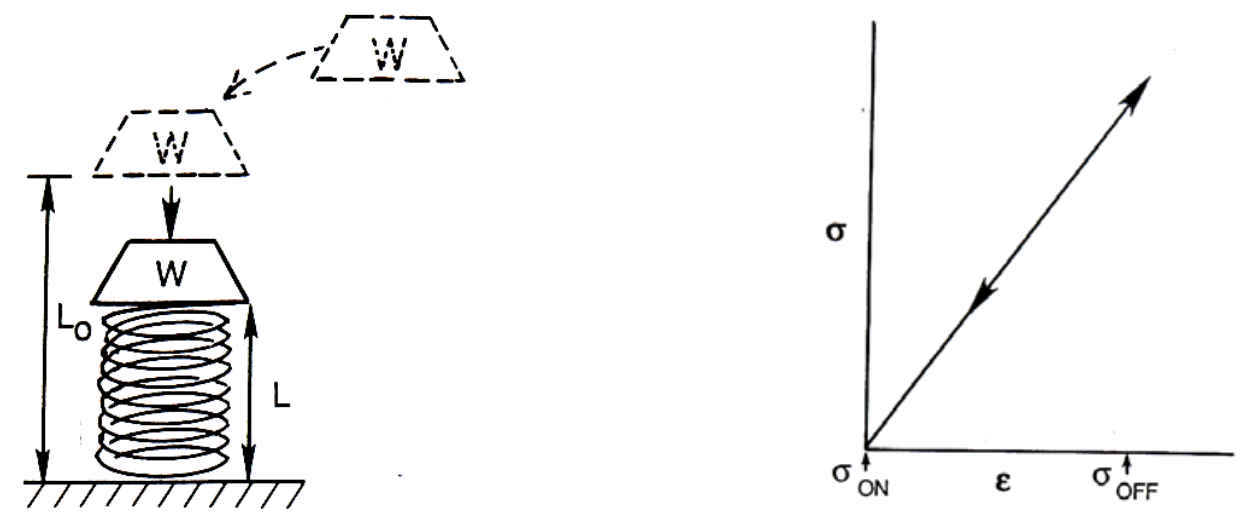

Figura 2.2 - Comportamento elástico linear sob carregamento e descarregamento: curva tensão( $\sigma)$-deformação( $(\varepsilon)$ (adaptado de McCrum et al, 1992).

Para este caso em particular da Figura 2.2, o material poderá ser considerado linear elástico e um modelo matemático para representar o comportamento do mesmo, que seja independente do tempo, poderá apresentar bons resultados.

Por outro lado, a Figura 2.3 demonstra um material que possui um atraso de resposta. Sendo assim, ao sofrer uma dada entrada constante $\sigma_{1}$, nota-se que o material apresenta uma deformação $\gamma_{1}$ que depende do tempo, ou seja, a resposta não é imediata como no caso linear elástico. 


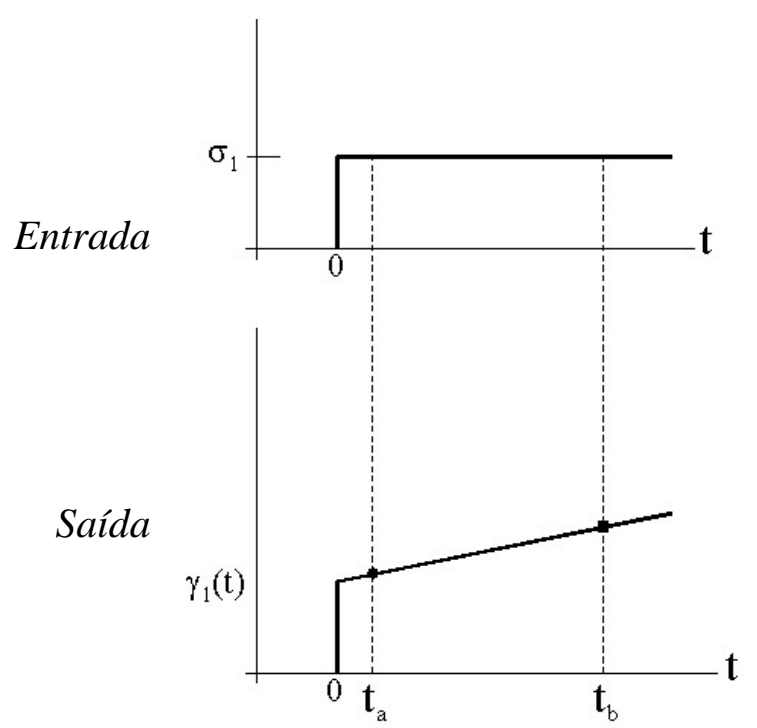

Figura 2.3 - Comportamento visco-elástico sob carregamento:

Entrada (tensão x tempo); Saída (deformação x tempo) (McCrum et al, 1992).

Para este caso apresentado na Figura 2.3, o material deverá ser considerado como visco-elástico e sua representação deverá incluir a variável tempo para apresentar bons resultados.

Já a Figura 2.4 demonstra um material que possui um comportamento linear elástico até o ponto A, após este ponto, inicia-se o processo de escoamento do material, caracterizando assim uma resposta não-linear.

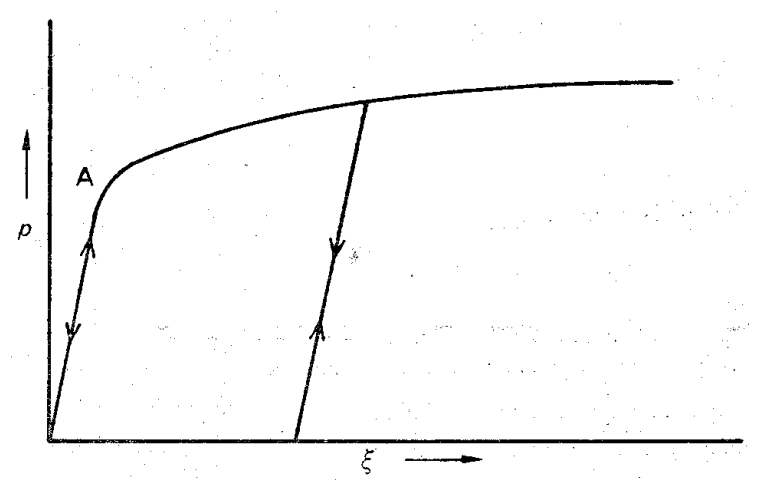

Figura 2.4 - Comportamento elasto-plástico sob carregamento e descarregamento: curva tensão(p)-deformação( $\xi$ ) (Williams, 1973). 
Dessa forma, ao ultrapassar o limite imposto pela tensão de escoamento, o material irá apresentar uma deformação residual quando sofrer descarregamento, ou seja, uma deformação permanente (deformação plástica) mesmo quando o nível de tensão for reduzido a zero. No entanto, durante o descarregamento e mesmo durante o re-carregamento tem-se que a inclinação da curva será semelhante à inclinação da curva linear elástica. Verifica-se assim que a resposta do material depende do histórico de carregamento, ou seja, depende do tempo. Por apresentar este tipo de comportamento durante o descarregamento e o re-carregamento, tal material considerado na Figura 2.4 pode ser considerado como elastoplástico.

Em alguns casos, a deformação aumenta exponencialmente após atingir um determinado nível de tensão. Apesar da curva representada na Figura 2.5 apresentar uma nãolinearidade acentuada, o comportamento da estrutura frente ao processo de carregamento e descarregamento mostra que as deformações independem do tempo.

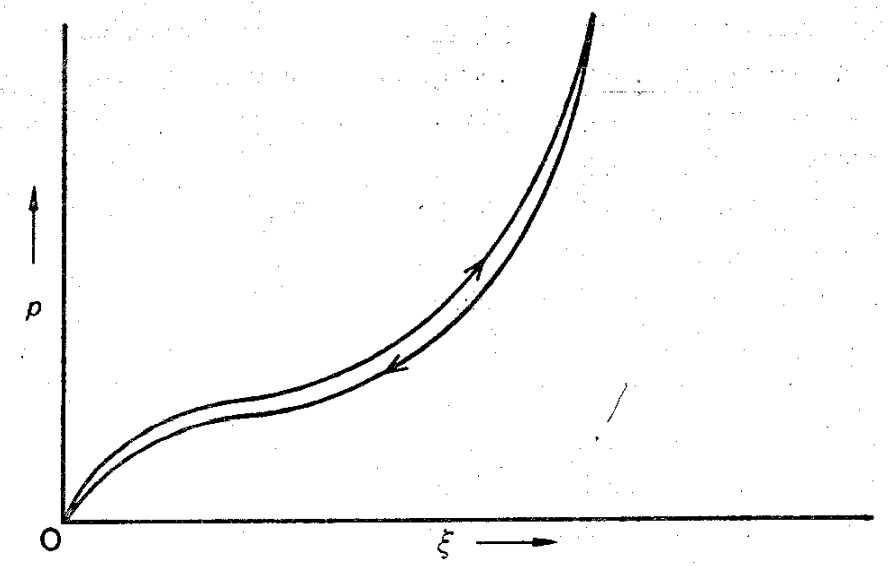

Figura 2.5 - Comportamento hiperelástico sob carregamento e descarregamento: curva tensão(p)-deformação( $\xi$ ) (Williams, 1973).

Dessa forma, tem-se que o material citado na Figura 2.5 é conhecido como hiperelástico, não apresentado assim, deformações permanentes e tensão limite de escoamento.

A Figura 2.6 demonstra um material que possui um comportamento não-linear bem acentuado após o ponto A. Nota-se que o mesmo ao sofrer descarregamento, após o ponto A, 
irá apresentar uma deformação residual, ou seja, uma deformação permanente (deformação plástica) mesmo quando o nível de tensão for reduzido a zero, ou seja, o material possui um comportamento similar aos materiais elastoplásticos. Porém, durante o descarregamento e o re-carregamento há a formação de um laço histerético. Isto evidencia um certo atraso de resposta, caracterizando um comportamento viscoso. Dessa forma, o presente material será considerado como visco-elasto-plástico.

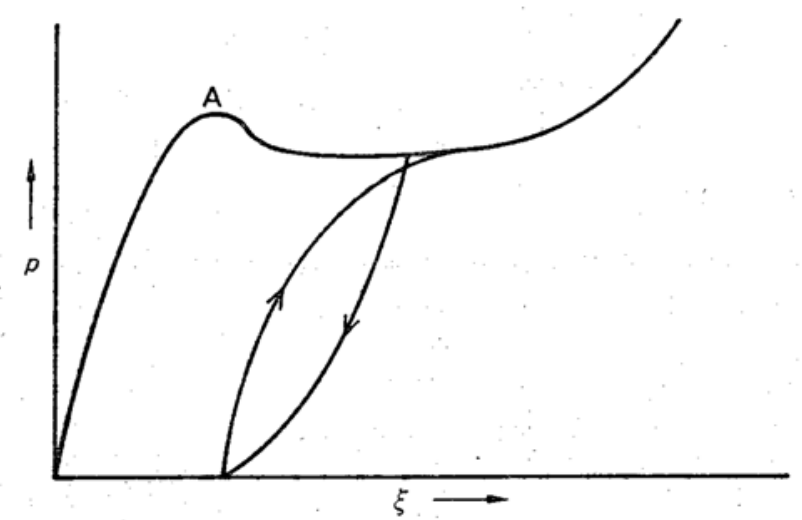

Figura 2.6 - Comportamento visco-elasto-plástico sob carregamento e descarregamento: curva tensão(p)-deformação( $\xi$ ) (Williams, 1973).

De acordo com Williams (1973), vários materiais poliméricos apresentam o comportamento descrito pela Figura 2.6. Sendo que para deformações abaixo de $0,5 \%$ muitos materiais podem ser descritos como linearmente visco-elásticos mas abaixo deste valor não existem não-linearidades perceptíveis. Além disso, em deformações entre 5 e 10\% ocorre um pico na curva tensão-deformação denotado pelo ponto A. Deve-se ressaltar que o ponto A pode ser considerado como um ponto de escoamento uma vez que as deformações posteriores a esse ponto são recuperáveis somente num período muito prolongado e são essencialmente permanentes.

Como consideração final, resultados preliminares provenientes de trabalhos anteriores com o biopolímero da resina da mamona demonstram que o material possui comportamento mecânico similar ao demonstrado na Figura 2.6. Dessa forma, tem-se a seguir um 
detalhamento do fenômeno de plastificação bem como do fenômeno de visco-elasticidade em materiais poliméricos.

\subsubsection{PLASTIFICAÇÃO ENVOLVENDO GRANDES DEFORMAÇÕES}

Shackelford (1996) classifica os polímeros como termoplásticos e termofixos e mostra que a diferença principal entre ambos está no comportamento frente a temperatura. Os termoplásticos se fundem como um líquido viscoso, enquanto os termofixos sofrem decomposição térmica.

Os polímeros termoplásticos consistem de cadeias moleculares lineares ou ramificadas que, ao serem aquecidos a sua consistência altera-se de sólido rígido para líquido viscoso. Posteriormente, eles são então moldados, geralmente sob pressão, e após adquirirem a forma desejada são resfriados, voltando ao estado sólido rígido. Neste caso, não ocorrem reações químicas ou decomposição, podendo assim ser re-aquecidos repetidamente. Por outro lado, os polímeros termofixos sofrem uma reação química irreversível durante a polimerização, conhecida como processo de cura. Durante esse processo são formadas ligações cruzadas covalentes entre as cadeias moleculares adjacentes, desenvolvendo uma estrutura tridimensional. Essas ligações cruzadas, à medida que se formam, causam diminuição da mobilidade das cadeias moleculares, provocando solidificação do polímero. Essa pequena mobilidade das cadeias polimérica faz com que os mecanismos físicos para a criação de deformação permanente ocorrem de forma diferente em materiais poliméricos e em materiais metálicos. Para os materiais metálicos, tem-se que essa deformação plástica deve-se à presença de discordâncias na estrutura cristalina do metal. Isto reduz a estabilidade do mesmo e facilita o escorregamento relativo entre planos atômicos, fazendo com que a estrutura se desloque para uma outra posição de equilíbrio, criando o fenômeno conhecido por deslocação. Tal mecanismo de deformação é irreversível e não implica em ruptura de ligações ou 
variações no volume da estrutura. Entretanto, para polímeros, a explicação do fenômeno de plastificação está associada à orientação das cadeias moleculares.

A Figura 2.7 demonstra a princípio que na fase A, a estrutura polimérica idealizada ainda não se deformou. $\mathrm{Na}$ fase $\mathrm{B}$, ocorre um determinado escorregamento das moléculas, deformando a estrutura cristalina que iniciará sua organização na fase C. Finalmente, na fase D, a estrutura estará completamente re-arranjada e alinhada em relação ao carregamento aplicado.

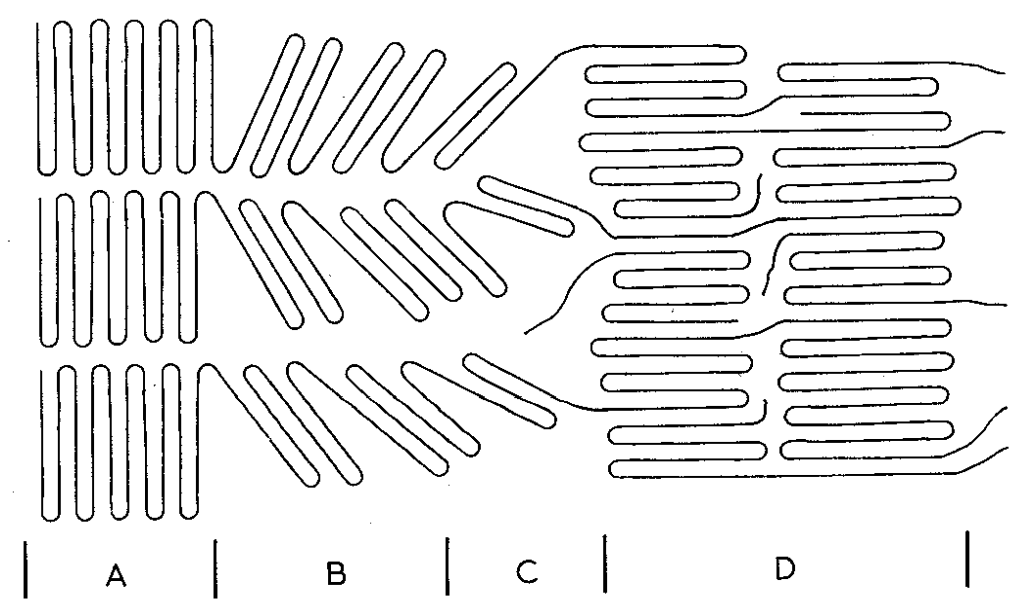

Figura 2.7 - Representação esquemática da deformação de um polímero em nível molecular (Young e Lovell, 1991).

Ainda com relação à Figura 2.7, este processo de alinhamento das cadeias moleculares altera a estrutura interna e proporciona uma variação no módulo de elasticidade do material. Sendo assim, a deformação plástica nos materiais poliméricos ocorre sem existir a quebra das moléculas, mas apenas há uma mudança de orientação das mesmas, se colocando de forma paralela ou perpendicular em relação ao eixo da cadeia molecular (Young e Lovell, 1991).

Além disso, o processo de encruamento (que pode ser entendido de forma simplificada como endurecimento do material, ou melhor, existe a necessidade de acréscimo de tensão para que o material continue se deformando) ocorre de forma diferente para carregamento uniaxial de tração e uniaxial de compressão. No primeiro caso de carregamento, há uma orientação 
uniaxial das cadeias poliméricas, mas no segundo caso, há uma orientação molecular planar (Boyce e Arruda, 1990).

Salienta-se que o biopolímero a base de óleo de mamona é classificado como um polímero termofixo, devendo assim sofrer reação de cura. Portanto, a estrutura tridimensional molecular formada é que irá determinar o comportamento deste material frente às diversas formas de carregamentos.

Outro aspecto que deve ser considerado durante a plastificação dos materiais poliméricos é a variação de volume. Ao contrário dos materiais metálicos, que não sofrem variação volumétrica e possuem coeficiente de Poisson próximo a 0,5 durante a plastificação, os materiais poliméricos terão seu processo de escoamento influenciado não somente pelas tensões desviadoras, mas também pelas tensões hidrostáticas. Tal fenômeno é descrito na literatura e pode ser encontrado no trabalho desenvolvido por G'Sell et al (2002).

Por fim, assim como os materiais metálicos, os materiais poliméricos possuem comportamento influenciado pela taxa de deformação. Essa taxa é definida como a variação da deformação em função do tempo ( $\dot{\varepsilon}=d \varepsilon / d t)$, e é convencionalmente expressa em $\mathbf{s}^{-1}$. Dessa forma, os valores de tensão de escoamento e de resistência do material dependem da velocidade de deformação aplicada no mesmo. A Figura 2.8 mostra que o aumento da taxa de deformação pode elevar os valores de tensão de escoamento e de ruptura do material. 


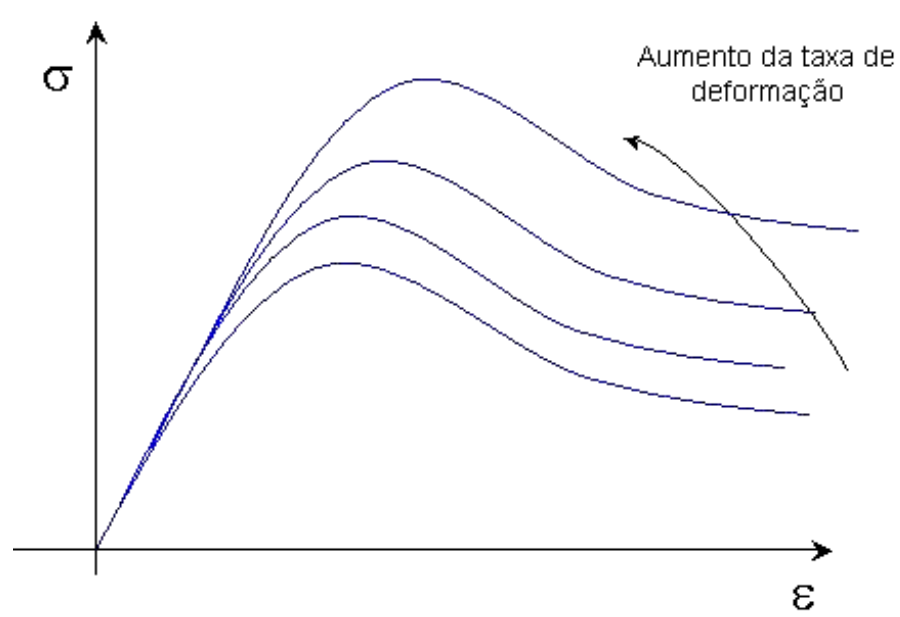

Figura 2.8 - Efeito da taxa de deformação.

\subsubsection{VISCO-ELASTICIDADE}

Segundo Malvern (1969), o comportamento visco-elástico é a combinação dos mecanismos elásticos associados aos viscosos, sendo intensamente marcante nos polímeros. Assim, durante a deformação, a resistência ao escoamento ou fluxo (viscosidade) e os efeitos elásticos influenciam o comportamento desses materiais. Está relacionado a distribuição energética que ocorre internamente durante o carregamento do material.

Segundo a literatura o comportamento visco-elástico é caracterizado por dois fenômenos:

- O fenômeno de Fluência (“Creep”);

- O fenômeno de Relaxação de Tensões (“Stress Relaxation”).

O fenômeno de fluência é observado normalmente como sendo um aumento na deformação, em função do tempo, quando o material é mantido numa tensão constante, abaixo da sua tensão de escoamento (Figura 2.9). A maioria dos materiais exibe esse fenômeno; nos metais é mais notado a altas temperaturas e nos polímeros à temperatura ambiente. Pode ser recuperável ou não, dependendo da natureza do processo de deformação 
interna. Nota-se que este tipo de fenômeno não ocorreria para um material puramente elástico, pois o nível de deformação seria atingido imediatamente e se manteria constante ao longo do tempo (linha tracejada).

(Fluência)

(Creep)

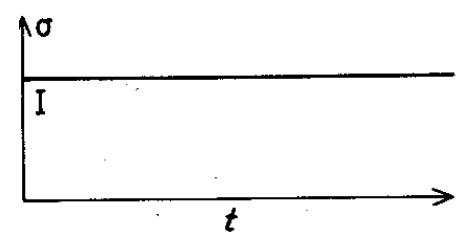

Relaxação

(Relaxation)

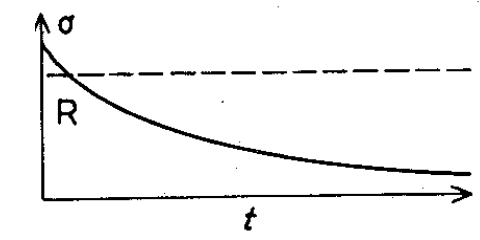

Curva tensão $\mathrm{x}$ tempo
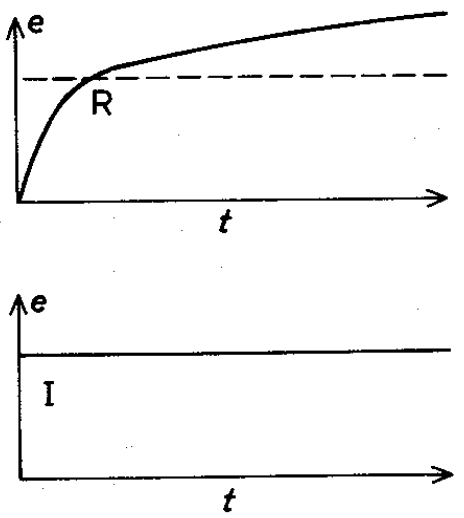

Curva deformação x tempo

Figura 2.9 - Representação esquemática da resposta (R) para entrada (I) de polímeros visco-elásticos: Fluência e Relaxação (Young e Lovell, 1991).

Por outro lado, o fenômeno de Relaxação é observado normalmente como sendo uma redução na tensão, em função do tempo, quando o material é mantido num nível de deformação constante (Figura 2.9). Nota-se que este tipo de fenômeno não ocorreria para um material puramente elástico, pois o nível de tensão se manteria constante (linha tracejada).

Um outro fenômeno apresentado pelos materiais visco-elásticos é conhecido como "Recovery" (Recuperação) e ocorre quando um certo nível de tensão é reduzido ou removido integralmente (Figura 2.10(a)). Sendo assim, as deformações recuperam níveis compatíveis com a tensão aplicada em função do tempo (Figura 2.10(b)). Nota-se que para materiais puramente elásticos a recuperação dos valores de deformação compatível com o nível de tensão seria imediata (linha tracejada). 


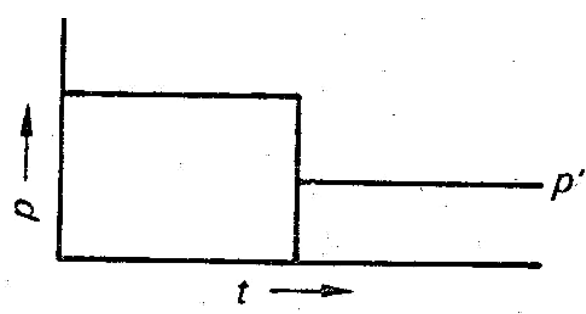

(a)

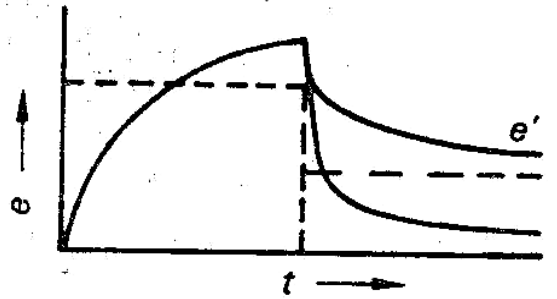

(b)

Figura 2.10 - O fenômeno de Recovery: (a) tensão x tempo;

(b) deformação x tempo (Williams, 1973).

\subsection{MODELO DE DRUCKER-PRAGER}

O Critério de Plastificação de Drucker-Prager definirá no espaço das tensões principais um cone que intercepta o eixo das tensões hidrostáticas $p$ onde $\sigma_{1}=\sigma_{2}=\sigma_{3}$, conforme esquematizado na Figura 2.11(a). Ou então, tem-se uma reta que intercepta em d (coesão do material) o eixo definido por $t$ (tensões desviadoras) e possui inclinação $\beta$ (ângulo de atrito interno do material) em relação ao eixo das tensões hidrostáticas quando a superfície do critério está definida no plano meridional definido pelos eixos dos invariantes de tensão (Figura 11(b)).

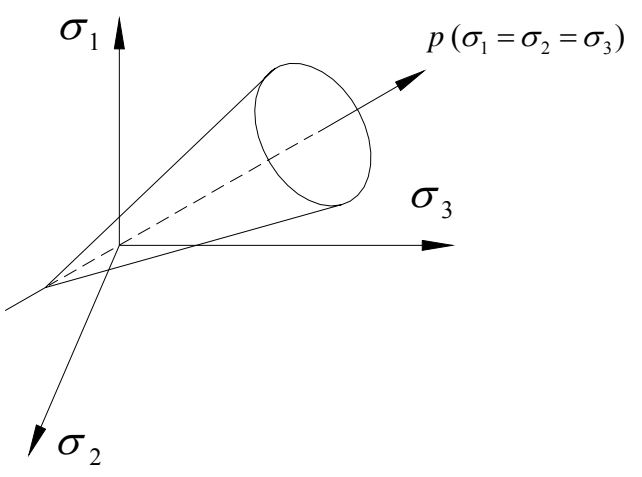

(a)

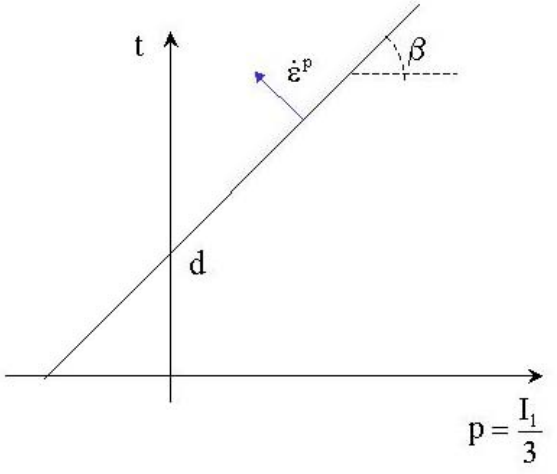

(b)

Figura 2.11 - Superfície do Critério de Drucker-Prager: (a) no espaço das tensões principais;

(b) segundo os eixos dos invariantes de tensão (Hibbit et al., 2000). 
Dessa forma, o Critério de Plastificação de Drucker-Prager segundo os invariantes de tensão será dado pela seguinte equação:

$$
\mathrm{f}\left(\mathrm{J}_{2}, \mathrm{I}_{1}\right)=\sqrt{\mathrm{J}_{2}}-\operatorname{tg}(\beta) \frac{\mathrm{I}_{1}}{3}-\mathrm{d} \leq=0
$$

Nota-se que caso haja evolução de deformações plásticas segundo a regra da normalidade tem-se que o material irá sofrer variação volumétrica devido à ação das tensões hidrostáticas (Figura 2.11(b)). No entanto, pode também ocorrer um fluxo plástico nãoassociativo, ou seja, as deformações plásticas não evoluírem seguindo uma reta normal à superfície de plastificação. Surge assim, o chamado ângulo de dilatação $\psi$ representado geometricamente na Figura 2.12.

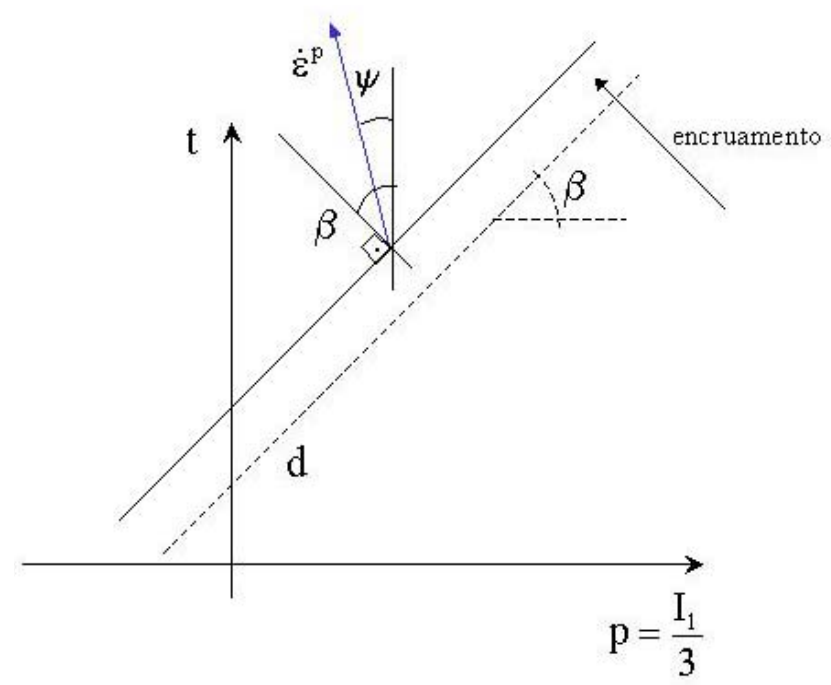

Figura 2.12 - Representação geométrica do ângulo de dilatação (adaptado de Hibbit et al., 2000).

No caso de encruamento definido por ensaio de compressão uniaxial de materiais poliméricos tem-se que o ângulo de dilatação será menor que $\beta$ (Hibbit et al., 2000). Dessa forma, quando $\psi$ for igual a zero, o material se comportará de forma incompressível com a 
evolução das deformações plásticas e caso $\psi$ seja maior que zero, o material terá comportamento compressível. Finalmente, se $\psi$ for igual a $\beta$, o fluxo plástico será associativo.

Tanto o critério de plastificação de Drucker-Prager como a lei de evolução plástica não-associativa estão implementados no programa ABAQUS ${ }^{\circledR}$. Dessa forma, para que uma estrutura fabricada em polímero possa ser analisada pelo programa, torna-se necessário fornecer os parâmetros associados ao critério. Uma alternativa de se obter esses parâmetros consiste na realização de ensaios triaxiais de compressão (Figura 2.13(a)) e de tração $(2.13(b))$

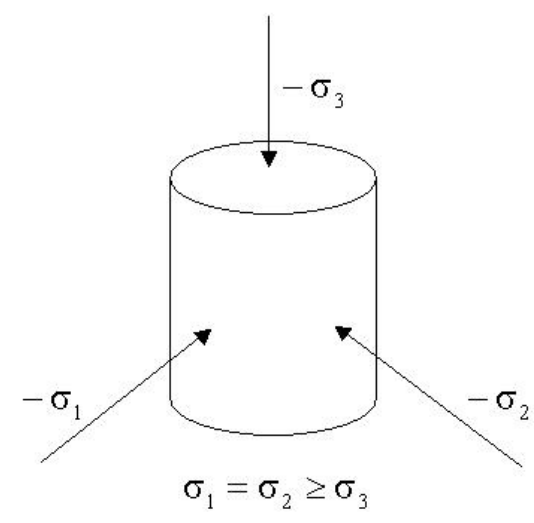

(a)

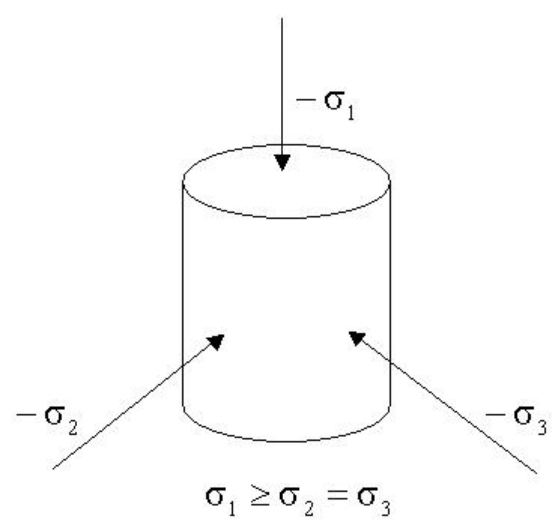

(b)

Figura 2.13 - Ensaios triaxiais: (a) compressão; (b) tração (Hibbit et al., 2000).

Os pontos escolhidos dos ensaios triaxiais (Figura 2.14(a)) são utilizados para o cálculo dos invariantes de tensão e assim são obtidos os pontos que definirão a forma e a posição da superfície de plastificação. Tal superfície será ajustada através da interpolação dos pontos escolhidos (Figura 2.14(b)) e assim os parâmetros $\beta$ e d serão determinados. 


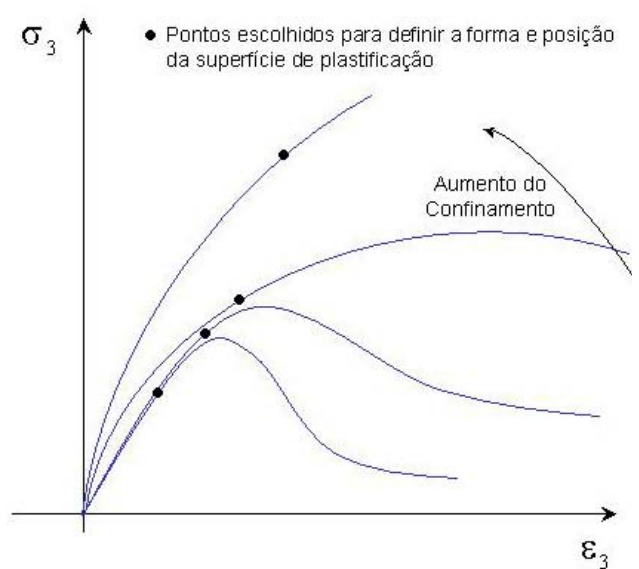

(a)

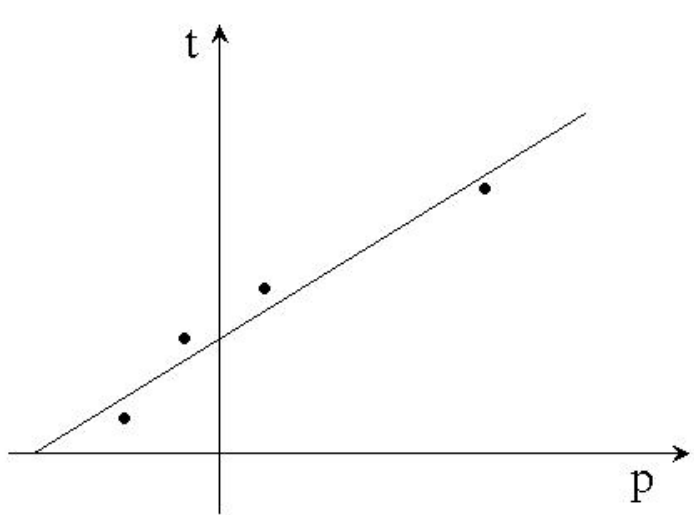

(b)

Figura 2.14 - (a) Curvas tensão-deformação de ensaios triaxiais;

(b) Superfície de plastificação obtida por interpolação (adaptado de Hibbit et al., 2000).

Uma segunda alternativa de se obter os parâmetros associados ao modelo de DruckerPrager é através da determinação dos parâmetros do modelo de falha de Mohr-Coulomb geralmente utilizado para analisar materiais frágeis. O modelo de Mohr-Coulomb é determinado com base nos Círculos de Mohr definidos pelas máximas e mínimas tensões principais. Assim, a linha de falha do modelo será a melhor linha reta que toca esses círculos, definindo, portanto, os parâmetros c (coesão) e $\phi$ (ângulo de atrito interno) (Figura 2.15).

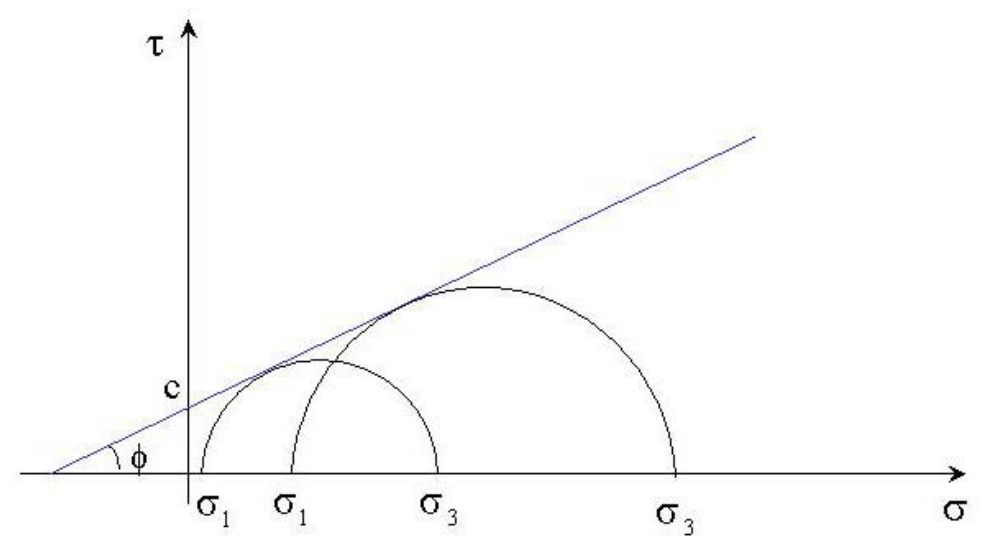

Figura 2.15 - Modelo de falha de Mohr-Coulomb (Hibbit et al., 2000).

Os parâmetros c e $\phi$ podem ser determinados em função dos valores de resistência à tração e à compressão do material, desde que sejam aplicadas algumas relações geométricas. Dessa forma, tem-se: 


$$
\begin{gathered}
\operatorname{sen} \phi=\frac{\left|\sigma_{\mathrm{c}}\right|-\sigma_{\mathrm{T}}}{\left|\sigma_{\mathrm{c}}\right|+\sigma_{\mathrm{T}}} \\
\mathrm{c}=\frac{1+\operatorname{sen} \phi}{2 \cos \phi}
\end{gathered}
$$

Onde:

$\sigma_{\mathrm{c}}=$ tensão de resistência à compressão

$\sigma_{\mathrm{t}}=$ tensão de resistência à tração

No entanto, o modelo de Mohr-Coulomb assume que a falha independe dos valores intermediários das tensões principais e o mesmo não ocorre com o modelo de Drucker-Prager. Sendo assim, é possível verificar a diferença existente entre os dois modelos através da Figura 2.16, sendo que o modelo de Mohr-Coulomb apresenta vértices quando projetados no Plano- $\pi$. Isto implica que pequenas mudanças nos valores de tensão podem causar mudanças significativas na direção do fluxo plástico.

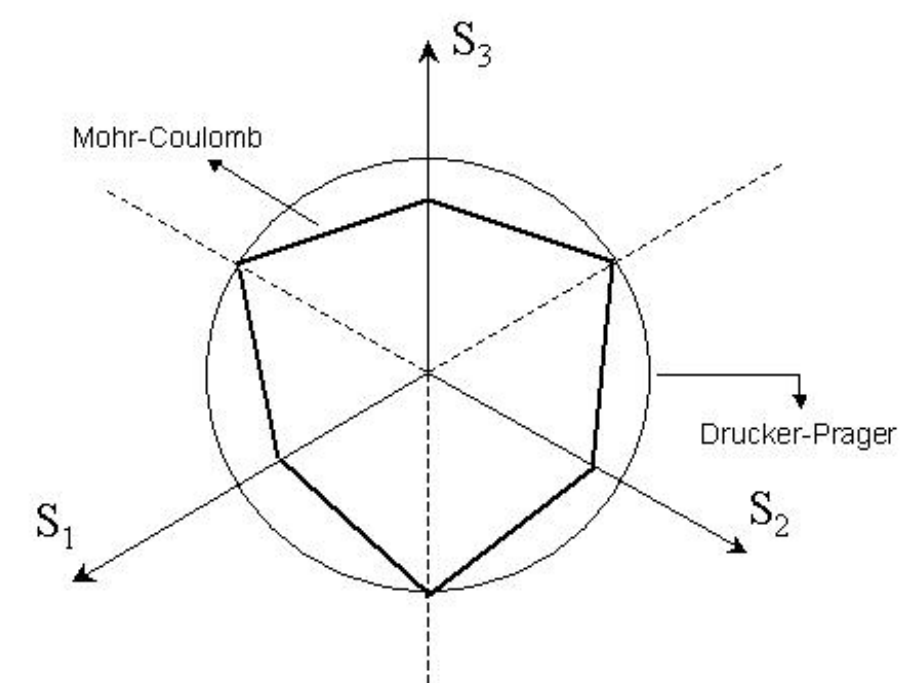

Figura 2.16 - Critério de Mohr-Coulomb e Drucker-Prager projetados no Plano- $\pi$ (Hibbit et al., 2000).

Segundo Hibbit et al. (2000), caso seja utilizada uma análise sob estado plano de deformações, tem-se que os parâmetros de Drucker-Prager estão relacionados com os parâmetros de Mohr-Coulomb através das seguintes equações: 
Se $\psi=\beta$ então $\tan \beta=\frac{\sqrt{3} \operatorname{sen} \phi}{\sqrt{1+\frac{1}{3} \operatorname{sen}^{2} \phi}} \quad$ e $\quad \frac{\mathrm{d}}{\mathrm{c}}=\frac{\sqrt{3} \cos \phi}{\sqrt{1+\frac{1}{3} \operatorname{sen}^{2} \phi}}$

Se $\psi=0$ (incompressível) então $\tan \beta=\sqrt{3} \operatorname{sen} \phi \quad$ e $\quad \frac{\mathrm{d}}{\mathrm{c}}=\sqrt{3} \cos \phi$

As expressões acima demonstram que para valores de $\phi$ acima de $50^{\circ}$, tem-se que os parâmetros de Drucker-Prager estão muito próximos dos parâmetros de Mohr-Coulomb. 


\section{Capítulo 3}

\section{MATERIAIS E MÉTODOS}

\section{1 - MATERIAIS}

A matéria-prima utilizada no presente trabalho é um biopolímero constituído de um poliuretano que se apresenta na forma de bicomponente, constando de um poliol e um pré-polímero. O poliol é sintetizado a partir do óleo de mamona e o pré-polímero é sintetizado a partir do difenilmetano diisocianato (MDI).

Ressalta-se que este material foi desenvolvido pelo Grupo de Química Analítica e Tecnologia de Polímeros (GQATP) do Instituto de Química de São Carlos da USP, que forneceu para este trabalho, um lote de pré-polímero, denominado de 329L, e um lote de poliol, denominado de 471 .

O material é sensível a umidade relativa do ar, tanto na forma de componentes quanto de sua mistura. As informações sobre o mesmo indicam que se o limite de $40 \%$ de umidade relativa do ar for excedido, será produzida uma quantidade excessiva de bolhas durante a polimerização. A formação de bolhas é devida a reação do Isocianato presente no prépolímero com a água, liberando $\mathrm{CO}_{2}$. Estas bolhas são elementos prejudiciais à qualidade dos CPs uma vez que se tornam pontos de concentração de tensão. Essa concentração de tensão afeta de maneira negativa a confiabilidade dos ensaios.

Devido a isso, as amostras necessárias para o desenvolvimento do presente trabalho foram fabricadas em ambiente com controle de temperatura e umidade. Onde a temperatura foi mantida em torno $22^{\circ} \mathrm{C}$ e a umidade relativa do ar próxima de $40 \%$, porém sem exceder esse patamar. 
O poliuretano é preparado através da mistura do pré-polímero ao poliol para que haja uma reação de cura. A relação estequiométrica para o preparo é de 1:0,7, sendo uma parte de pré-polímero para 0,7 partes de poliol, em peso.

A fabricação das amostras foi realizada no Laboratório de Tribologia e Compósitos do Departamento de Engenharia Mecânica (EESC-USP) e foram divididas em dois grandes grupos:

- Corpos-de-Prova (CPs de tração e compressão);

- Próteses de quadril.

Ressalta-se que a fabricação dos CPs visa tanto a obtenção de valores confiáveis das propriedades de material necessárias para realizar simulações computacionais via elementos finitos quanto o registro do histórico do comportamento mecânico do material quando solicitado. O registro dos dados do comportamento do material assim como os do ensaio experimental da prótese de quadril objetivam a comparação do comportamento verificado experimentalmente com a análise computacional através do método dos elementos finitos.

\section{A) CORPOS-DE-PROVA}

Na busca da aplicação da metodologia mais adequada para a confecção dos CPs em poliuretano, decidiu-se realizar a moldagem através de molde aberto fabricado em silicone translúcido. Para este trabalho foi utilizado silicone da marca VANTICO com código dos componentes RP4644R e RP4644E. Dessa forma as cavidades dos moldes foram obtidas a partir de modelos CPs de tração e compressão, confeccionados em aço. A figura 3.1 mostra as cavidades (em silicone) para CPs de ensaios de tração e compressão sendo preenchidas com biopolímero. 


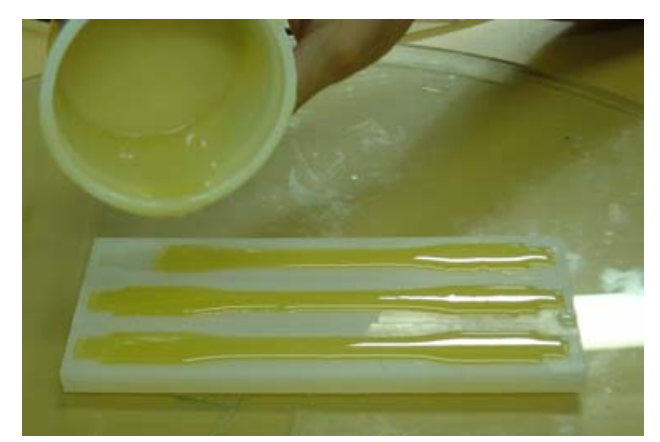

(a)

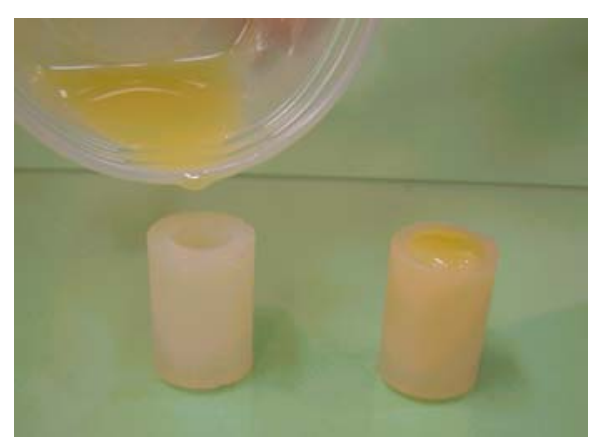

(b)

Figura 3.1: moldagem em molde aberto fabricado em silicone.

(a) molde de tração e (b) moldes de compressão.

\section{B) PRÓTESES DE QUADRIL}

Assim como aplicado para a obtenção de CPs, as próteses de quadril foram fabricadas utilizando molde de silicone translúcido. No entanto, o molde empregado é do tipo fechado e bipartido e suas cavidades foram obtidas a partir de um protótipo físico da prótese em plástico ABS (Acrylonitrile Butadiene Styrene). Tal protótipo foi confeccionado via técnica de prototipagem rápida FDM (Fused Deposition Modeling). A Figura 3.2(a) mostra o protótipo em ABS e a Figura 3.2(b) o processo de obtenção do molde em silicone utilizando o modelo prototipado.

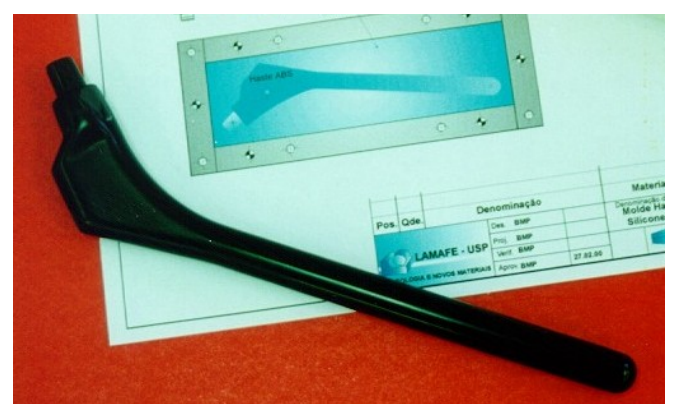

(a)

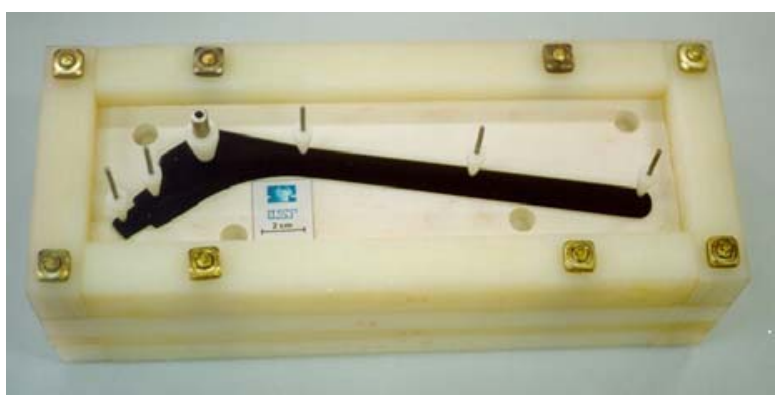

(b)

Figura 3.2: Protótipo da prótese de quadril. (a) Modelo prototipado em ABS;

(b) caixa de moldagem para obtenção do molde utilizando o modelo prototipado. 


\section{2 - MÉTODOS}

As amostras necessárias para o desenvolvimento do presente trabalho foram fabricadas em ambiente com controle de temperatura e umidade, uma vez que o material é sensível a umidade relativa do ar. Tal procedimento foi adotado, pois caso contrário existe à inserção de uma quantidade elevada de bolhas nas amostras durante a polimerização.

Assim sendo, temperatura foi mantida em torno $22^{\circ} \mathrm{C}$ e a umidade relativa do ar próxima de $40 \%$ o que melhorou sobremaneira a qualidade dos CPs. Ressalta-se que esses valores foram utilizados após a realização de todo um estudo preliminar e uma ampla pesquisa sobre o assunto levando em conta tanto o manuseio quanto o comportamento do material quando solicitado nos ensaios normalizados. Nesse estudo vários procedimentos foram pesquisados, utilizados, cronometrados e testados. A partir dos dados obtidos foi possível estipular métodos ótimos de manuseio e armazenamento tanto das resinas quanto dos CPs já prontos. Os procedimentos e tempos que se concluiu serem ótimos foram seguidos fielmente na preparação de todas as amostras.

Durante qualquer período de espera ou transição de uma fase de fabricação para outra, além de serem mantidos em ambiente climatizado, as resinas e os CPs foram armazenados em compartimento contendo sílica-gel, denominado caixa-seca, e monitorados através de termohigrômetro para garantir as condições prescritas de umidade relativa do ar e temperatura.

O item "3.2 - Métodos", é dividido em 4 itens assim denominados:

A - Obtenção dos CPs;

B - Obtenção das próteses de quadril;

C - Análise experimental;

D - Análise computacional.

Em cada um destes itens é apresentado o detalhamento de métodos e procedimentos adotados neste trabalho. 


\section{A) OBTENÇÃO DOS CORPOS-DE-PROVA}

Na fabricação dos CPs, tanto para tração quanto para compressão, foi utilizado a experiência (do inglês "know-how") de fabricação em moldes abertos, feitos em silicone translúcido. Em tal método é dada a forma desejada ao molde através de matrizes que neste caso foram fabricadas em aço carbono através de usinagem e retificação. A retificação foi realizada a fim de se obter um modelo com precisão dimensional e acabamento superficial com uma rugosidade $\mathrm{Ra}=0,2 \mu \mathrm{m}$. A precisão dimensional mencionada visa atender a tolerância especificada pelas normas utilizadas. Após a confecção das matrizes, as mesmas foram posicionadas numa caixa de moldagem de maneira que sua forma fosse copiada por um bloco de silicone e uma cavidade, assim, fosse obtida, concluindo a fabricação dos moldes.

Para obtenção dos CPs em biopolímero inicialmente o pré-polímero e o poliol são misturados em um recipiente à pressão e à temperatura ambiente, segundo a relação estequiométrica de 1:0,7, respectivamente. Para isso foi utilizada uma balança eletrônica OHAUS $^{\circledR}$, modelo TS4000D com capacidade para $4.000 \mathrm{~g}$ e sensibilidade de $0,01 \mathrm{~g}$. Em seguida, a mistura é agitada manualmente por 2 minutos para que fique homogênea. Transcorrido esse tempo, o recipiente com a mistura é inserido num dessecador acoplado a uma bomba de vácuo com o objetivo de eliminar as bolhas de ar que surgem durante a agitação da mistura. O tempo de permanência da mistura no vácuo é de 5 minutos. Nesta etapa, utilizou-se uma bomba de vácuo PFEIFFER BALZERS ${ }^{\circledR}$ com capacidade de pressão de $1 \times 10^{-4}$ mbar e um fluxo de $8 \mathrm{~m}^{3} / \mathrm{h}$. Terminado o processo de retirada de bolhas, a mistura é derramada dentro da cavidade do molde de silicone aberto (Figura 3.1). O processo de inserção da mistura no molde não possui um tempo específico de realização devendo ocorrer o mais rapidamente possível. No caso dos CPs de tração, o preenchimento do molde deve ser iniciado numa de suas extremidades, derramando a mistura sempre em sua frente de 
escoamento no molde (Figura 3.1(a)). Por outro lado, para os moldes de compressão, devido a sua geometria, tal tarefa não pôde ser realizada da mesma forma (Figura 3.1(b)).

A desmoldagem do CP é realizada depois de transcorridas no mínimo 12 horas após o preenchimento, tempo em que o poliuretano solidificou-se o suficiente para que não ocorram danos nem ao molde nem nas dimensões do CP para a realização desta operação. Depois de transcorridas no mínimo 36 horas desde a desmoldagem, os CPs de tração foram cuidadosamente lixados para a retirada de rebarbas e adequação as dimensões especificadas pela norma, sendo que essas dimensões foram cuidadosamente conferidas com um instrumento de medição adequado. Destaca-se que o lixamento dos CPs de tração foi realizado cuidadosamente e apenas nas bordas segundo a espessura do mesmo. Já os CPs de compressão, após desmoldados foram submetidos a um faceamento (torneamento das faces) para garantir que as seções transversais da base e do topo estivessem paralelas entre si e perpendiculares ao eixo de giração do CP. Ressalta-se que essa operação conferiu à superfície usinada uma rugosidade $\mathrm{Ra}=2,9 \mu \mathrm{m}$ e que para tanto, foi utilizado um torno mandrilador KÖBÁNYAI GYÁRIA - SZIM, modelo EGM-200, o qual apresenta uma precisão de $0,005 \mathrm{~mm}$ em $300 \mathrm{~mm}$ no sentido longitudinal e de $0,01 \mathrm{~mm}$ no sentido transversal (EGM200, 1969).

O tempo de manuseio do poliuretano, desde a mistura até o envase no molde de silicone, é determinado segundo o seu "pot life"". O poliuretano utilizado apresenta um "pot life" de 20 minutos aproximadamente para a quantidade utilizada de mistura e a cura quase total é aproximadamente de 48 horas. No entanto, mesmo após esse período, segundo Grupo de Química Analítica e Tecnologia de Polímeros (GQATP), nem todas as ligações cruzadas possíveis foram efetuadas, porém essas ligações podem ocorrer indefinidamente ao longo do tempo. Porém, essas ligações ainda podem ocorrer, ou seja, podem ser introduzidas nesta

${ }^{1}$ Pot life = tempo necessário para que o sistema de resina formulado retenha a viscosidade em níveis baixos o suficiente para ser utilizada no processamento. 
etapa, desde que os CPs sejam expostos a um aumento de temperatura num dado período de tempo. Nesse sentido, um outro aspecto é que para seu emprego em cirurgias para reparar defeitos decorrentes de perdas ósseas bem como para implante de próteses, o biopolímero deve ser esterilizado. No processo de esterilização, o mesmo é submetido a uma temperatura de $80^{\circ} \mathrm{C}$ por 3 horas (Enfatiza-se, porém, que a esterilização do biopolímero é executado através de raios gama). Assim sendo, após 48 horas de desmoldagem, efetuou-se o transporte dos CPs a um forno micro-controlado para serem expostos ao aumento de temperatura durante o tempo determinado. Esse procedimento foi utilizado com o intuito de simular a elevação de temperatura do processo de esterilização ao qual o material seria submetido antes de ser implantado bem como realizar a polimerização remanescente no biopolímero. Este processo de aquecimento também auxilia na eliminação de tensões residuais que podem ter sido introduzidas durante a moldagem. Na Figura 3.3 são mostrados CPs de tração no forno microcontrolado.

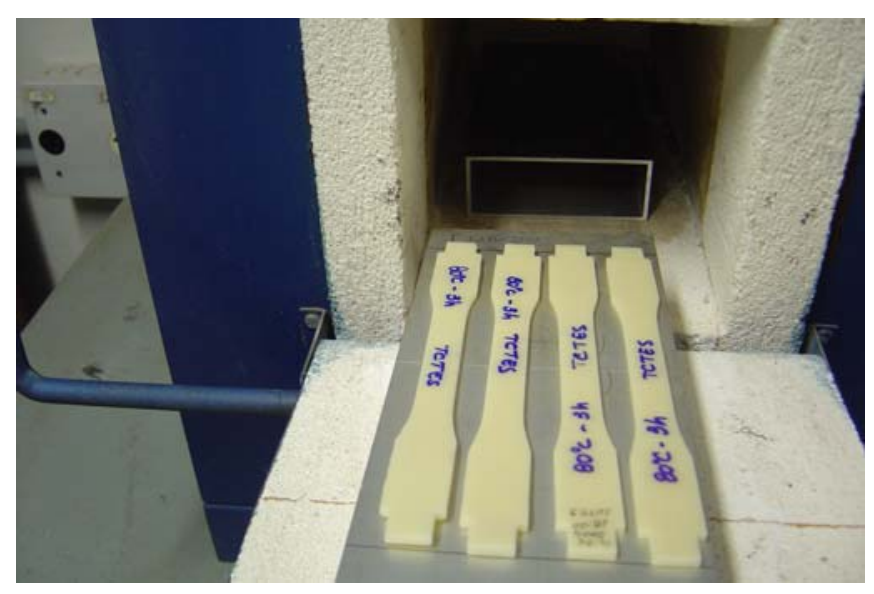

Figura 3.3 - CPs de tração levados a um forno micro-controlado.

Finalizada esta etapa, partiu-se para o tratamento superficial do local de colagem dos strain gages. Tal tratamento é feito através de lixa de granulação 320. Concluiu-se ser essa a melhor especificação de lixa devido à observação do comportamento dos testes com o primeiro lote de strain gages adquiridos. Com essa configuração de lixa também não foi introduzido nenhum defeito que exercesse influência negativa nos dados coletados. Em 
seguida se procedeu a colagem do mesmo através do adesivo apropriado. Ressalta-se que tanto os strain gages quanto o adesivo utilizado são descritos no tópico "C. Análise Experimental", ainda dentro do item "3.2 - Métodos".

Os CPs também receberam marcações para posicionamento nas garras da máquina universal de ensaio e para o posicionamento de extensômetro (CPs de tração) de acordo com a normatização utilizada. Um aspecto importante no caso dos CPs de tração é a observação do chamado comprimento de medição ou gage length, pois é a dimensão que se utiliza nos cálculos de deformação e tensão. Para os CPs de tração utilizados a medida é de $50 \mathrm{~mm}$, ou seja, a partir do centro do CP se mede $25 \mathrm{~mm}$ para cada extremidade no sentido longitudinal (vide Figura 3.4).

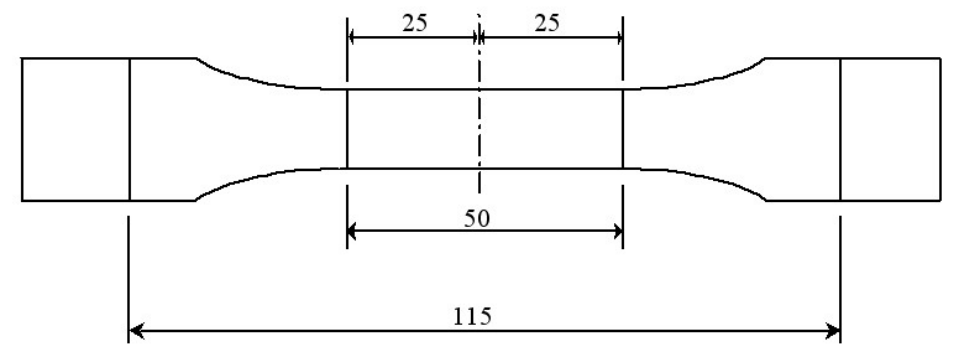

Figura 3.4 - Marcações para posicionamento nas garras $(115 \mathrm{~mm})$ e de extensômetro (50mm ou gage length) (ASTM D638-96- Tipo I).

Ao final do processamento os CPs foram armazenados em recipiente adequado contendo sílica-gel para garantir condições de baixa umidade relativa do ar e temperatura constante descritas anteriormente, mesmo que nesta próxima fase esta não exerça ou exerça pouca influência sobre o biopolímero. Tal procedimento foi adotado uma vez que após realização de pesquisa foi verificada a inexistência de informações acerca de efeitos da umidade e temperatura sobre o material curado ${ }^{2}$. 


\section{B) OBTENÇÃO DAS PRÓTESES DE QUADRIL}

As próteses de quadril foram fabricadas utilizando molde de silicone translúcido, assim como efetuado com os CPs. No entanto, devido ao seu formato irregular, o molde empregado é do tipo fechado e bipartido e suas cavidades foram obtidas a partir de um protótipo físico da prótese em plástico ABS. Tal protótipo foi confeccionado através da técnica de prototipagem rápida tipo FDM (Modelo feito por deposição de material fundido do inglês Fused Deposition Modeling), utilizando uma máquina STRASYS 500 do Núcleo de Prototipagem Rápida do PARQTEC de São Carlos/SP. O modelo da haste de implante de quadril para prototipagem foi concebido conforme projeto proposto por Silvestre Filho (2001), ilustrado na Figura 3.5.

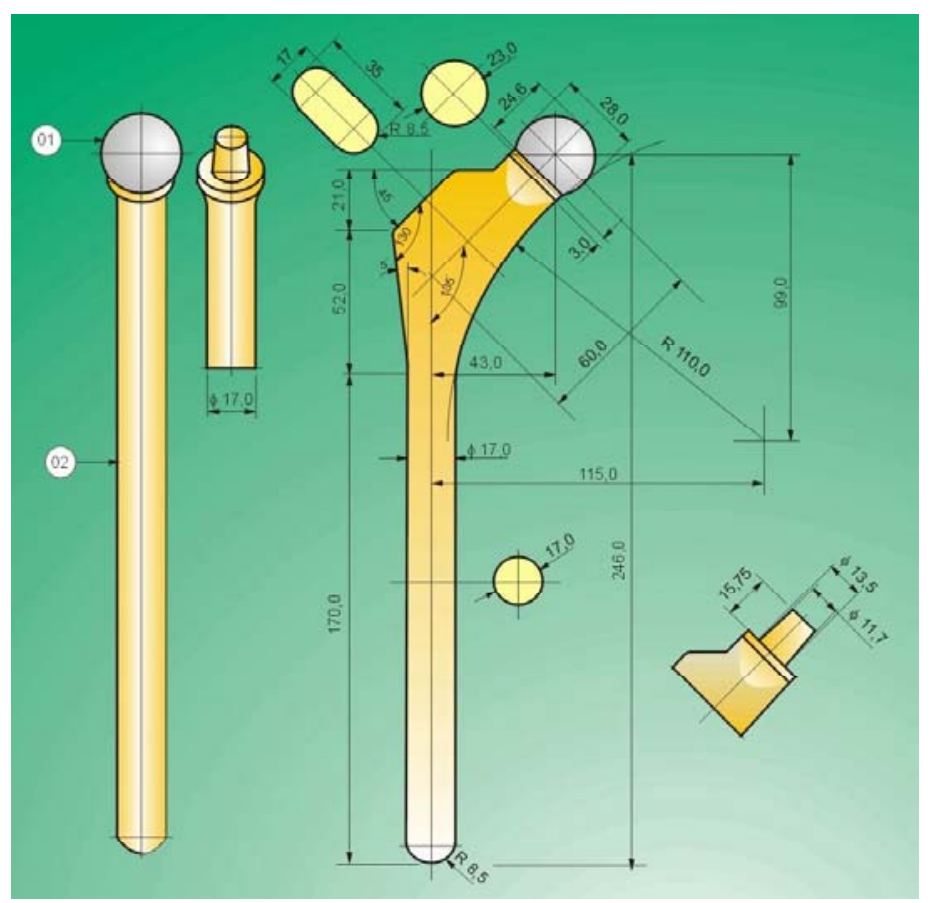

Figura 3.5 - Projeto de haste de implante de quadril proposto por Silvestre Filho (2001).

Após a confecção do modelo em ABS, o mesmo foi posicionado numa caixa de moldagem de tal forma que a primeira metade do molde pudesse ser obtida. Depois de pronta a primeira metade, a outra metade do molde foi obtida posicionando-se o protótipo físico 
sobre a primeira metade do molde de silicone e adicionando pinos para a criação dos canais de vazamento e de saída de ar (Figura 3.2).

Finalmente, com as duas partes do molde prontas, o procedimento para obtenção das próteses de quadril em biopolímero é semelhante ao de obtenção dos CPs, sendo que a mistura pré-polímero com poliol é vazada no molde fechado através do canal de vazamento. Após a desmoldagem as rebarbas são retiradas e da mesma forma procedida com os CPs, depois de transcorridas 48 horas, as próteses são levadas a um forno micro-controlado. Finalmente, o mesmo procedimento utilizado para a instrumentação dos CPs com strain gages foi também utilizado para as hastes de quadril e seu armazenamento é feito da mesma forma como procedido com os CPs.

\section{C) ANÁLISE EXPERIMENTAL}

Os corpos-de-prova foram submetidos a uma ampla gama de ensaios monotônicos (quase-estáticos) e cíclicos sob tração e compressão que visaram tanto a obtenção de valores confiáveis das propriedades de material necessárias para realizar as simulações computacionais empregando o programa de elementos finitos, quanto efetuar o registro do histórico do comportamento mecânico do material quando solicitado. $\mathrm{O}$ registro dos dados do comportamento do material quando na forma de corpos-de-prova assim como no aspecto de prótese de quadril tem o objetivo de servir como base de comparação entre o comportamento mecânico verificado experimentalmente e análise computacional. Para isso se-recorreu às normas ASTM, bem como, a norma ISO, visando à obtenção de padronização experimental. Tais normas possuem recomendações que vão desde geometria de corpos-de-prova até velocidades de deslocamento do cabeçote móvel (crosshead) da máquina de ensaios.

Nesta etapa, os equipamentos utilizados nos ensaios foram: uma máquina de ensaio EMIC modelo DL10000 com classificação conforme NBR 6156/1983 e velocidade de 
operação de 0,01 a $500 \mathrm{~mm} / \mathrm{min}$, interligada ao sistema de coleta de dados Test Works ${ }^{\mathrm{TM}}$, instalada no Departamento de Materiais, Aeronáutica e Automobilística (EESC-USP); uma máquina Universal de Ensaios Instron 5500R instalada no Departamento de Engenharia de Materiais (DEMA-UFSCar). Ambas são dotadas de extensômetros que proporcionaram uma coleta de dados com precisão significativa. Com a instrumentação proporcionada por estes equipamentos já foi possível coletar dados bem confiáveis uma vez que os resultados obtidos estiveram próximos uns dos outros e as máquinas citadas possuíam aferição recente.

No entanto, para se possuir total segurança acerca dos dados experimentais, também foram realizados ensaios com strain gages (extensômetros resistivos), proporcionando uma medida mais localizada, quase que pontual. No caso, devido às características deste material polimérico, a presença de grandes deformações indicava a necessidade de aquisição de straingages adequados. Sendo assim, foi realizada uma ampla pesquisa na busca do aparato mais adequado para a utilização nos experimentos realizados, que indicaram a escolha de straingages da "KYOWA ELECTRONIC INSTRUMENTS CO, LTD” representada no Brasil pela PANAMBRA. Dessa forma, strain-gages KFEL-2-120-C1 (uniaxial), capazes de medir até $15 \%$ de deformação e que possui um tamanho total da folha de $8 \mathrm{X} 4 \mathrm{~mm}$ e resistência de $120 \Omega$, foram utilizados (KYOWA, 2004a). Utilizou-se também o modelo biaxial de strain gage KFEL cujo modelo é o KFEL-2-120-D34, que possui um tamanho total da folha de $10 \mathrm{X}$ 10mm e resistência também de $120 \Omega$. Para os ensaios com a haste de implante de quadril também foi usado o modelo triaxial denominado KFEL-2-120-D35, que possui tamanho de folha e resistência iguais ao modelo biaxial. Segundo KYOWA (2004a), esse tipo de strain gage, KFEL, foi desenvolvido para medir níveis de deformação elásticos e plásticos.

Devido ao percentual de deformação apresentado pelo strain gage tipo KFEL, necessita-se de adesivo que também suporte esta amplitude de deformação. O indicado pelo fabricante dos strain gages é um adesivo à base de resina cianoacrilato denominado CC-36, 
cuja temperatura de operação está entre -10 a $80^{\circ} \mathrm{C}$ e requer cerca de 24 horas para curar completamente (KYOWA, 2004b), Vale ressaltar que tentou-se utilizar até a própria resina como adesivo para o strain-gage, porém os testes com esse tipo de configuração não se mostraram satisfatórios, havendo assim, descolamento do strain-gage antes do mesmo completar a aquisição de dados necessária.

Para coleta e interpretação dos sinais dos strain gages foi utilizado um sistema de aquisição de dados HBM (Hottinger Baldwin Messtechnik) modelo MGCplus com AB22A / AB32 pertencente ao Departamento de Materiais, Aeronáutica e Automobilística (EESCUSP). Esse equipamento possui módulo AP815 que tem capacidade para 8 strain gages que podem ser ou $1 / 4$ de ponte, ou $1 / 2$ ponte ou ainda ponte completa (HBM, 2002). O equipamento possui também programa para manipulação de dados CATMAN 5.0. Possui módulos AP14 e AP78 que foram necessários quando da utilização da célula de carga e do LVDT (Linear Variable Differential Transformer). O LVDT foi utilizado para medida de deslocamento do travessão da máquina de ensaios universal proporcionando assim a medida do deslocamento do CP. O mesmo é da marca KYOWA, modelo DTH-A-20, do Departamento de Estruturas (EESC-USP), com capacidade de deslocamento de 0 a 20 milímetros e resolução de aproximadamente $0.001 \mathrm{~mm}$.

Para o registro dos carregamentos aplicados foi utilizada uma célula de carga com capacidade para $2000 \mathrm{Kg}$ inserida adicionalmente na configuração de ensaio. A célula de carga utilizada era modelo ST2K, adquirida da Vincere do Brasil Ltda. Utilizou-se tal célula, pois havia necessidade de que os dados de força ficassem combinados com o tempo e o deslocamento que seriam gravados pelo dispositivo HBM. 


\section{C.1) ENSAIOS QUASE-ESTÁTICOS}

De maneira geral, os CPs dos ensaios quase-estáticos (tração, compressão e flexão) tiveram a sua geometria especificada pelas normas ASTM (American Society for Testing and Materials) e foram importantes para a determinação das propriedades elásticas bem como para a obtenção de varias curvas, tais como: tensão-deformação; carga-deslocamento; tensãotempo; deformação-tempo e carga-tempo.

\section{C.1.1) ENSAIOS DE TRAÇÃO}

Para o experimento de tração foram adotadas as especificações da norma ASTM D638-96 (Tipo I) que orientam quanto a obtenção dos CPs para este tipo de ensaio assim como em relação aos dados a se pode determinar:

- O módulo de elasticidade à tração (E): curvatura inicial da curva tensão-deformação;

- O coeficiente de Poisson v: relação entre a deformação transversal pela deformação longitudinal (- $\left.\varepsilon_{\text {transversal }} / \varepsilon_{\text {longitudinal }}\right)$

- A resistência à tração;

- A tensão de escoamento à tração;

- O limite de deformação à tração.

A Figura 3.6 apresenta as dimensões em milímetros do CP de tração Tipo I da norma ASTM D638-96 (Tipo I).

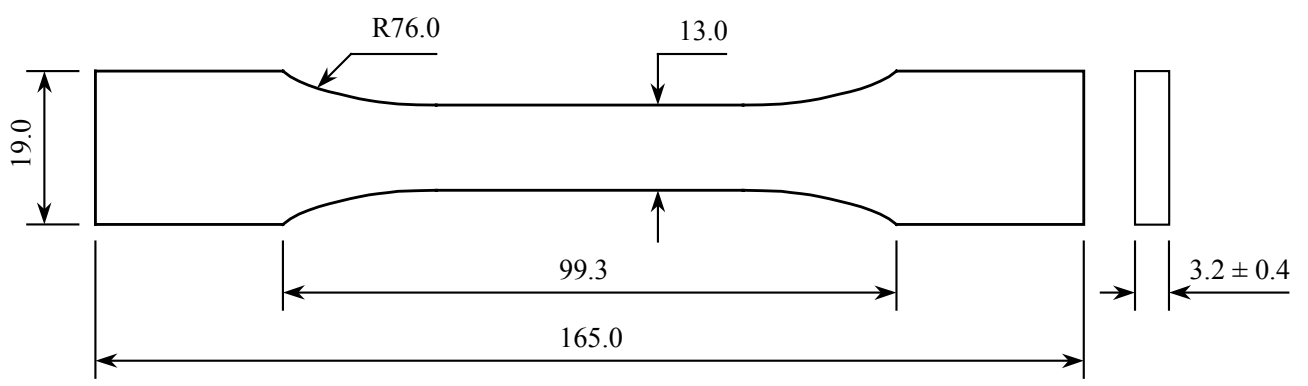

Figura 3.6 - Dimensões em milímetros do CP de tração (ASTM D638-96- Tipo I) 
Inicialmente, foram realizados ensaios monotônicos de tração (somente carregamento) empregando um extensômetro na direção longitudinal à força aplicada, a fim de medir a deformação longitudinal da amostra. Em seguida, o valor do coeficiente de Poisson foi obtido através de dois extensômetros (Figura 3.7(a)), onde um foi posicionado na direção longitudinal, enquanto o outro foi posicionado transversalmente em relação à direção do carregamento aplicado. O coeficiente de Poisson foi obtido também através de dois straingages (Figura 3.7(b)).

Também foram realizados ensaios com ciclos de carregamento-descarregamento e recarregamento a fim de avaliar o comportamento do biopolímero em função do tempo.

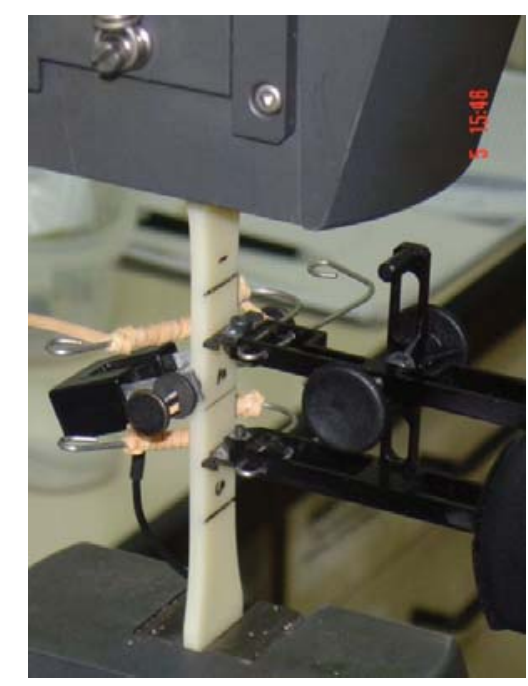

(a)

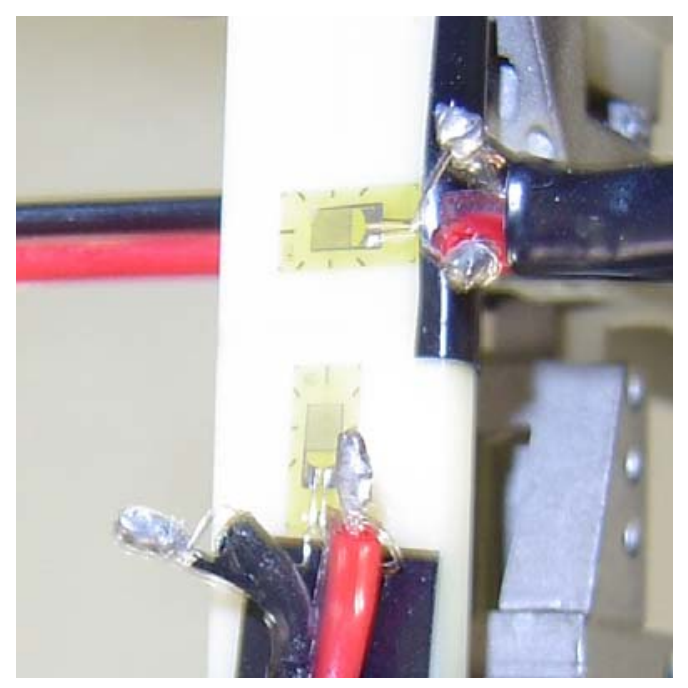

(b)

Figura 3.7 - Determinação do coeficiente de Poisson por: (a) extensômetros; (b) strain gages.

Durante os ensaios monotônicos, com o objetivo de se verificar a influência da taxa de deformação, o comportamento mecânico do biopolímero foi avaliado em duas velocidades diferentes de aplicação de deslocamento: 5,0 e 0,8 mm/min. Porém, os ensaios com ciclos de carregamento-descarregamento e re-carregamento (não-monotônicos) foram realizados sob apenas uma velocidade $(0,8 \mathrm{~mm} / \mathrm{min})$. 


\section{C.1.2) ENSAIOS DE COMPRESSÃO}

Para a obtenção dos CPs dos ensaios de compressão, adotou-se as especificações da norma ASTM D695-96 que estabelece um corpo-de-prova cilíndrico com uma relação de 1:2 entre diâmetro e comprimento respectivamente, sugerindo também a utilização de um cilindro com $12,7 \mathrm{~mm}$ de diâmetro e $25,4 \mathrm{~mm}$ de comprimento, sendo esta a configuração utilizada neste trabalho.

Seguindo a orientação da norma citada acima, é possível determinar:

- O módulo de elasticidade à compressão $\left(\mathrm{E}_{\mathrm{c}}\right)$ : curvatura inicial da curva tensãodeformação;

- A resistência à compressão;

- A tensão de escoamento à compressão;

- O limite de deformação à compressão.

Inicialmente, foram realizados ensaios monotônicos de compressão (apenas carregamento) onde a deformação do CP na direção longitudinal à força aplicada foi medida com auxílio do travessão da máquina (Figura 3.8).

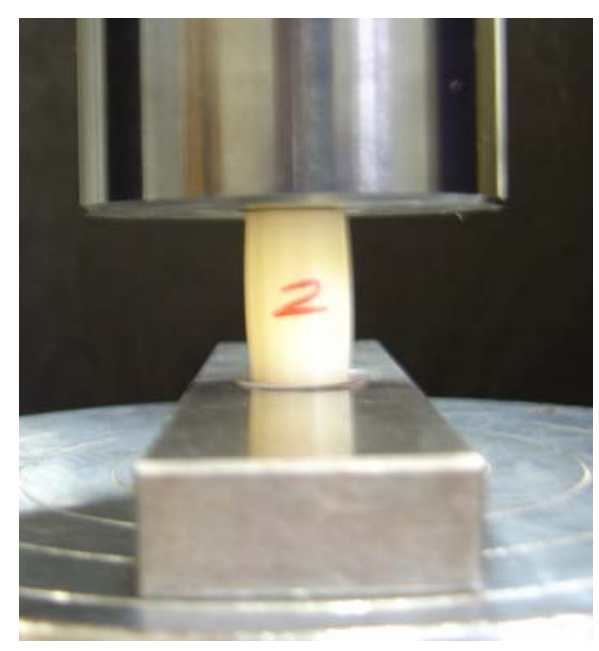

Figura 3.8 - Ensaios de compressão: medida de deformação através do travessão. 
Numa outra etapa foram empregados dois strain-gages, idênticos aos do ensaio de tração, posicionando-se um na direção longitudinal (Figura 3.9(a)) e o outro na direção transversal (Figura 3.9(b)).

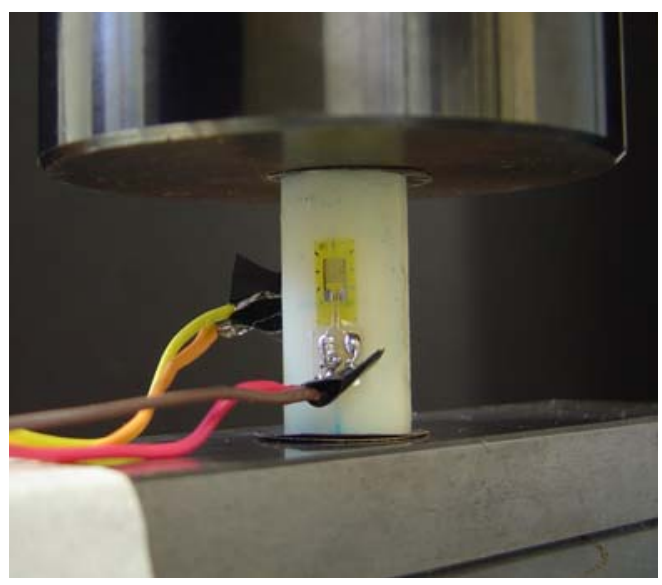

(a)

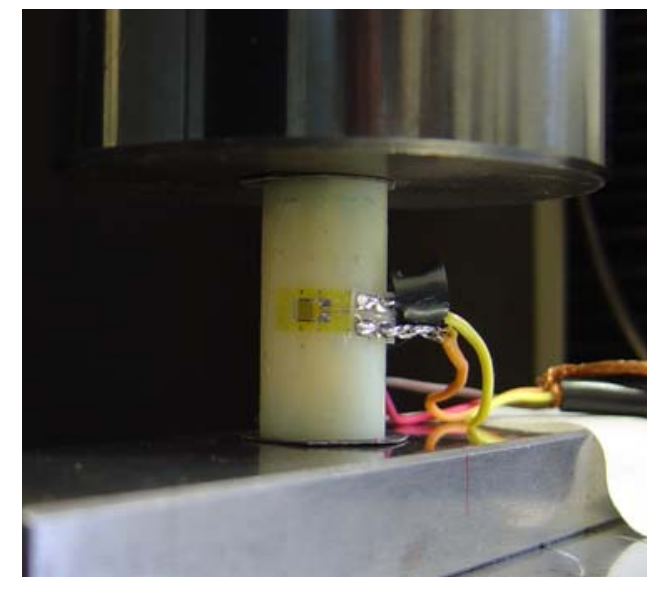

(b)

Figura 3.9 - Ensaios de compressão com medida de deformação através de strain gages, colados no mesmo CP, nos sentidos (a) longitudinal e (b) transversal.

Foram realizados ainda ensaios com ciclos de carregamento-descarregamento e recarregamento a fim de avaliar o comportamento do biopolímero em função do tempo.

Durante os ensaios monotônicos, utilizou-se somente uma velocidade de aplicação de deslocamento que foi igual a $0,8 \mathrm{~mm} / \mathrm{min}$. Esta velocidade também foi a utilizada nos ensaios com ciclos de carregamento-descarregamento e re-carregamento (não-monotônicos).

\section{C.1.3) ENSAIOS DA PRÓTESE DE QUADRIL}

No presente trabalho, para avaliar o desempenho das próteses de quadril fabricadas em biopolímero, é utilizada a norma ISO 7206-3 que aborda a aplicação de carregamento de flexão. De acordo com esta norma, uma prótese de quadril deve ser fixada em um dispositivo a fim de simular a situação de carregamento, caso a mesma tivesse sido implantada em uma pessoa. 
Em seu trabalho de mestrado, Silvestre Filho (2001) já havia desenvolvido um dispositivo para ensaios num modelo prótese de quadril, cuja geometria foi proposta naquele trabalho. Para a realização do presente trabalho, no entanto foi utilizado um novo dispositivo, melhorado, desenvolvido no Laboratório de Tribologia e Compósitos do Departamento de Engenharia Mecânica (EESC-USP) pelo referido autor. Com este novo dispositivo vislumbrava-se ensaios com resultados mais criteriosos e consistentes do que aqueles obtidos em 2001. Com base nesses dados objetiva-se avaliar a capacidade dos modelos de material utilizados pelo pacote comercial ABAQUS ${ }^{\circledR}$ representarem o comportamento do biopolímero frente a carregamentos complexos.

A configuração experimental possui dois aparatos básicos denominados mecanismos inferior e superior, conforme ilustrado na Figura 3.10(a). Assim sendo, o mecanismo inferior do dispositivo é constituída de um cilindro oco, com um sistema de travamento, que receberá em seu interior um dispositivo bipartido especial, visando assim engastar a prótese de quadril com uma esfera de alumina (Figura 3.10(b)).

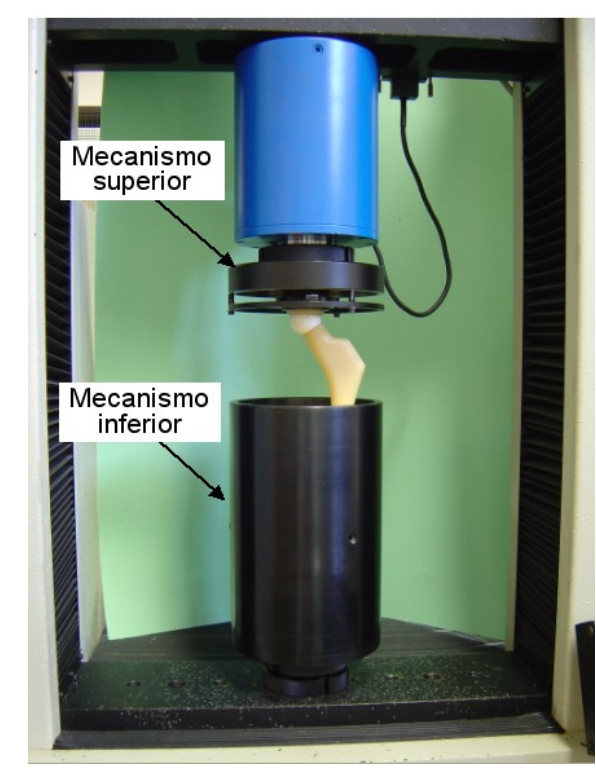

(a)

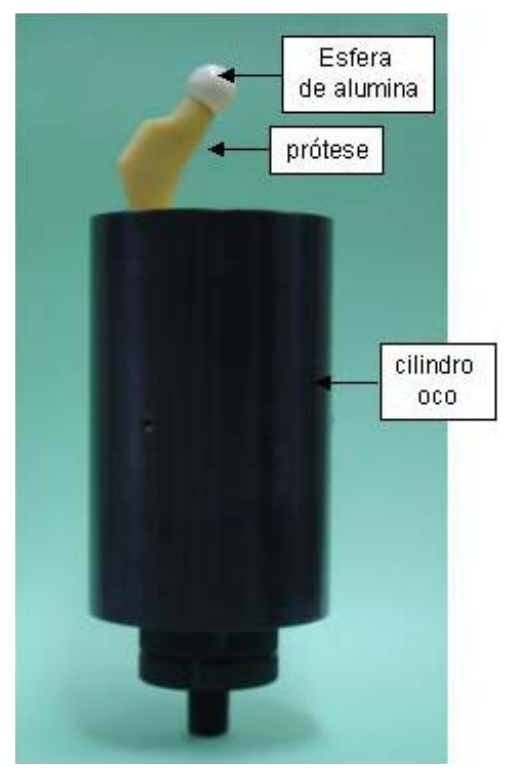

(b)

Figura 3.10 - Dispositivo para avaliar prótese de quadril: (a) configuração geral mostrando os mecanismos inferior e superior; (b) mecanismo inferior. 
O dispositivo bipartido especial (Figura 3.11(a)) é composto de uma gaiola de açoliga, de duas partes, especialmente projetada (Figura 3.11(b)) para abraçar um corpo de granito sintético, que engastará a prótese de quadril com uma esfera de alumina de $26 \mathrm{~mm}$ de diâmetro na sua extremidade superior (Figura 3.11(a)).

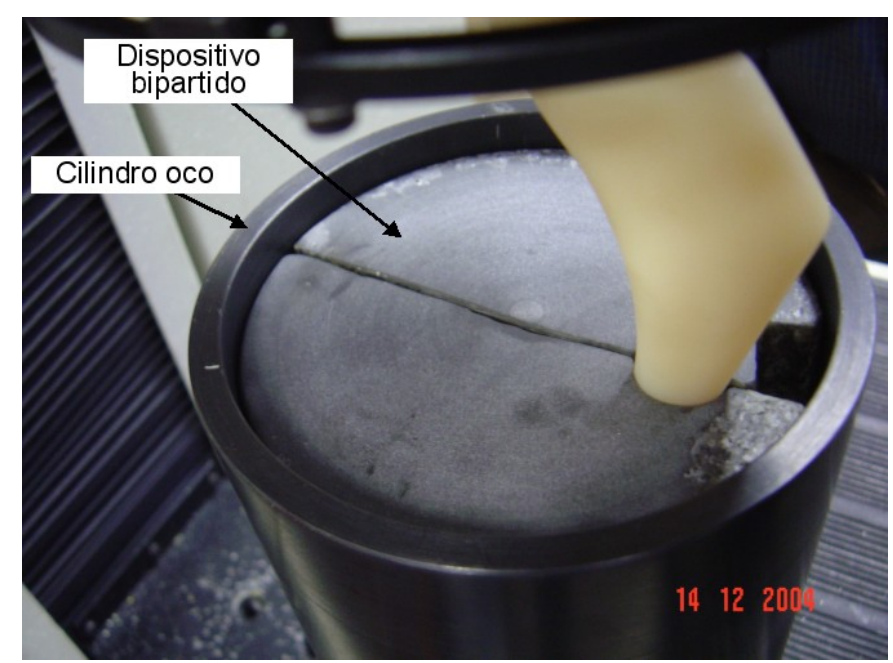

(a)

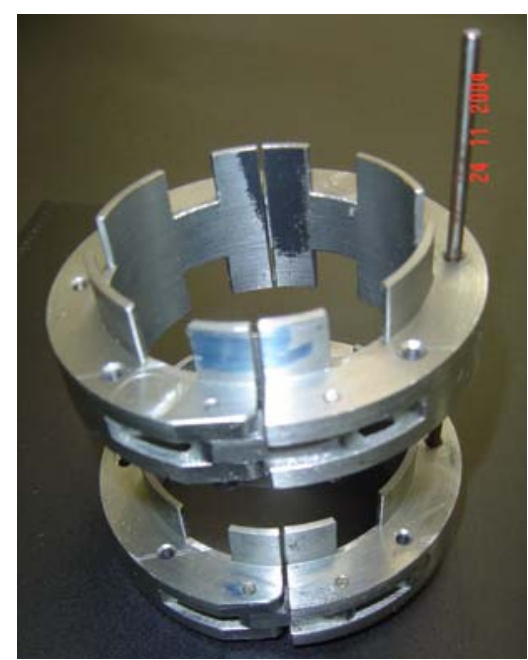

(b)

Figura 3.11 - Mecanismo inferior do Dispositivo para avaliar prótese de quadril: (a) Cilindro oco com o dispositivo bipartido e prótese acoplados; (b) gaiola em aço-liga.

A mecanismo superior é constituído de dois itens principais: uma pista de deslizamento e o assento com rolamento (Figura 3.12(a)). A pista de deslizamento foi confeccionada em aço de alta resistência com tratamento superficial, retificado e com aferição de planicidade. Ao assento com rolamento será montado o acetábulo (Figura 3.12(b)) ao qual será acoplada a cabeça da prótese (esfera de alumina). 


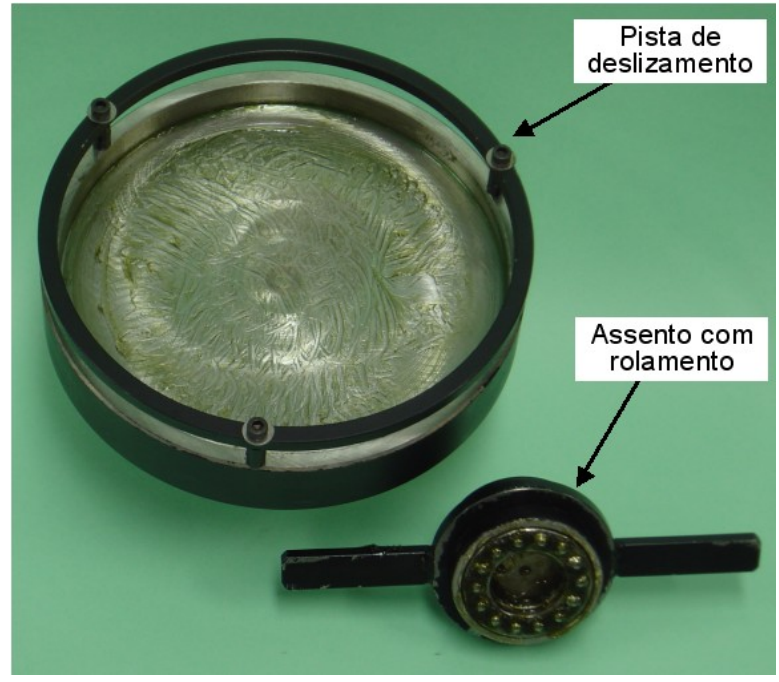

(a)

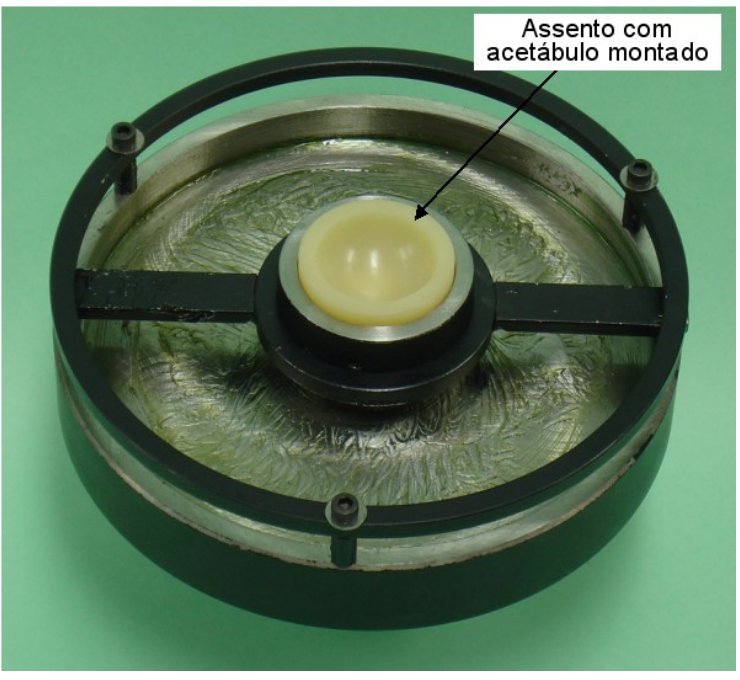

(b)

Figura 3.12 - Parte superior do dispositivo para avaliar prótese de quadril:

(a) Componentes - pista de deslizamento e assento com rolamento;

(b) Componentes montados e já com acetábulo instalado no assento.

Essa configuração proporcionará o deslizamento do rolamento sobre a pista durante a realização do experimento fazendo com que o carregamento esteja sempre na posição vertical em relação à cabeça da prótese, passando pelo centro da esfera de alumina (Figura 3.13(a)). O dispositivo montado foi acoplado a uma máquina de ensaio EMIC (Figura 3.13(b)), interligada ao sistema de coleta de dados Test Works ${ }^{\mathrm{TM}}$, instalada no Departamento de Materiais, Aeronáutica e Automobilística (EESC- USP). Os ensaios realizados são monotônicos com velocidade igual a $0,8 \mathrm{~mm} / \mathrm{min}$, obtendo-se o deslocamento através do travessão da máquina, bem como ensaios com ciclos de carregamento-descarregamento e recarregamento a fim de avaliar o comportamento visco-elasto-plástico da haste em biopolímero. 


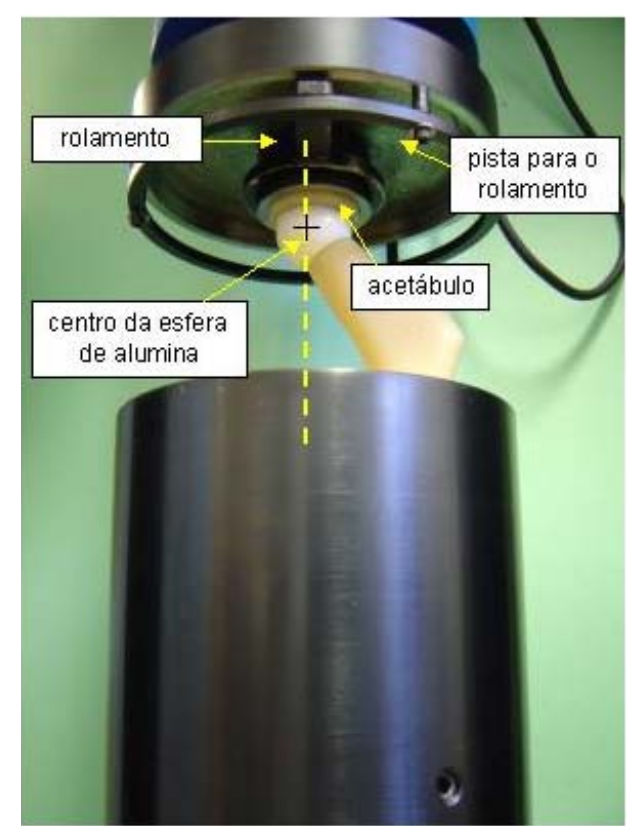

(a)

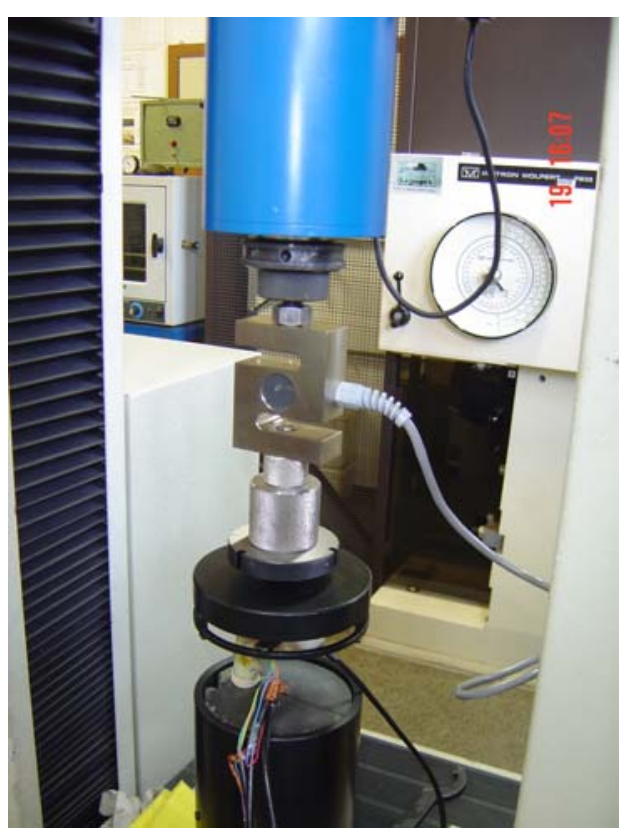

(b)

Figura 3.13 - (a) Montagem do dispositivo: parte inferior e parte superior (b) Dispositivo acoplado a uma máquina de ensaio EMIC.

Os experimentos com a prótese de implante de quadril foram realizados com duas configurações: Apenas com medição de deslocamento através do travessão da máquina de ensaio (Figura 3.14(a)) e também registros de deformação com auxílio de strain gages (Figura 3.14(b)). Neste segundo caso foram utilizados os strain gages triaxiais modelo KFEL2-120-D35 (KYOWA, 2004a).

\section{D - ANÁLISE COMPUTACIONAL}

Todos os modelos computacionais efetuados para o presente trabalho foram desenvolvidos no programa ABAQUS ${ }^{\circledR}$, mais especificamente a versão 6.3.1, utilizando-se do Método dos Elementos Finitos. A seleção deste aplicativo foi feita em virtude do referido possuir toda formulação do modelo de Drucker-Prager implementada (Hibbit et al, 2000). 


\section{D.1) ANÁLISE COMPUTACIONAL PARA TRAÇÃO}

Os modelos dos ensaios de tração foram realizados com o intuito de verificar as potencialidades e restrições do modelo de Drucker-Prager em representar o comportamento mecânico do biopolímero sob este tipo de carregamento.

\section{Geometria do modelo}

Devido à simetria inerente a este tipo de espécime para ensaios de tração, a geometria utilizada no modelo basicamente representa 1/8 do comprimento útil (gage length) do corpode-prova de tração, cujas dimensões são especificadas pela norma ASTM D638-96 (Tipo I). Tal simplificação foi feita com a inserção das devidas condições de simetria. Usando deste artifício o modelo é devidamente representado o que também possibilita a diminuição do tempo de processamento e o custo computacional.

\section{Malha de elementos finitos com condicões de contorno}

Para o modelo de tração foi construída uma malha com elementos tridimensionais devido ao estado triplo de tensões produzido pelo fenômeno de "necking". A abordagem desse fenômeno é melhor explicada no capítulo 4 - Resultados e Discussões, mais especificamente dentro do item 4.2 - Resultados computacionais. A utilização do procedimento computacional com tal enfoque foi baseada em pesquisa bibliográfica e dentre as referências consultadas se pode citar (Bridgman, 1952), (Ling, 1996), (Zhang et al, 1999) e (Zhang et al, 2001).

Os elementos utilizados são do tipo sólido hexaédricos sendo cada um denominado Elemento C3D8R. Os elementos C3D8R contém 8 nós com 3 graus de liberdade cada um (translação em x, y e z), sua função de interpolação é linear e a integração é do tipo reduzida (Hibbit et al, 2000). O modelo com malha é mostrado na Figura 3.15. 

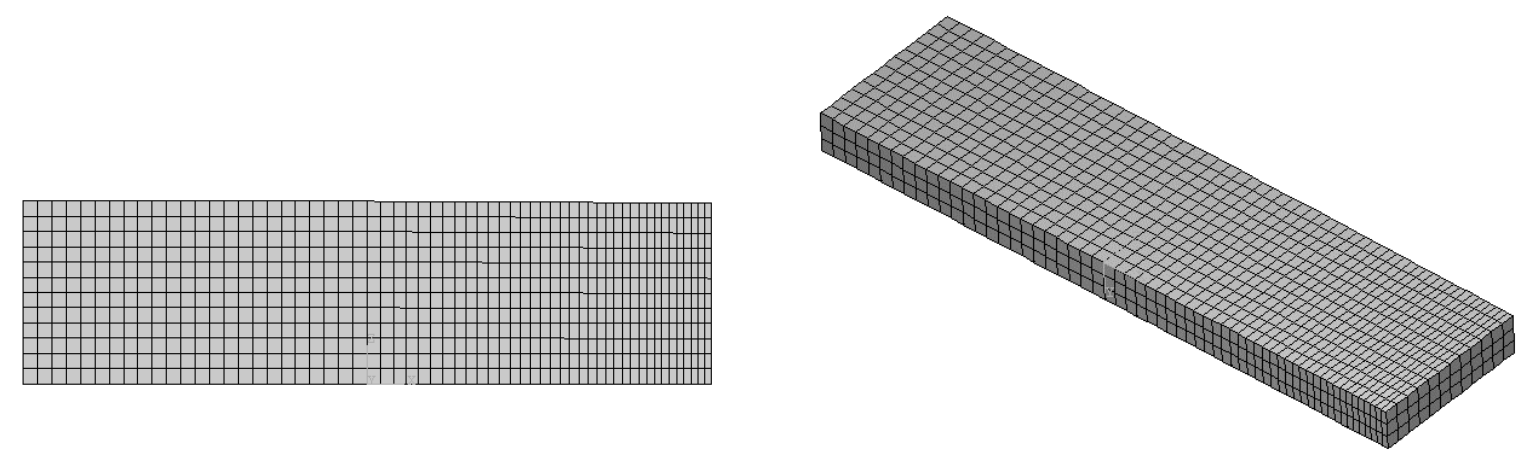

Figura 3.15 - Malha de 1/8 do modelo de tração.

Nota-se ainda pela Figura 3.15 que há uma densidade de uma malha mais refinada em uma das extremidades do modelo. Nessa região deve existir a ocorrência do "necking".

Para o análise de tração, as vinculações e os carregamentos foram executados ao modelo representativo de $1 / 8$ do CP de forma a simular toda a situação do comprimento útil do CP quando submetido ao deslocamento imposto pelo travessão da máquina (Figura 3.16).
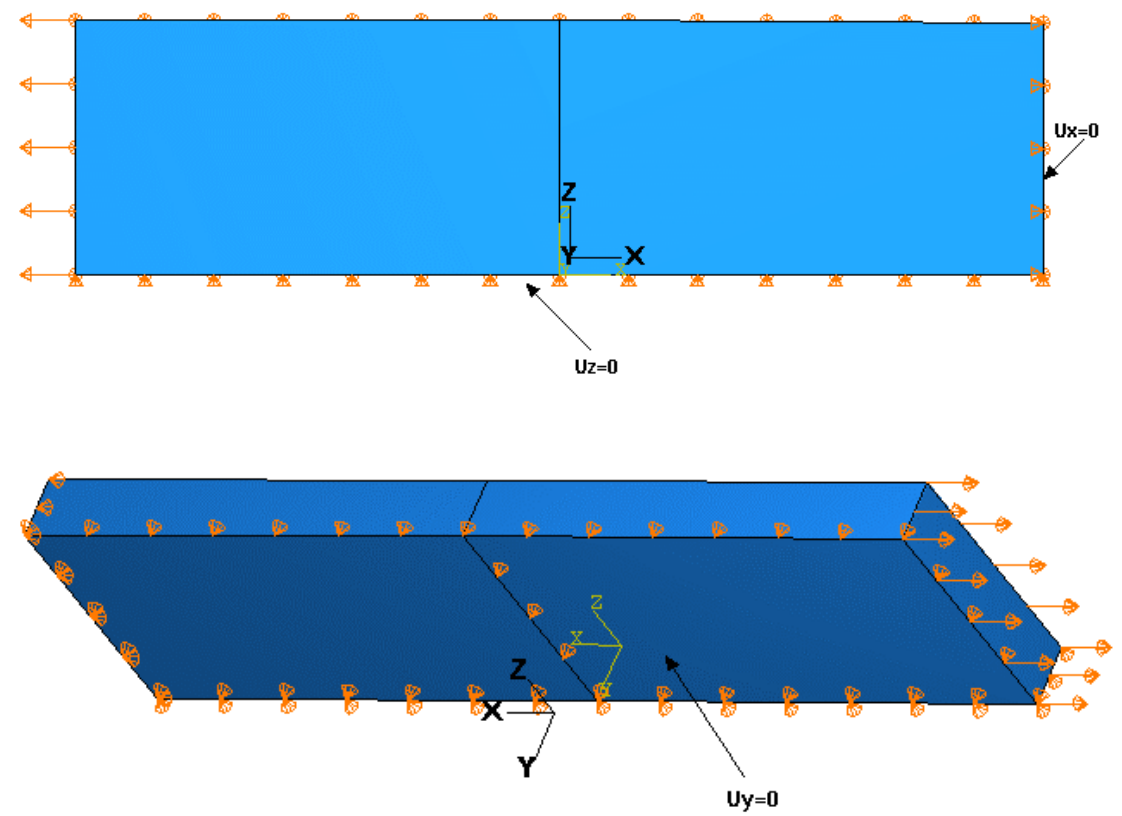

Figura 3.16 - Vinculações simulando a simetria de 1/8 do modelo de tração e imposição dos deslocamentos.

A execução do mapeamento da malha segue uma padronização simples efetuando-se subdivisões das arestas no número de elementos desejado. 


\section{Modelos de Material}

Com base nos resultados dos ensaios experimentais de tração e compressão sob velocidade de $0,8 \mathrm{~mm} / \mathrm{min}$, determinou-se os parâmetros associados ao modelo de DruckerPrager apresentados no Capítulo 2. Assim, além das propriedades elásticas do material sob tração, no caso o módulo de Young (E) e o coeficiente de Poisson (v) foram introduzidos os valores de ângulo de dilatação $(\psi)$, coesão $(d)$ e ângulo de atrito $(\beta)$. O cálculo destes valores foi feito tomando-se os valores das tensões de tração e compressão da seguinte forma: quando a superfície do critério está definida no plano meridional definido pelos eixos dos invariantes de tensão (Figura 3.17) tem-se uma reta que intercepta em d (coesão do material) o eixo definido por t e possui inclinação $\beta$ (ângulo de atrito interno do material) em relação ao eixo das tensões hidrostáticas.

No plano das tensões hidrostáticas $(p)$ pelas desviadoras $(t), p$ é definido pela equação (3.1) como sendo a tensão média definida em função do primeiro invariante das tensões $\left(I_{1}\right)$,

$$
p=\frac{I_{1}}{3}=\frac{\left(\sigma_{1}+\sigma_{2}+\sigma_{3}\right)}{3}
$$

onde $I_{1}=\sigma_{1}+\sigma_{2}+\sigma_{3}$ e $\sigma_{1}, \sigma_{2}$ e $\sigma_{3}$ são as tensões principais.

Para o caso do ensaio de tração uniaxial no qual se tem $\sigma_{2}=\sigma_{3}=0$, o valor de $p$ será dado por

$$
p=\frac{\sigma_{1}}{3}
$$

positivo para tração e negativo parta compressão. $q$ é a tensão equivalente de von Mises dada pela equação abaixo em função do segundo invariante de tensões desviadoras $\left(\mathrm{J}_{2}\right)$, 


$$
q=\sqrt{3 J_{2}}=\sqrt{\frac{1}{2}\left[\left(\sigma_{1}-\sigma_{2}\right)^{2}+\left(\sigma_{2}-\sigma_{3}\right)^{2}+\left(\sigma_{3}-\sigma_{1}\right)^{2}\right]}
$$

Para o caso uniaxial no qual se tem $\sigma_{2}=\sigma_{3}=0$, o valor de $p$ será dado por,

$$
q=\sigma_{1}
$$

Desta forma, com os valores das tensões de escoamento para tração e compressão, $\sigma_{t} \mathrm{e}$ $\sigma_{\mathrm{c}}$ respectivamente, determinadas pelos ensaios experimentais, são calculados dois pares de valores $p \mathrm{X} t$. Traçando a reta pelas duas coordenadas definidas pelos pares citados, obteremos o valor da coesão $(d)$ onde a reta intercepta o eixo vertical $(t)$, sendo a inclinação da reta o ângulo de atrito interno do material $(\beta)$. A Figura 3.17 mostra o esboço do gráfíco para o cálculo dos coeficientes de Drucker-Prager.

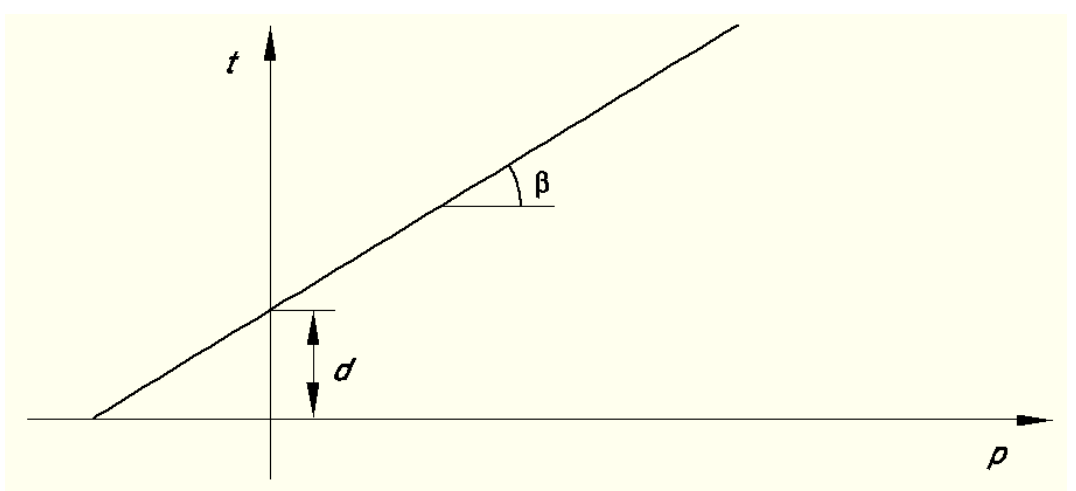

Figura 3.17 - Superfície do Critério de Drucker-Prager segundo os eixos dos invariantes de tensão (Hibbit et al, 2000).

Além da determinação dos parâmetros de Drucker-Prager, torna-se necessário obter a curva tensão-deformação plástica verdadeira para expressar a evolução do encruamento. O cálculo da deformação plástica é feito através da diferença entre a deformação total e deformação elástica, da seguinte forma: $\varepsilon_{\text {plástica }}=\varepsilon_{\text {total }}-\varepsilon_{\text {elástica }}\left(\right.$ Onde $\varepsilon_{\text {elástica }}=\sigma_{\mathrm{e}} / \mathrm{E}$, sendo $\sigma_{\mathrm{e}} \mathrm{a}$ 
tensão de escoamento para tração). Os valores calculados são apresentados no Capítulo 4 Resultados e discussões.

\section{D.2) ANÁLISE COMPUTACIONAL PARA COMPRESSÃO}

Os modelos dos ensaios de compressão foram desenvolvidos com o intuito de verificar as potencialidades e restrições do modelo de Drucker-Prager em representar o comportamento mecânico do biopolímero sob este tipo de carregamento.

\section{Geometria do modelo}

A geometria do modelo segue basicamente as dimensões especificadas pela norma ASTM D695-96, que estabelece um cilindro com 12,7 mm de diâmetro e 25,4 mm de comprimento. Porém, devido a axissimetria (simetria em torno de um eixo de giração) do CP, pode-se modelar apenas metade da secção transversal do mesmo (Figura 3.18).

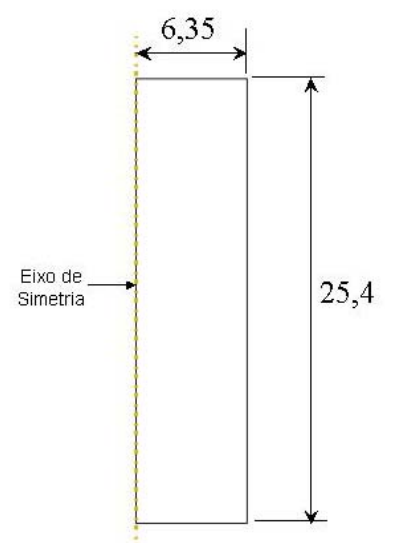

Figura 3.18 - Geometria do modelo de compressão com eixo de simetria (unidade = milímetro).

\section{Malha de elementos finitos com condiç̃es de contorno}

Devido a axissimetria, a construção da malha pode ser efetuada com elementos denominados axissimétricos, implicando assim numa razoável redução de custo computacional. Portanto, os modelos de compressão são constituídos por elementos do tipo axissimétrico designado Elemento CAX8R (Figura 3.19). Os elementos CAX8R contém 8 
nós com 2 graus de liberdade cada um (translação na direção radial e na direção axial), sua função de interpolação é quadrática e a integração é do tipo reduzida (Hibbit et al, 2000).

A Figura 3.19 mostra as condições de vinculação impostas ao modelo na base e no topo do CP, simulando os contatos com o dispositivo de compressão, bem como o deslocamento imposto pelo travessão da máquina. A relação de contato estabelecida no contato e no topo permite simular as condições de lubrificação que foram estabelecidas no experimento realizado, variando-se o coeficiente de atrito entre $\mathrm{CP}$ e aplicadores de carga.

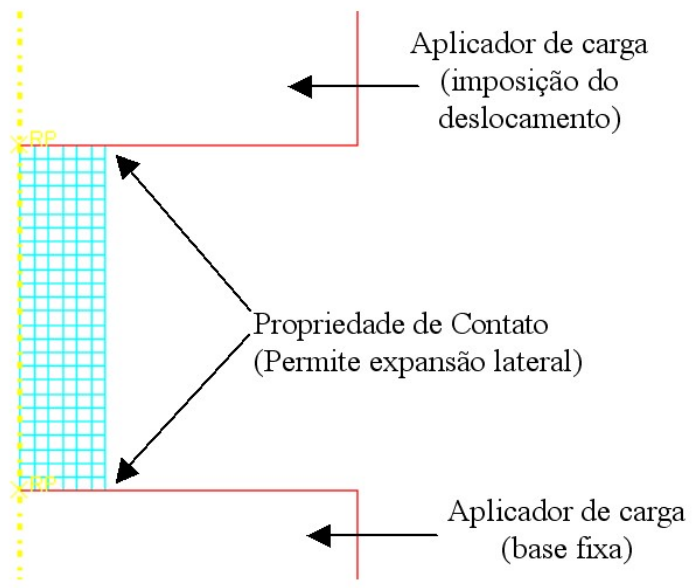

Figura 3.19 - Malha de 1/2 da seção transversal do modelo de compressão e imposição das condições da análise semelhante ao ensaio experimental.

\section{Modelos de Material}

Com base nos resultados dos ensaios experimentais sob velocidade de $0,8 \mathrm{~mm} / \mathrm{min}$, determinou-se os parâmetros associados ao modelo de Drucker-Prager apresentados no Capítulo 3. A obtenção destes valores foi realizada da mesma forma descrita para o modelo de material de tração do item D.1, anteriormente apresentado neste capítulo.

Além da determinação dos parâmetros de Drucker-Prager, torna-se necessário obter a curva tensão-deformação plástica (verdadeira) para expressar a evolução do encruamento em materiais poliméricos, que ocorre de forma diferente sob carregamentos de tração e de compressão. No entanto, como foi discutido anteriormente, a determinação da curva tensão- 
deformação após o conhecido Ponto A, não é uma tarefa simples, pois envolve um aumento considerável do diâmetro do CP, principalmente em níveis elevados de deformação. Todavia, com auxílio dos strain-gages longitudinal e transversal pode-se obter esta curva tensãodeformação com uma certa precisão. Dessa forma, tem-se na Figura 3.20 uma curva de encruamento estimada com base na curva obtida através dos strain-gages.

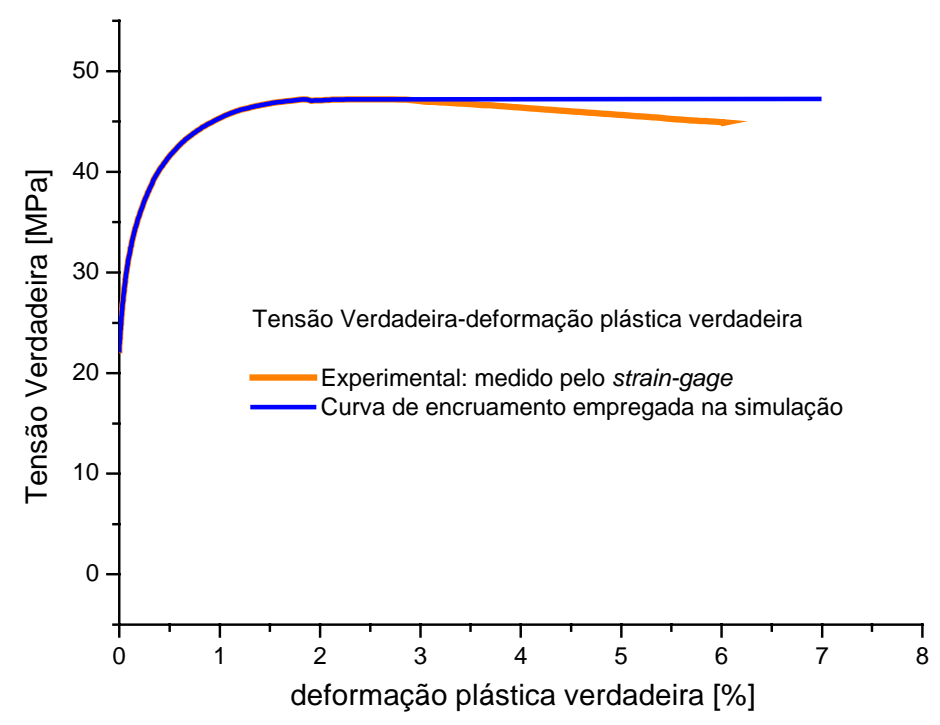

Figura 3.20 - Curva de encruamento de compressão estimada para o biopolímero.

Finalmente, aplica-se ao modelo da Figura 3.20, o Modelo de Drucker-Prager juntamente com curva de encruamento estimada e, compara-se assim, a curva cargadeformação numérica com a curva experimental, a fim de verificar se a curva de encruamento estimada é consistente fisicamente.

\section{D.3) ANÁLISE COMPUTACIONAL PARA HASTE DE QUADRIL}

Os modelos dos ensaios de haste de implante de quadril foram desenvolvidos com o intuito de verificar as potencialidades e restrições do modelo de Drucker-Prager em representar o comportamento mecânico do biopolímero sob este tipo de carregamento. 


\section{Geometria do modelo}

A geometria do modelo da prótese de quadril segue as dimensões especificadas em Silvestre Filho (2001), já mencionadas no item B - Obtenção das próteses de quadril, do tópico 3.2 - Métodos, e exemplificada pela Figura 3.5.

Ressalta-se que para analisar a haste de implante de quadril no software de elementos finitos primeiramente era necessário que se construísse o modelo sólido da mesma. O programa CAE utilizado, porém, não oferece a gama de recursos necessários para esse tipo de operação, isso devido às características geométricas descritas no projeto da prótese em Silvestre Filho (2001). Assim foi preciso utilizar um software CAD para a construção da geometria para posteriormente exportá-la para o aplicativo CAE.

A Figura 3.21 mostra o modelo sólido da haste confeccionado no aplicativo CAD.

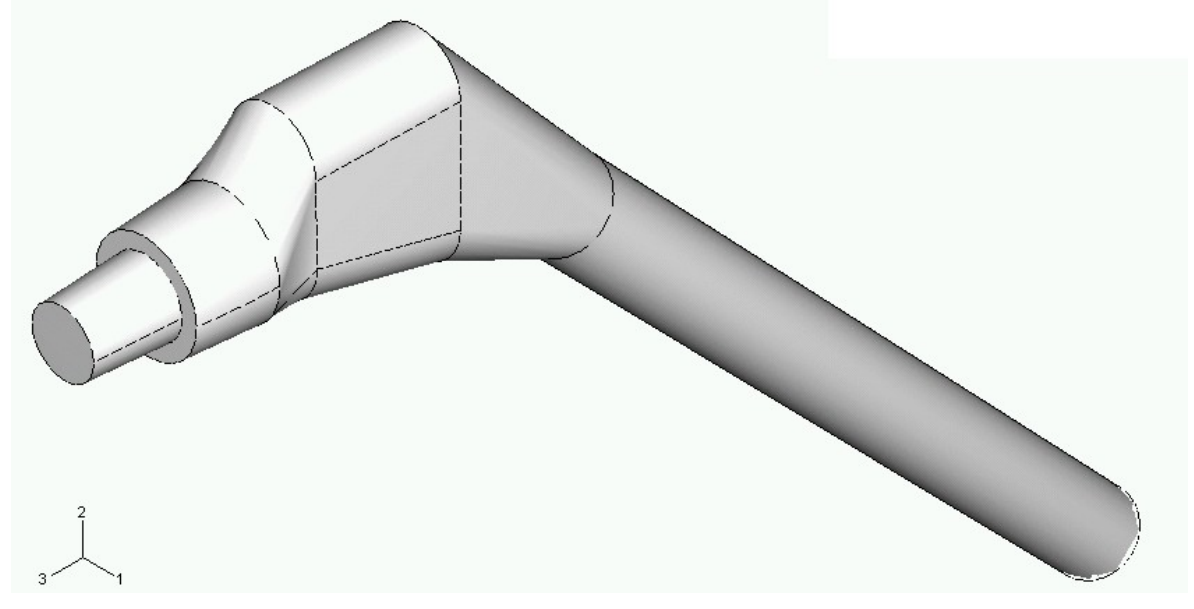

Figura 3.21: Modelo sólido confeccionado em software de CAD segundo dimensões especificadas em Silvestre Filho (2001).

Numa outra operação, este modelo foi exportado para o programa CAE com o auxílio da interface IGES (Initial Graphics for Exchange Specification), utilizada para transferência de dados entre sistemas gráficos (Ferneda, 1999).

Também foi construído o modelo da esfera de alumina, cuja geometria segue as dimensões especificadas nas normas ASTM F370-94 e ASTM F1636-95 (Wregge, 2000). Essa esfera possui diâmetro de $26 \mathrm{~mm}$ e alojamento ao qual se acopla a cabeça da prótese de 
quadril. A Figura 3.22 ilustra a geometria segundo Wregge (2000) e o modelo sólido da esfera de Alumina. Essa geometria foi confeccionada diretamente no aplicativo CAE.

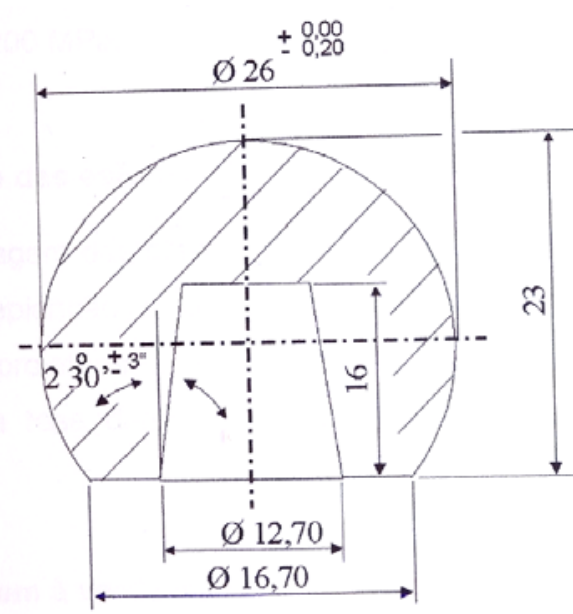

(a)

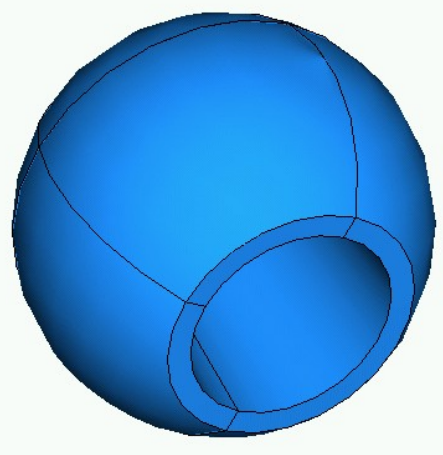

(b)

Figura 3.22 - Esfera de Alumina segundo normas ASTM F370-94 e ASTM F1636-95:

a) Geometria (Wregge, 2000); b) Modelo sólido.

\section{Malha de elementos finitos com condiç̃es de contorno}

Primeiramente, o conjunto esfera-prótese precisou ser acoplado. Efetuou-se então a montagem desses elementos se utilizando o módulo adequado do aplicativo CAE. Este módulo é denominado "assembly" e sua função é a de efetuar o posicionamento adequado dos elementos do conjunto. Tal montagem necessita ainda de uma condição interação entre os itens denominada contato. O ABAQUS define contato entre dois corpos em termos de duas superfícies que podem interagir; estas superfícies são chamadas de par de contato (Hibbit et al, 2000). Entre o par de contato, um elemento é escolhido como "master" e o outro como “slave”. A regra básica de escolha utilizada é atribuir a superfície "master" ao componente mais rígido. Para o par definido por esfera e haste a propriedade de contato utilizada foi a de “tie contact", presente no módulo de interações do programa. Resumidamente, tal interação consiste em se restringir cada um dos nós sobre a superfície slave ter o mesmo valor de deslocamento, temperatura, pressão pura ou potencial elétrico que o ponto na superfície "master" que ele está em contato. No ABAQUS a formulação de contato tipo "tie" restringe 
apenas os graus de liberdade de translação nas simulações mecânicas. Os graus de liberdade rotacionais dos elementos estruturais envolvidos no par em contato não são restringidos.

Nesta relação entre a esfera e a cabeça da haste de quadril, as superfícies do interior da esfera e a externa da ponta da haste são escolhidas como "slave" e "master", respectivamente (Figura 3.23). A Figura 3.23 mostra as superfícies selecionadas para cada item separadamente.

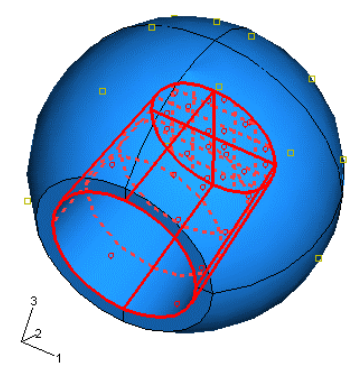

(a)

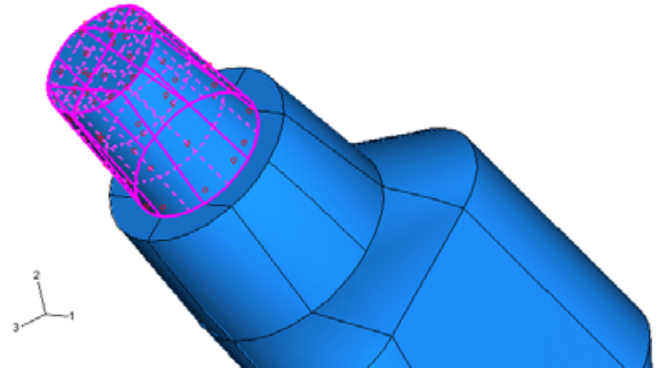

(b)

Figura 3.23 - Superfícies selecionadas para interação do tipo "tie-contact":

(a) na esfera de alumina e (b) na cabeça da prótese de quadril.

Numa relação de contato desse tipo é recomendado que a superfície definida como "slave" esteja bem refinada, uma vez que são seus nós que "grudarão" na superfície definida como "master" (Hibbit et al, 2000). A Figura 3.24 ilustra a interação adotada entre esferahaste e o procedimento executado.

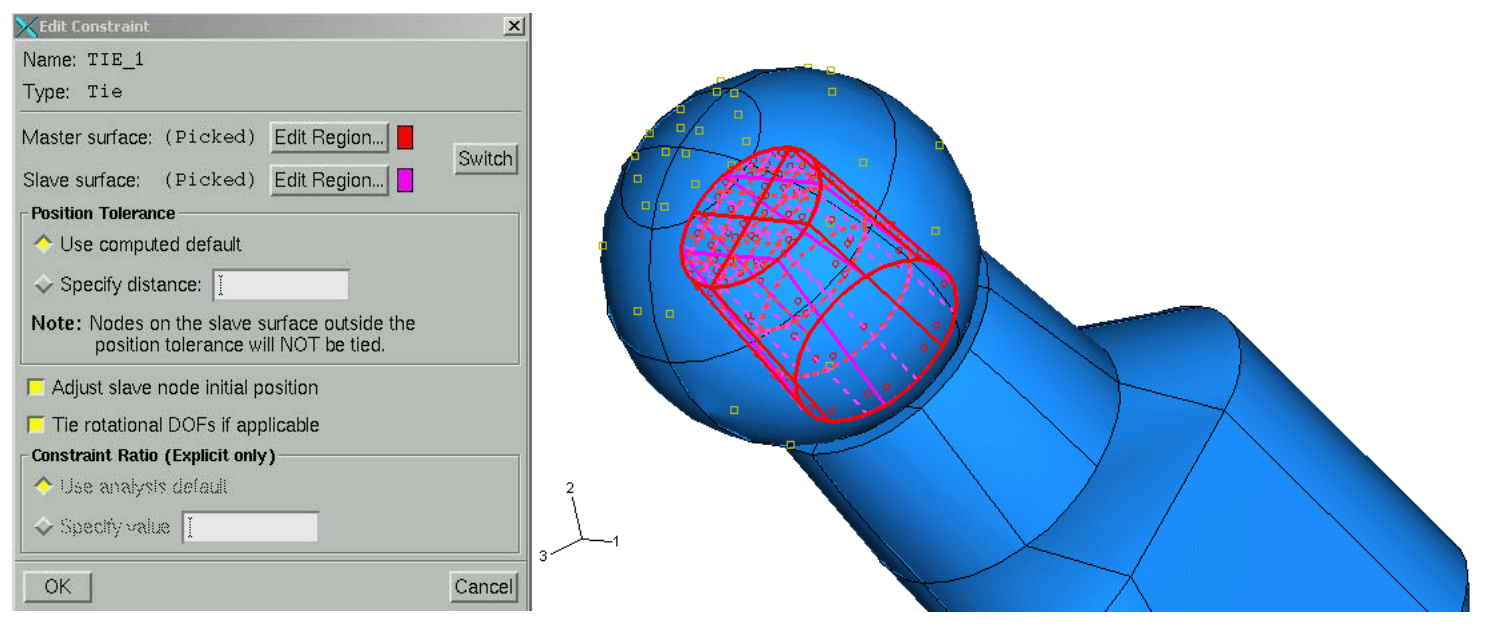

Figura 3.24: Interação do tipo "tie-contact" entre a esfera de alumina e a cabeça da prótese de quadril. 
Assim, para o modelo com estes dois componentes posicionados, foi construída uma malha com elementos tridimensionais do tipo sólido sendo cada um denominado Elemento C3D8R. Os elementos C3D8R contém 8 nós com 3 graus de liberdade cada um (translação em x, y e z), sua função de interpolação é linear e a integração é do tipo reduzida (Hibbit et al, 2000). O modelo com malha é mostrado na Figura 3.25.
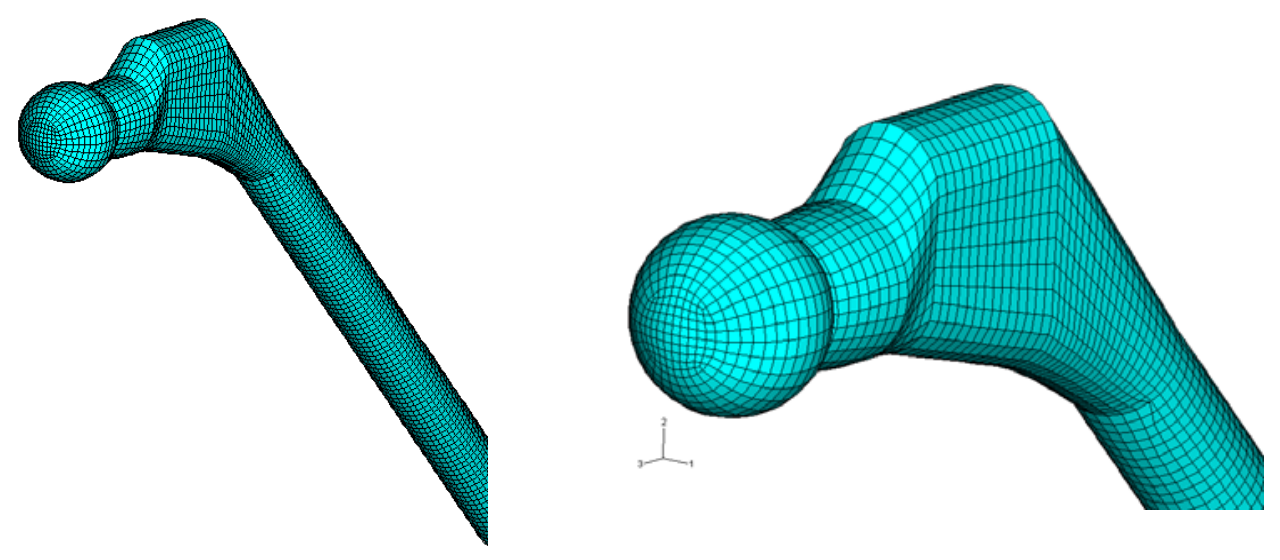

Figura 3.25 - Malha para o conjunto esfera e haste com elementos tridimensionais, do tipo sólido, denominados C3D8R.

Para completar o modelo do implante de quadril, o sólido do acetábulo foi gerado primeiramente como uma superfície rígida diretamente no ABAQUS ${ }^{\circledR}$ e posteriormente inserido na montagem foi incorporado ao conjunto e modelado. Em sua inserção foi necessário o estabelecimento de um outro tipo de relação de contato entre o mesmo e a esfera de alumina. Para esse caso tem-se duas opções: finite sliding ou small sliding (HIBBIT et al., 2000), (CANTO, 2002):

- Finite sliding é o modelo mais geral e possibilita qualquer tipo de movimento como a separação, deslizamento de grandes amplitudes e rotações arbitrárias entre as superfícies em contato. Apresenta maior custo computacional, pois o algoritmo analisará o contato de cada nó da superfície "slave" com toda a superfície "master". Conforme esquematizado na Figura 3.26, o nó 101 da superfície "slave", por exemplo, pode entrar em contato em qualquer ponto 
ao longo da superfície "master", e quando em contato, estará restrito a movimentar-se ao longo dessa superfície.
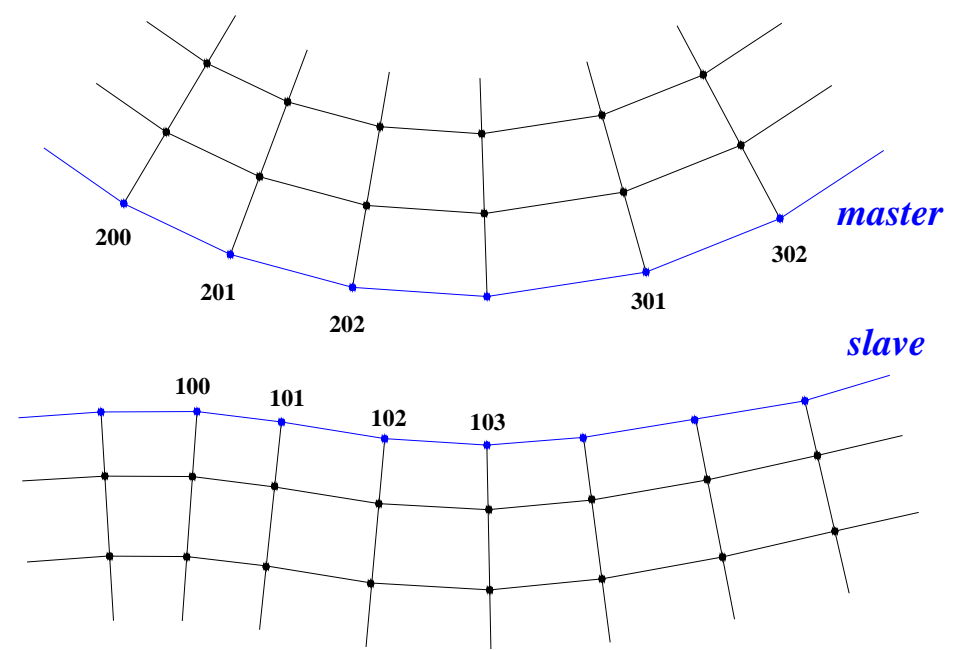

Figura 3.26 - Contato entre duas superfícies utilizando a interação finite sliding (HIBBIT et al., 2000).

Na Figura 3.27 é mostrada uma possível evolução do contato entre o nó 101 e a superfície "master". No instante $\mathrm{t}=\mathrm{t}_{1} \mathrm{o}$ nó 101 está em contato com a face do elemento definida pelos nós 201 e 202 e a transferência das forças de contato se dá somente entre o nó 101 e os nós 201 e 202. Mais tarde, no instante $\mathrm{t}=\mathrm{t}_{2}$, o nó 101 poderá estar em contato com a face do elemento definida pelos nós 301 e 302 e a transferência das forças de contato se dá somente entre o nó 101 e os nós 301 e 302.

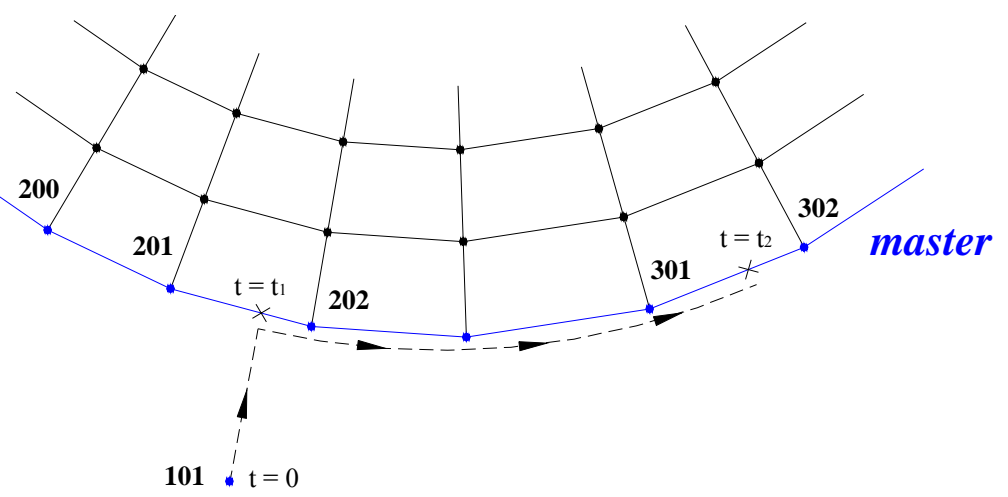

Figura 3.27 - Possível evolução do contato entre o nó 101 e a superfície "master" utilizando finite sliding (HIBBIT et al., 2000). 
- Small sliding é um modelo mais simplificado e de menor custo computacional quando comparado com o modelo finite sliding, pois o algoritmo analisará o contato do nó da superfície "slave" com uma superfície tangente local a um ponto de projeção do nó da superfície "slave” na superfície "master", conforme esquematizado na Figura 3.28. Cada plano tangente local é definido por um ponto âncora (anchor point) $X_{0}$ na superfície "master" associado a um vetor de orientação $N\left(X_{0}\right)$.

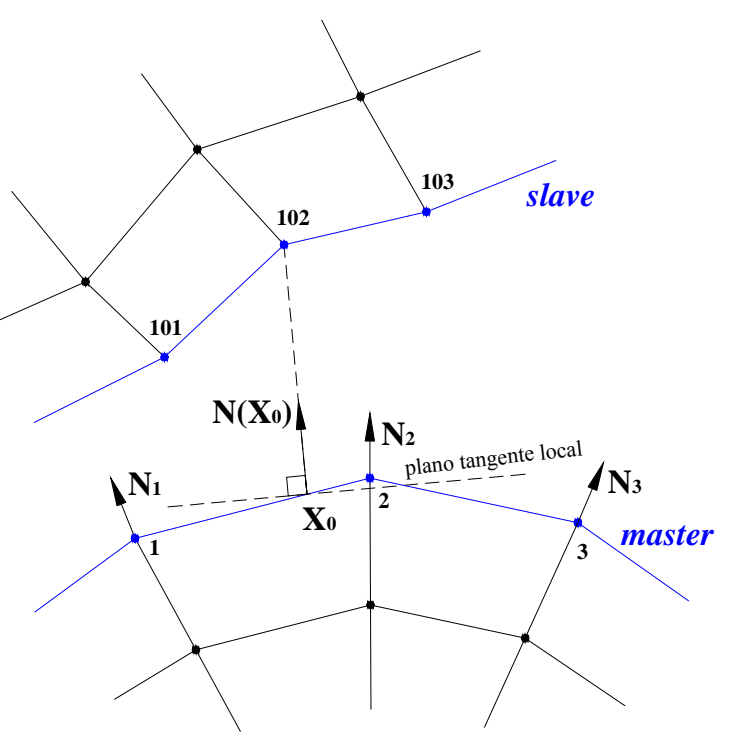

Figura 3.28 - Contato entre duas superfícies utilizando a interação small sliding (HIBBIT et al., 2000).

As direções dos vetores nodais unitários de orientação $N_{n}$ são definidas pela média entre as normais das faces dos elementos adjacentes que pertencem à superfície "master". O vetor de orientação $N\left(X_{0}\right)$ é definido pela função de forma do elemento com a face que contém os nós 1 e 2 calculada com base nos vetores $N_{1}$ e $N_{2}$. Assim o ponto âncora é definido quando a projeção de $N\left(X_{0}\right)$ intercepta o nó 102 da superfície "slave".

Dessa forma, modelou-se o contato no conjunto esfera-acetábulo com a condição finite sliding. As superfícies selecionadas para o acetábulo e a esfera de alumina são mostradas na Figura 3.29. 

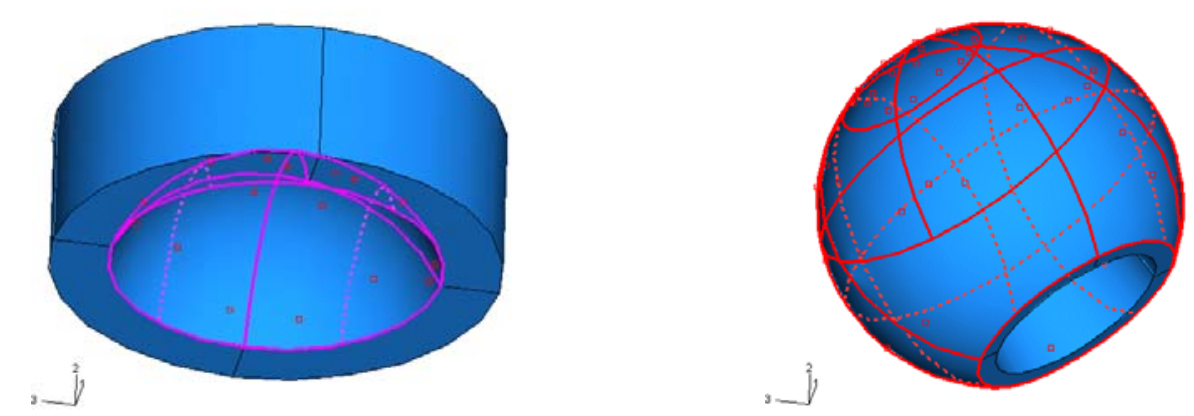

Figura 3.29 - As superfícies selecionadas para o acetábulo e a esfera de alumina.

O conjunto com a interação acetábulo-esfera de alumina é mostrado na Figura 3.30.

No caso a superfície da esfera foi escolhida como "master" enquanto que a superfície escolhida no acetábulo designada como "slave".

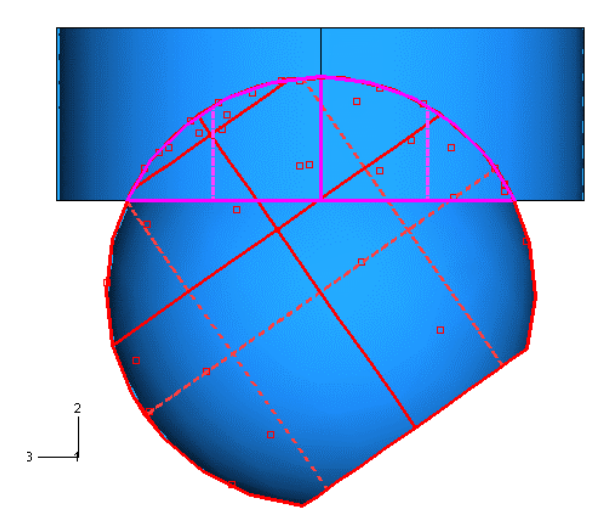

Figura 3.30 - Interação acetábulo-esfera de alumina.

Segundo a norma ISO 7206-3, no ensaio experimental o eixo longitudinal do corpo da haste deve estar posicionado com uma inclinação de $10^{\circ}$ em relação ao eixo vertical (Figura 3.31). O deslocamento imposto de estar na direção vertical e deve permanecer nesta direção até o final do ensaio. 


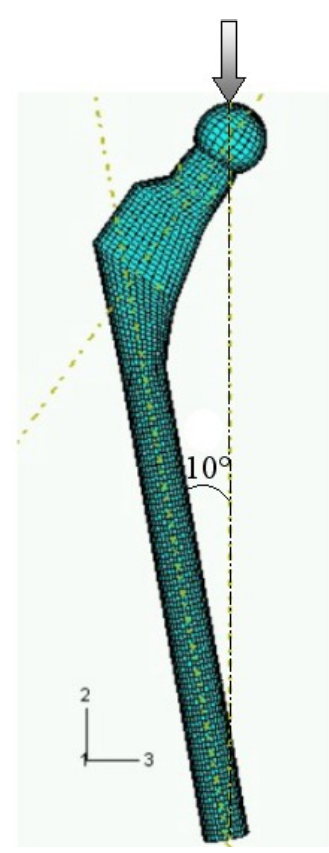

Figura 3.31 - Modelo posicionado com inclinação de $10^{\circ}$ e carga na direção vertical.

Considerando que o engastamento entre prótese e cilindro de granito foi obtido de maneira eficiente nos ensaios experimentais, o mesmo foi simplificado através de condições de contorno denominada "encastre" na análise computacional (Figura 3.32). Dessa forma as análises consideraram a presença de uma adesão perfeita entre prótese e "granito sintético".

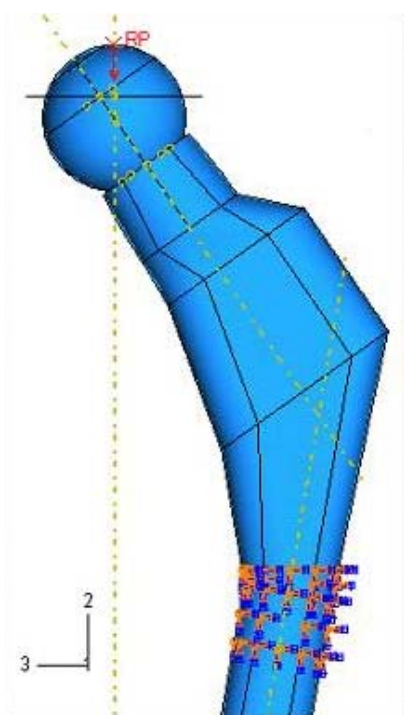

Figura 3.32 - Modelamento do engastamento da haste no bloco de granito.

Quanto à carga imposta, a direção de sua resultante deve passar pelo centro da esfera em todo o ensaio. Com as considerações implementadas no modelo do presente trabalho, tais 
exigências foram atendidas como pode ser percebido pela Figura 3.33 que mostra o conjunto na posição indeformada (Figura 3.33(a)) e na posição deformada (Figura 3.33(b)), onde o acetábulo permanece sempre em posição normal em relação à esfera.

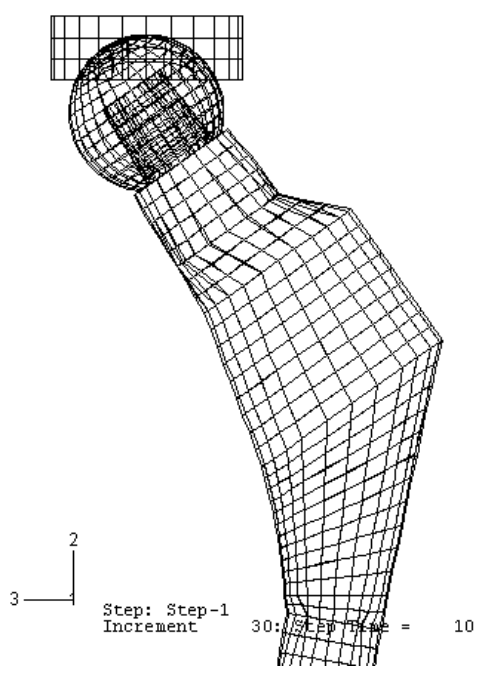

(a)

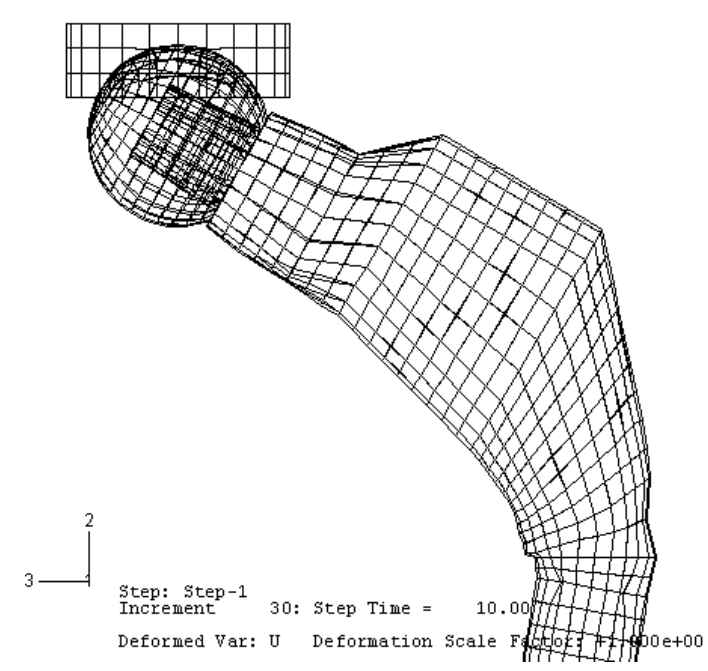

(b)

Figura 3.33 - Posição do implante (a) no inicio da análise, indeformada e (b) no final da análise, deformada.

\section{Modelos de Material}

A esfera de alumina foi modelada de acordo com dados obtidos em Wregge (2000). Por outro lado, a prótese de quadril e o acetábulo, ambos fabricados a partir do biopolímero, foram modelados com base nos resultados dos ensaios experimentais sob velocidade de $0,8 \mathrm{~mm} / \mathrm{min}$ a partir dos quais se determinou os parâmetros associados ao modelo de DruckerPrager (apresentados no Capítulo 3). A obtenção destes valores foi realizada da mesma forma descrita anteriormente para o modelo de material de tração (item D.1 do Capitulo 3).

Além da determinação dos parâmetros de Drucker-Prager, também é necessário se obter a curva tensão-deformação plástica verdadeira para expressar a evolução do encruamento em materiais poliméricos (que ocorre de forma diferente sob carregamentos de tração e de compressão). 


\section{Capítulo 4}

\section{RESULTADOS E DISCUSSÕES}

\subsection{RESULTADOS EXPERIMENTAIS}

\section{Considerações Gerais:}

Para a realização dos ensaios de tração inicialmente seguiu-se a norma ASTM D638M - 96 (Tipo I), como já mencionado no Capítulo 4, a qual sugere uma velocidade de ensaio de $5 \mathrm{~mm} / \mathrm{min}$. Porém, foram realizados ensaios preliminares com a finalidade de se projetar todo o desenvolvimento dos ensaios. No transcorrer da bateria de ensaios preliminares foi verificado que realizando os ensaios a esta velocidade ocorria um fenômeno que prejudicava a coleta de dados. Resumidamente, a realização do ensaio consiste em se imprimir um deslocamento ao travessão da máquina de ensaios e se verificar a relação entre tempo, força e deslocamento, podendo-se utilizar estes dados posteriormente da maneira mais adequada. Este fenômeno consistia em que mesmo com a interrupção do deslocamento do travessão num dado instante do ensaio, o material continuava se deformando chegando até a ruptura do $\mathrm{CP}$, mesmo com seu deslocamento interrompido. Esse tipo de comportamento prejudicava a aquisição de dados. Desta maneira, com a finalidade de encontrar uma velocidade que fosse mais adequada a coleta dos dados e com maior facilidade, alguns ensaios com variadas velocidades foram realizados. A Figura 4.1 apresenta dados acerca de algumas velocidades testadas. 


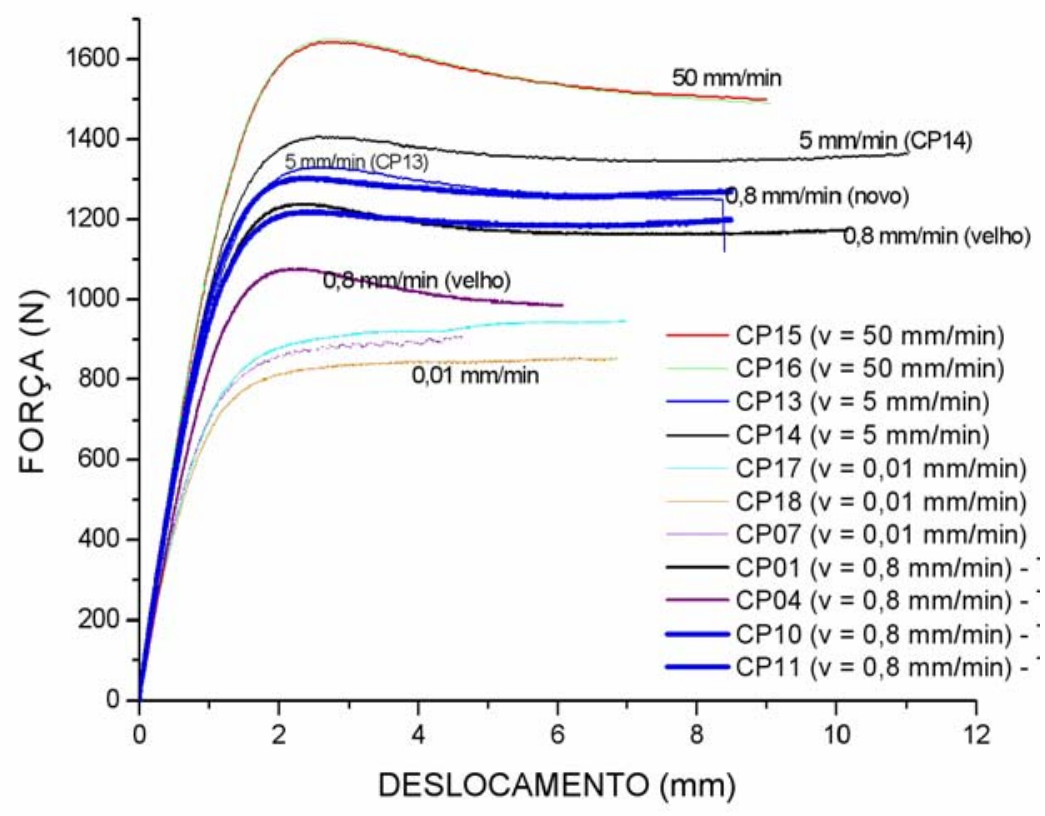

Figura 4.1 - Teste para várias velocidades de ensaio.

Desta maneira, após analisar os resultados colhidos tanto como o comportamento do CP durante o ensaio, a velocidade de $0,8 \mathrm{~mm} / \mathrm{min}$ foi adotada para se desenvolver todos os ensaios experimentais. Ressalta-se que mesmo essa velocidade sendo menor do que a sugerida pela norma os efeitos viscoelásticos e viscoplásticos ainda estavam presentes, porém, desta forma os dados podem ser coletados com mais facilidade do que com velocidades maiores. Ressalta-se também que quando a velocidade imposta foi de $0,01 \mathrm{~mm} / \mathrm{min}$ o comportamento do material se aproximou ou se assemelhou ao elastoplástico. E se pode comprovar o descrito no item 2.1.1 do capítulo 2 e ilustrado pela Figura 2.8 deste trabalho que ressaltam que o aumento da taxa de deformação pode elevar os valores de tensão de escoamento e de ruptura do material.

Assim estabelecido, os parâmetros e procedimentos para a realização dos ensaios foram selecionados com base nos testes preliminares realizados conforme se pode ver a seguir. 


\subsection{A) RESULTADOS DOS ENSAIOS DE TRAÇÃO}

Tem-se que os ensaios de tração estão basicamente divididos em dois grupos:

1. Ensaios monotônicos de tração;

2. Ensaios com ciclos de carregamento-descarregamento e re-carregamento.

Os ensaios monotônicos de tração foram realizados com o intuito de determinar as propriedades elásticas e avaliar o comportamento mecânico do biopolímero. Este é o tipo de ensaio no qual o carregamento do CP (através do deslocamento do travessão da máquina de ensaio) é efetuado em passo único. Isto é, com a máquina de ensaios EMIC descrita no tópico 3.2 - Métodos no item C - Análise experimental, é possível se ensaiar tanto com a aplicação de deslocamento na velocidade estabelecida $(0,8 \mathrm{~mm} / \mathrm{min})$ quanto com a aplicação de força.

Para o presente trabalho, os ensaios monotônicos também serviram para ajustar os parâmetros associados do modelo de Drucker-Prager apresentado no Capítulo 2 (juntamente com os ensaios monotônicos de compressão). Assim, foram determinadas as seguintes propriedades para tração: o módulo de elasticidade; deformação de escoamento; a tensão de escoamento e o limite de deformação elástica.

\section{Ensaios Monotônicos de Tração}

A Figura 4.2 mostra os primeiros resultados obtidos do teste monotônico de tração sob velocidade de $5 \mathrm{~mm} / \mathrm{min}$, caracterizando o comportamento de um material dúctil. 


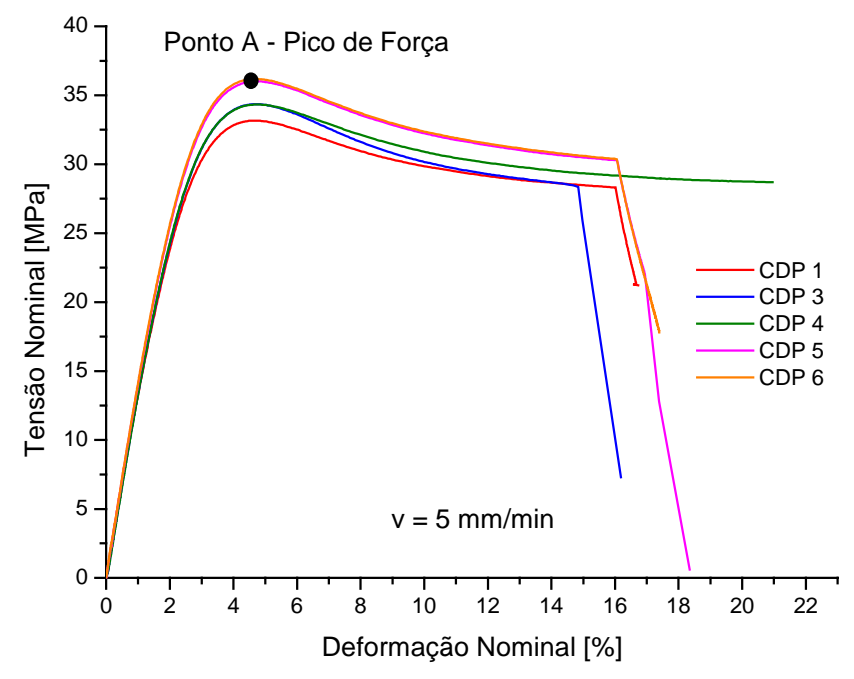

Figura 4.2 - Curvas tensão-deformação de engenharia: ensaio monotônico de tração sob $5 \mathrm{~mm} / \mathrm{min}$.

Verifica-se que as curvas são dadas por tensão nominal $\sigma$ (tensão de engenharia) em função da deformação nominal $\varepsilon$ (deformação de engenharia), ou seja, os valores obtidos são provenientes das seguintes equações:

$$
\begin{gathered}
\sigma=\frac{F}{A_{o}} \\
\varepsilon=\frac{\Delta L}{L_{0}}
\end{gathered}
$$

Onde F corresponde ao valor da força que atua na direção perpendicular à secção transversal do $\mathrm{CP}, \mathrm{A}_{\mathrm{o}}$ corresponde ao valor inicial da área transversal do $\mathrm{CP}$ e $\mathrm{L}_{\mathrm{o}}$ está associado ao comprimento de abertura inicial do extensômetro utilizado (50 mm). Nota-se, portanto, que os valores de tensão e de deformação são determinados tomando como referência valores iniciais. Porém, sob grandes deformações, torna-se necessário tomar como referência valores atuais. Para tal, deve-se empregar o cálculo de tensões verdadeiras $\sigma_{\mathrm{v}} \mathrm{e}$ deformações verdadeiras $\varepsilon_{\mathrm{v}}$, dadas por: 


$$
\begin{gathered}
\sigma_{\mathrm{v}}=\frac{\mathrm{F}}{\mathrm{A}}=\sigma(1+\varepsilon) \\
\varepsilon_{\mathrm{v}}=\int_{\mathrm{L}_{\mathrm{o}}}^{\mathrm{L}_{\mathrm{f}}} \frac{\mathrm{dL}}{\mathrm{L}}=\ln \frac{\mathrm{L}_{\mathrm{f}}}{\mathrm{L}_{\mathrm{o}}}=\ln (1+\varepsilon)
\end{gathered}
$$

Onde A corresponde ao valor atual da área transversal do $\mathrm{CP}$ e $\mathrm{L}_{\mathrm{f}}$ está associado ao comprimento de abertura atual do extensômetro. Todavia, deve-se ressaltar que a expressão 4.3 é obtida considerando conservação de volume durante o processo de deformação, ou seja, $\mathrm{AL}_{\mathrm{f}}=\mathrm{A}_{\mathrm{o}} \mathrm{L}_{\mathrm{o}}$. Porém, como foi visto no Capítulo 2, os materiais poliméricos são compressíveis durante a plastificação e segundo Williams (1973), a tensão de escoamento para esses materiais pode ser adotada quando há um pico de força (Ponto A). Para o presente biopolímero, este pico de força ocorre próximo aos 5\% de deformação nominal (Figura 4.2). Após este pico de força ocorrem deformações plásticas permanentes consideráveis e, portanto, os gráficos tensão-deformação verdadeira serão analisados apenas até este pico. Isto faz com que seja possível determinar: o módulo de elasticidade; a tensão de escoamento e o limite de deformação elástica.

A Figura 4.3 mostra a comparação das curvas tensão-deformação (verdadeira e de engenharia) obtidas do teste monotônico de tração sob velocidade de $5 \mathrm{~mm} / \mathrm{min}$. Verifica-se que para pequenas deformações, os gráficos coincidem, porém com o aumento da deformação, as curvas divergem. Sendo assim, o valor da tensão de escoamento $\sigma_{\mathrm{y}}$ medido pelo gráfico de tensão-deformação verdadeira difere do valor medido pelo gráfico tensãodeformação de engenharia. Além disso, ambas as curvas evidenciam, logo após o valor máximo de tensão ser atingido, um fenômeno conhecido como softening, ou seja, perda de rigidez com o aumento da tensão. 


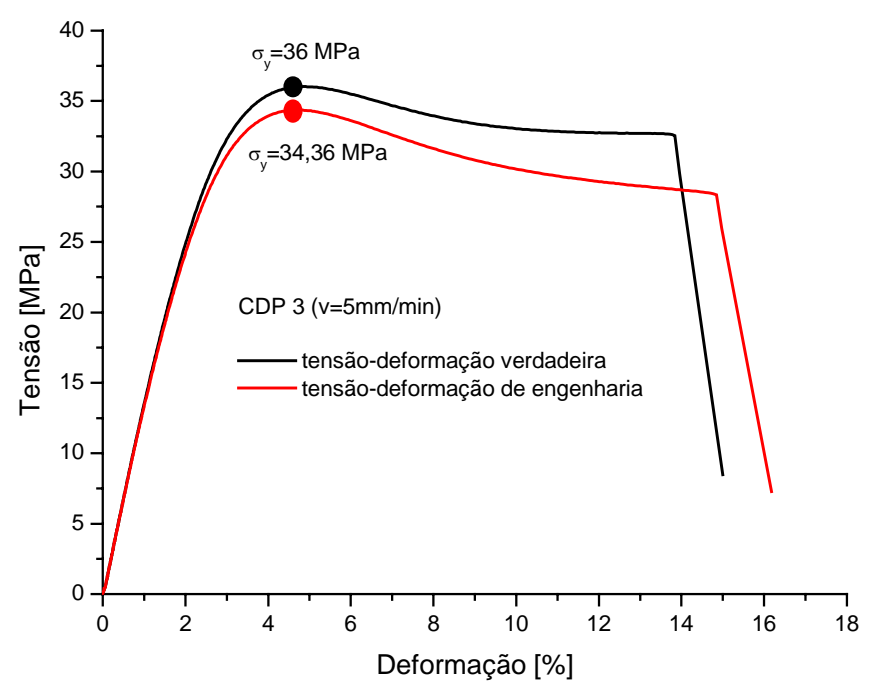

Figura 4.3 - Curva tensão-deformação de engenharia x verdadeira (ensaio monotônico de tração sob $5 \mathrm{~mm} / \mathrm{min}$ ).

Com base nas curvas tensão-deformação verdadeira apresentadas na Figura 4.4, tem-se que o módulo de elasticidade oscilou de um valor mínimo igual a 1,36 GPa até um valor máximo igual a 1,43 GPa para $5 \mathrm{~mm} / \mathrm{min}$. Por outro lado, a tensão de escoamento variou entre 34,74 MPa e 37,77 MPa. Essa variação de valores se deve principalmente à qualidade dos CPs, ou seja, provavelmente há uma menor presença de bolhas para os CPs que forneceram valores superiores. Porém, a tensão de escoamento também pode ser modificada em função da taxa de deformação aplicada.
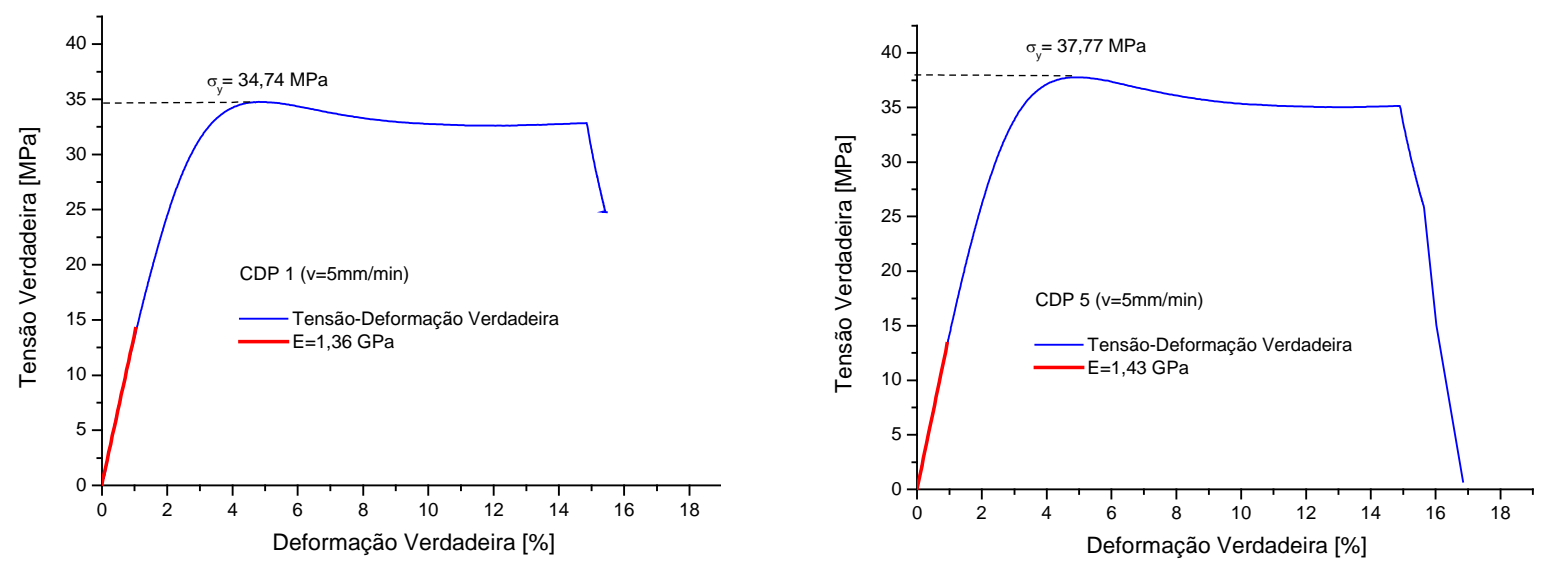

Figura 4.4 - Módulo de elasticidade e tensão de escoamento: ensaio monotônico de tração sob $5 \mathrm{~mm} / \mathrm{min}$. 
A Figura 4.5 mostra curvas de tensão-deformação verdadeira obtidas a partir de ensaios monotônicos de tração sob velocidade de $0,8 \mathrm{~mm} / \mathrm{min}$. Vale ressaltar que a presença do softening é menos acentuada do que nos ensaios anteriores, verificando posteriormente, um certo encruamento do material.

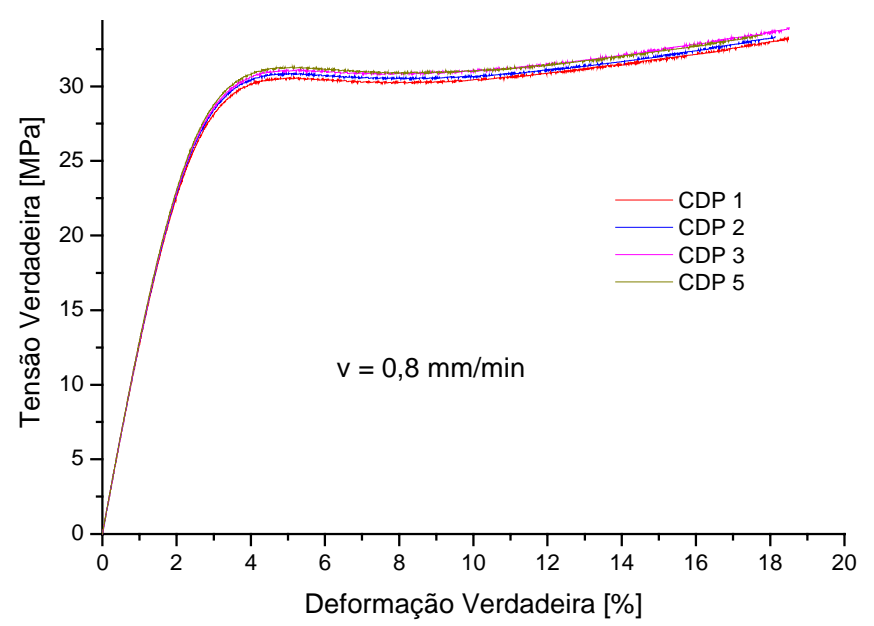

Figura 4.5 - Curvas tensão-deformação verdadeira: ensaio monotônico de tração sob $0,8 \mathrm{~mm} / \mathrm{min}$.

A Figura 4.6 mostra que o módulo de elasticidade praticamente não se altera, ao passo que o valor da tensão de escoamento é reduzido. Sendo que o valor da tensão de escoamento obtido para velocidade igual a $0,8 \mathrm{~mm} / \mathrm{min}$ está abaixo dos piores valores obtidos para velocidade igual a $5 \mathrm{~mm} / \mathrm{min}$.

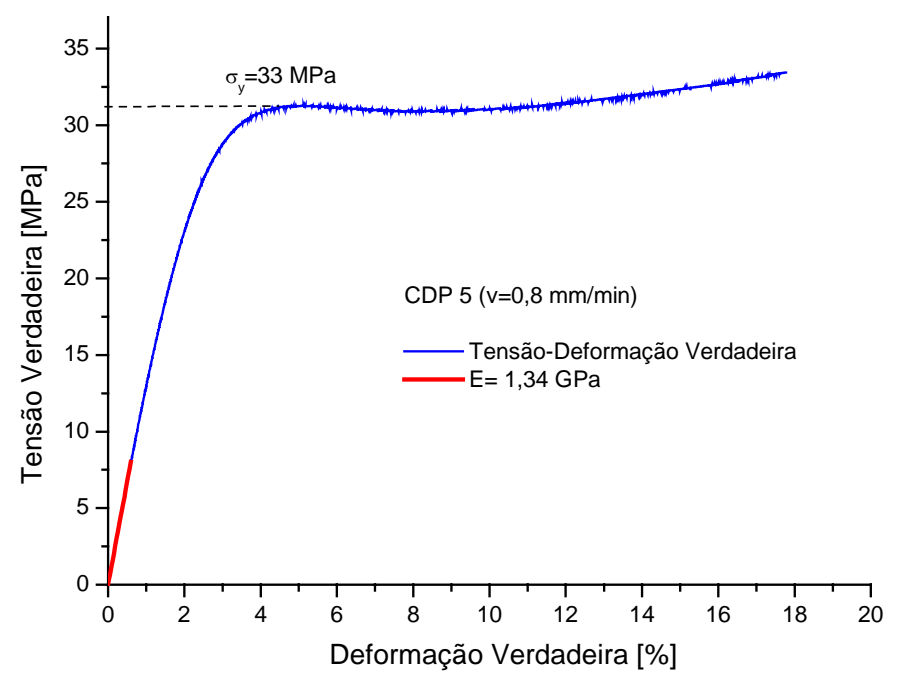

Figura 4.6 - Módulo de elasticidade e pico de tensão: ensaio monotônico de tração sob $0,8 \mathrm{~mm} / \mathrm{min}$. 
Além do módulo de elasticidade e da tensão de escoamento, determinou-se também o coeficiente de Poisson sob a velocidade de $0,8 \mathrm{~mm} / \mathrm{min}$. Para a determinação deste coeficiente foram utilizados dois métodos. Sendo assim, a Figura 4.7(a) mostra os resultados obtidos via extensômetros e a Figura 4.7(b) mostra os resultados obtidos via strain-gages.

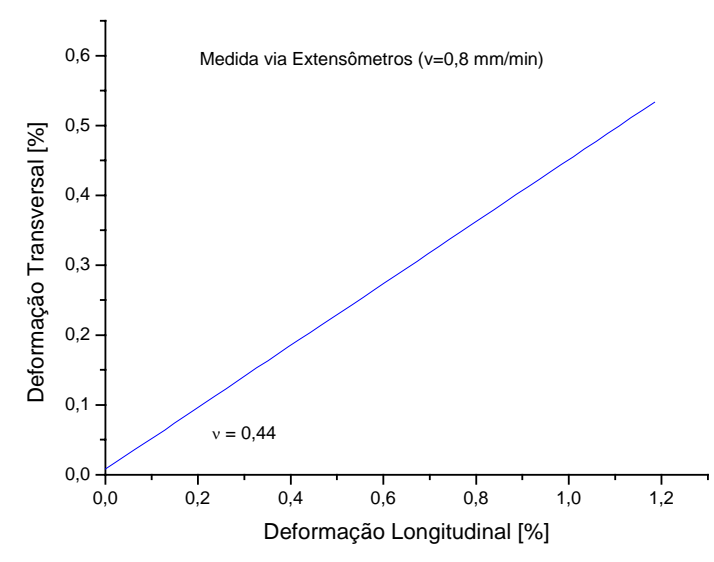

(a)

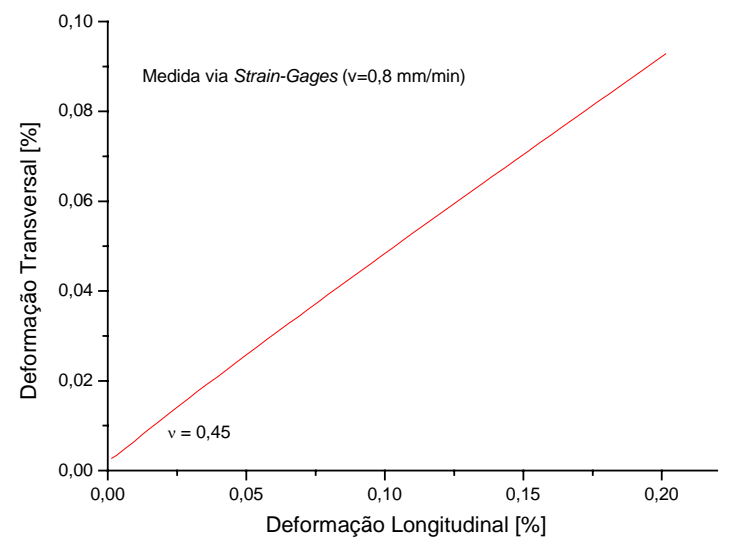

(b)

Figura 4.7 - Curva deformação transversal-deformação longitudinal (ensaio monotônico de tração sob 0,8 $\mathrm{mm} / \mathrm{min}$ ): (a) extensômetros; (b) strain-gages.

Baseado nos gráficos mostrados na Figura 4.7 é demonstrado, através dos dois métodos de medição, que o coeficiente de Poisson do biopolímero oscila entre 0,44 e 0,45 para pequenas deformações. Tal valor pode ser considerado elevado, haja vista que materiais quase que totalmente incompressíveis, como os elastômeros, possuem coeficiente de Poisson de aproximadamente 0,49 .

\section{$\underline{\text { Ensaios de Tração com Ciclos }}$}

Os resultados a seguir são de testes onde a amostra sofreu vários ciclos de carregamento, descarregamento e re-carregamento sob velocidade igual a $0,8 \mathrm{~mm} / \mathrm{min}$. Dessa forma, tornase possível avaliar não apenas as curvas carga-deslocamento e tensão-deformação, mas também, as curvas tensão-tempo e deformação-tempo.

A Figura 4.8 mostra curvas carga-deslocamento com ciclos de carregamento, descarregamento e re-carregamento medidas com o auxílio do extensômetro. Nota-se que 
durante o descarregamento e o re-carregamento, a curva carga-deslocamento possui uma inclinação similar à inclinação inicial. Caso o descarregamento fosse mantido, verificar-se-ia uma deformação permanente, o que caracteriza um comportamento elastoplástico. Além disso, forma-se um laço histerético caracterizando assim um comportamento visco-elastoplástico (Figura 4.9).

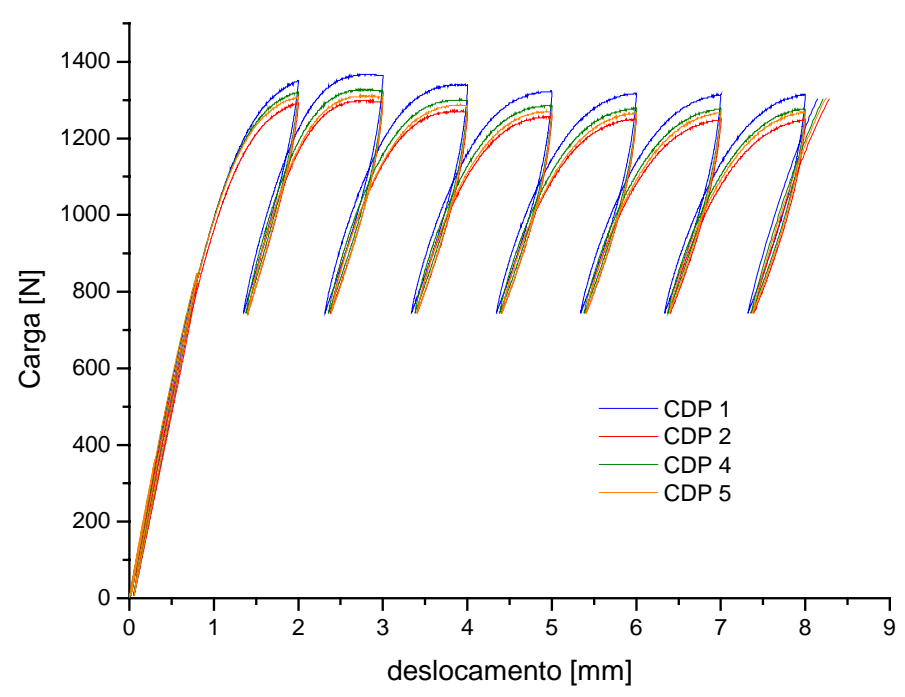

Figura 4.8 - Curvas carga-deslocamento com ciclos sob $0,8 \mathrm{~mm} / \mathrm{min}$ (ensaio de tração).

Caso o gráfico seja visualizado de forma mais detalhada, pode-se perceber a existência de dois ciclos de carregamento-descarregamento e re-carregamento em níveis de deslocamento bem pequenos, ou seja, abaixo da tensão de escoamento do material (abaixo do pico de força). Dessa forma, pode-se obter a curva tensão-deformação para ambos os ciclos, pois o CP ainda não iniciou o processo de “necking”. Conseqüentemente, tem-se ainda um estado uniaxial de tensão e as expressões (4.3) e (4.4) são válidas. 


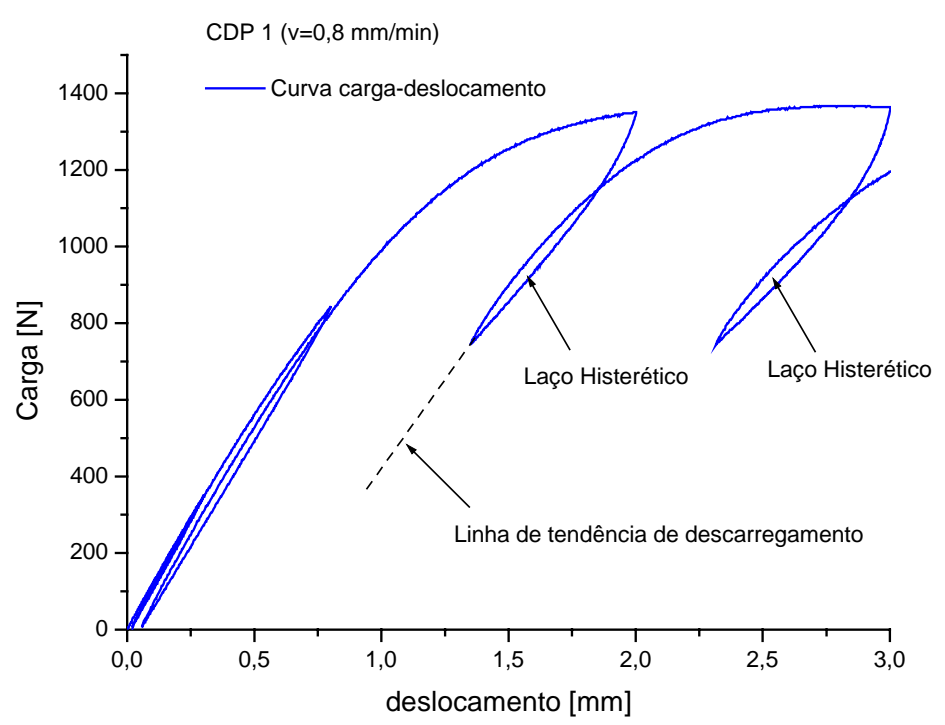

Figura 4.9 - Linhas de tendência de descarregamento e laço histerético.

Pela Figura 4.10 se pode verificar que após o descarregamento do $1^{\mathrm{o}}$ ciclo (iniciado em 0,5\% de deformação), há uma pequena parcela de deformação residual igual a $0,04 \%$. No entanto, segundo Williams (1973), materiais poliméricos com deformações abaixo de $0,5 \%$ podem ser considerados como linearmente viscoelásticos. Por outro lado, no $2^{\underline{o}}$ ciclo, a parcela de deformação residual é igual a $0,1 \%$ e os efeitos viscoelásticos não-lineares tornamse mais acentuados. Dessa forma, com o intuito de uma investigação preliminar do fenômeno de relaxação ("relaxation"), fez-se um ensaio com controle de deslocamento onde a amostra foi submetida por um tempo pré-determinado sob uma dada deformação e verificou-se a queda de tensão ao longo desse tempo. 


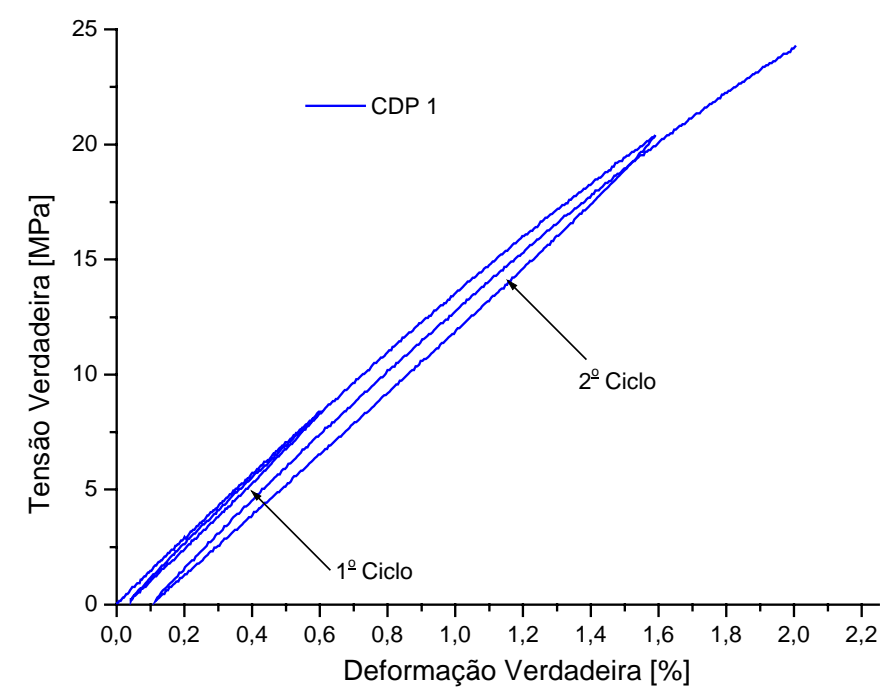

Figura 4.10 - Curva tensão-deformação para os dois primeiros ciclos.

A Figura 4.11 mostra uma curva tensão-deformação onde há três ciclos de carregamento-descarregamento e re-carregamento em pequenos níveis de deslocamento. Sendo que antes de ocorrer o descarregamento, aguardou-se um tempo pré-determinado para que o biopolímero relaxasse. Após esse tempo, a amostra foi descarregada até um nível zero de tensão e então logo em seguida foi re-carregada.

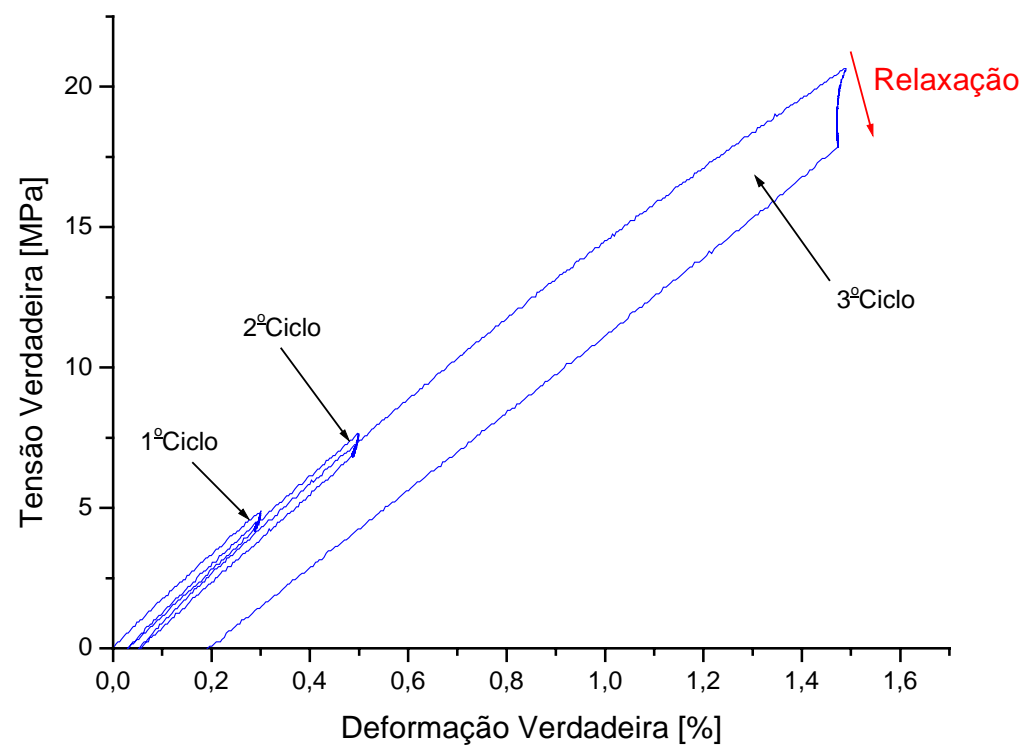

Figura 4.11 - Curva tensão-deformação para três ciclos. 
Como os fenômenos viscoelásticos (fluência e relaxação) são verificados em função do tempo, torna-se interessante mostrar as curvas tensão-tempo e deformação-tempo para os três ciclos (Figura 4.12).

Verifica-se pela Figura 4.12 que o fenômeno da relaxação é mais acentuado no $3^{0}$ ciclo, onde o polímero consome cerca de 720 segundos para atingir o nível de tensão compatível ao nível de deformação aplicado. Contudo, tanto o fenômeno de relaxação como o de fluência serão investigados com maior profundidade na segunda fase desse projeto.

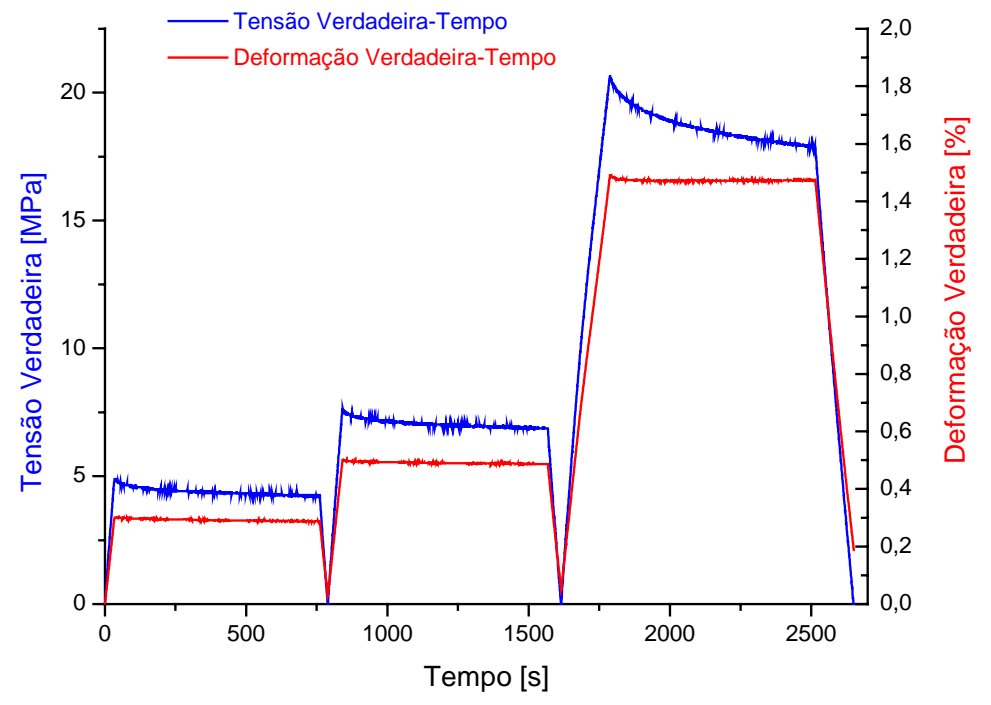

Figura 4.12 - Curvas tensão-tempo e deformação-tempo para três ciclos.

Por fim, os strain-gages não foram apenas utilizados para medir o coeficiente de Poisson, mas também para medir a evolução das deformações transversais. A Figura 4.13 mostra curva deformação transversal-tempo medida com auxílio de strain-gages e curva tensão-tempo, geradas por um ensaio com ciclos de carregamento-descarregamento e recarregamento. 


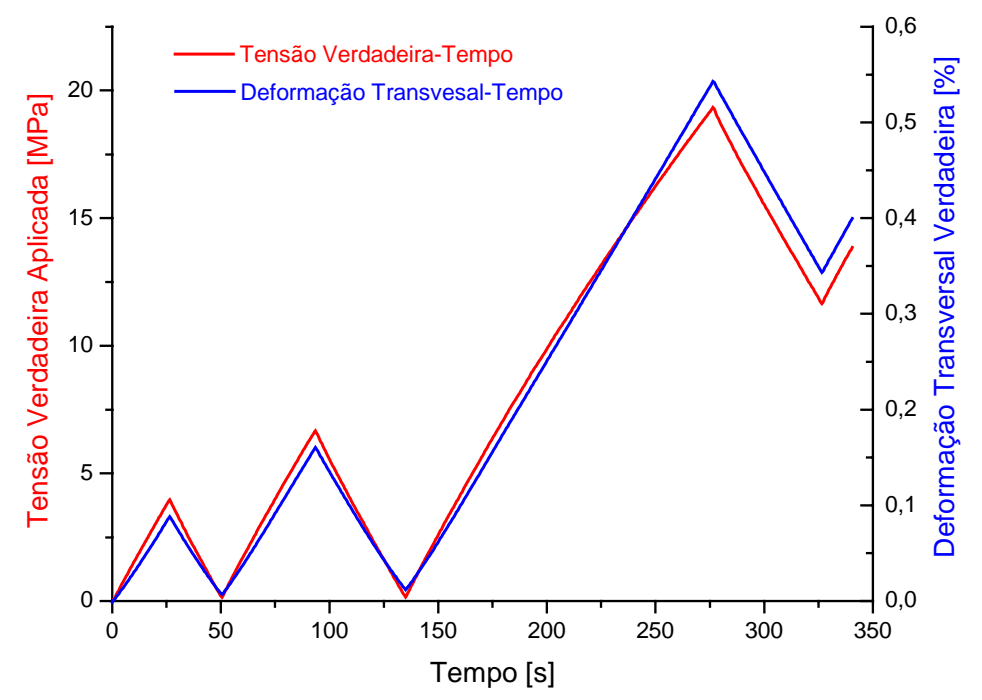

Figura 4.13 - Curvas tensão aplicada-tempo e deformação transversal-tempo (medida por "strain-gages").

\subsection{B) RESULTADOS DOS ENSAIOS DE COMPRESSÃO}

Assim como os ensaios de tração, os ensaios de compressão estão basicamente divididos em dois grupos:

1. Ensaios monotônicos de compressão;

2. Ensaios com ciclos de carregamento-descarregamento e re-carregamento.

Os ensaios monotônicos de compressão foram realizados com o intuito de determinar o comportamento mecânico do biopolímero sob este tipo de carregamento, sendo que as curvas tensão-deformação são apresentadas e discutidas.

Posteriormente, os resultados dos ensaios monotônicos de compressão foram utilizados para obtenção dos parâmetros associados ao modelo de Drucker-Prager apresentado no Capítulo 2 (juntamente com os ensaios monotônicos de tração).

\section{$\underline{\text { Ensaios Monotônicos de Compressão }}$}

A Figura 4.14 mostra os primeiros resultados dos testes monotônico de compressão sob velocidade de $0,8 \mathrm{~mm} / \mathrm{min}$, obtidos com auxílio do travessão da máquina. Os CPs 
apresentam um comportamento dúctil e atingem níveis de deformação bem superiores aos CPs de tração. Além disso, tanto o fenômeno de softening como de encruamento apresentamse mais acentuados do que nos testes de tração. Isto ocorre devido à deformação planar das cadeias moleculares do polímero quando o mesmo está sob a ação de carregamento uniaxial de compressão (Boyce e Arruda, 1990).

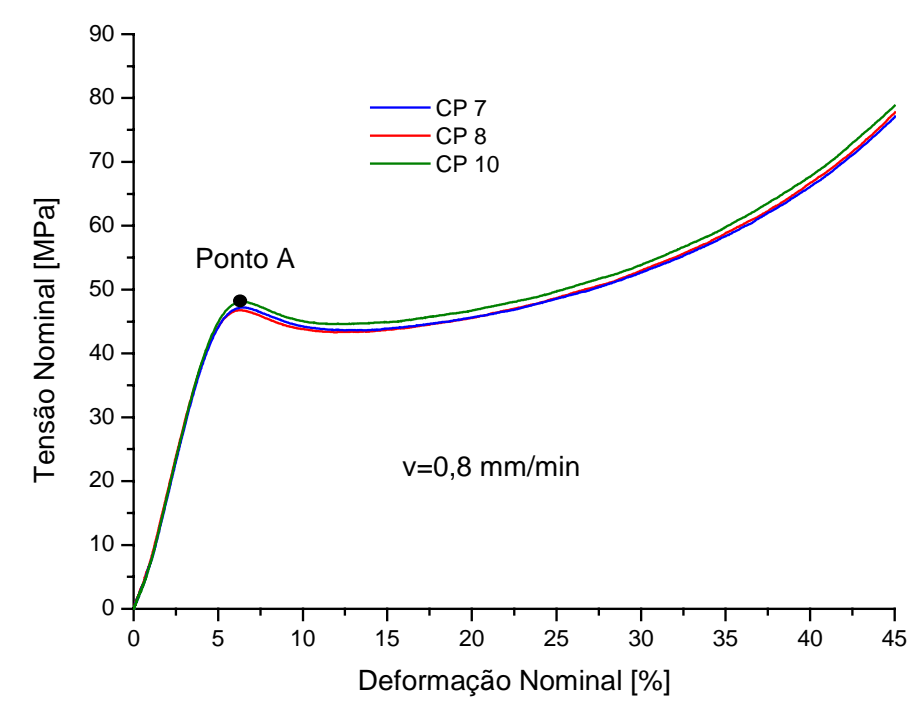

Figura 4.14 - Curvas tensão-deformação de engenharia: ensaio monotônico de compressão sob $0,8 \mathrm{~mm} / \mathrm{min}$.

Nota-se, portanto, que os valores de tensão e de deformação são determinados tomando como referência valores iniciais de área e de comprimento do CP. Porém, sob grandes deformações, torna-se necessário tomar como referência valores atuais, aplicando-se assim os cálculos das tensões verdadeiras $\sigma_{\mathrm{v}}$ e deformações verdadeiras $\varepsilon_{\mathrm{v}}$, dados pelas expressões (4.3) e (4.4). Todavia, deve-se ressaltar que a expressão 4.3 é obtida considerando conservação de volume durante o processo de deformação, ou seja, $\mathrm{AL}_{\mathrm{f}}=\mathrm{A}_{\mathrm{o}} \mathrm{L}_{\mathrm{o}}$. Porém, como foi visto no Capítulo 2, os materiais poliméricos são compressíveis durante a plastificação e segundo Williams (1973), a tensão de escoamento para esses materiais pode ser adotada no Ponto A. Para o presente biopolímero, este ponto A ocorre próximo aos $6 \%$ de deformação nominal de compressão (Figura 4.14). Após o ponto A, ocorrem deformações plásticas permanentes consideráveis e, portanto, os gráficos tensão-deformação verdadeira serão 
analisados apenas até este ponto. Isto faz com que seja possível determinar: o módulo de elasticidade; a tensão de escoamento e o limite de deformação elástica à compressão. No entanto, não será possível a determinação da tensão de ruptura à compressão. Além disso, é importante acrescentar que após a ocorrência do ponto A, acentua-se um fenômeno onde o CP de compressão sofre um aumento no seu diâmetro (Figura 4.15(a)), fazendo com que o mesmo deixe de ser um cilindro perfeito e passe para o formato de barril.

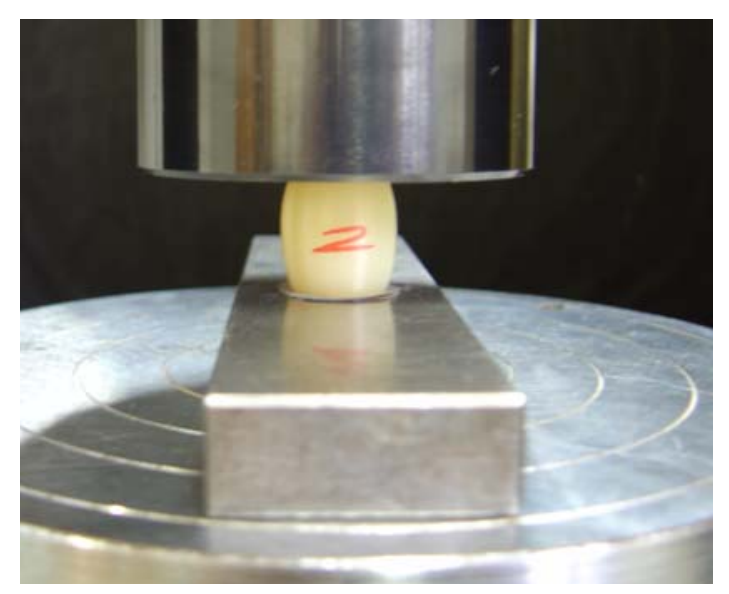

(a)

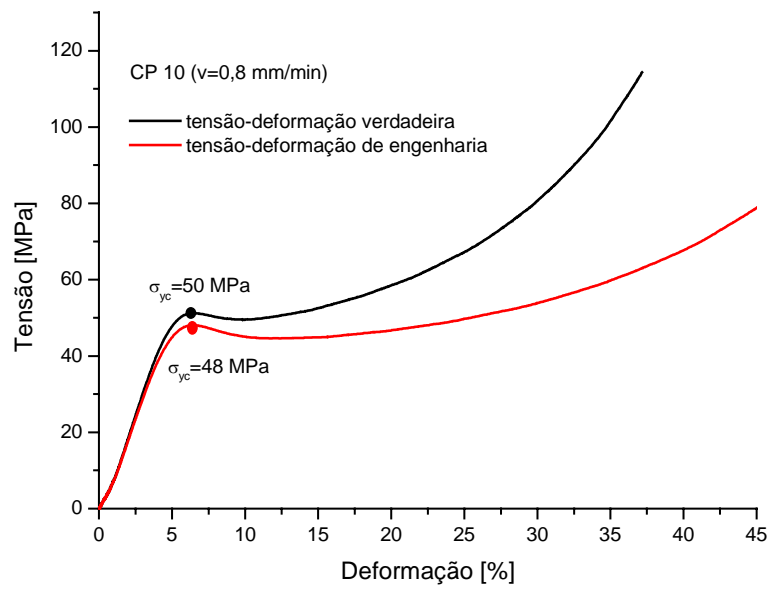

(b)

Figura 4.15 - (a) Aumento do diâmetro do CP de compressão (b) Curva tensão-deformação de engenharia $\mathrm{x}$ verdadeira (ensaio monotônico de compressão sob $0,8 \mathrm{~mm} / \mathrm{min}$ ).

A Figura 4.15(b) mostra a comparação das curvas tensão-deformação (verdadeira e de engenharia) obtidas do teste monotônico de compressão sob velocidade de $0,8 \mathrm{~mm} / \mathrm{min}$.

Verifica-se que para pequenas deformações que os gráficos coincidem, porém com o aumento da deformação as curvas divergem. Sendo assim, assim como nos ensaios de tração, o valor da tensão de escoamento $\sigma_{\mathrm{yc}}$ medido pelo gráfico de tensão-deformação verdadeira difere do valor medido pelo gráfico tensão-deformação de engenharia.

Com base na curva tensão-deformação verdadeira apresentada na Figura 4.16, tem-se que o módulo de elasticidade de compressão medido pelo deslocamento do travessão da máquina é aproximadamente $1,1 \mathrm{GPa}$, ao passo que a tensão de escoamento à compressão oscilou entre $48 \mathrm{MPa}$ e $50 \mathrm{MPa}$. Vale ressaltar que a curva apresenta uma pequena não-linearidade entre 
$0 \%$ e $0,5 \%$ de deformação verdadeira. Isto provavelmente ocorreu devido a um período de acomodação do sistema mecânico, pois o deslocamento foi medido pelo movimento do travessão da máquina. Dessa forma, o módulo de elasticidade foi quantificado somente após esse fenômeno ter finalizado.

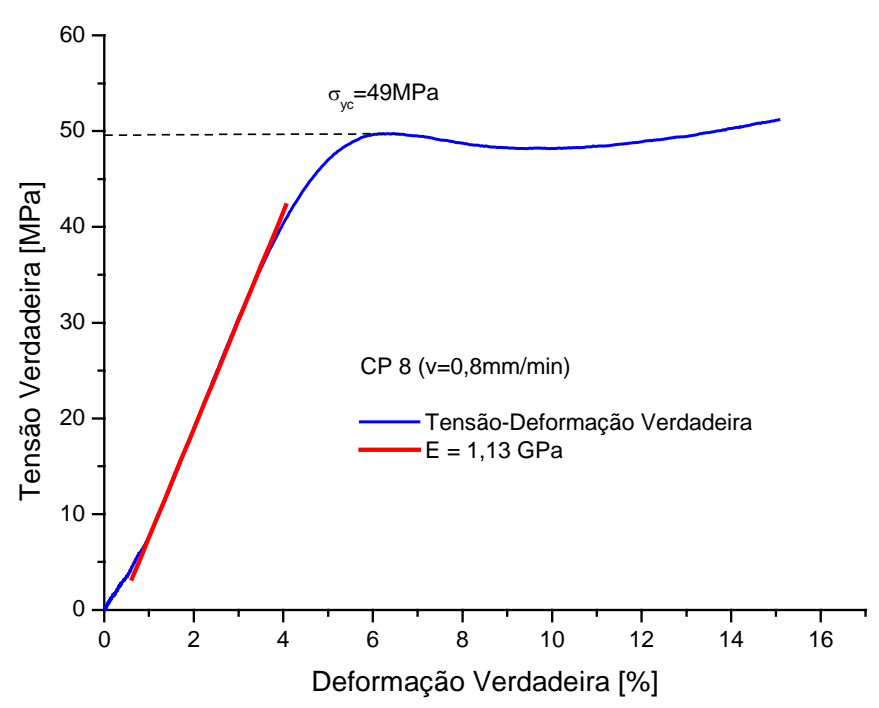

Figura 4.16 - Módulo de elasticidade e tensão de escoamento (travessão da máquina): ensaio monotônico de compressão sob $0,8 \mathrm{~mm} / \mathrm{min}$.

A fim de evitar a influência da rigidez da máquina nos ensaios de compressão, foram também realizados ensaios com strain-gages localizados na direção longitudinal e transversal dos CPs.

Ressalta-se, entretanto, que a teoria para materiais isotrópicos exprime que num $\mathrm{CP}$ sob carregamento uniaxial de compressão ocorre uma redução do comprimento na direção do carregamento e uma expansão na direção transversal. Assim, procurou-se uma outra forma de realização para o presente ensaio no qual o $\mathrm{CP}$ possuísse um comportamento similar ao anteriormente descrito, a menos do embarrilamento. Verificou-se na literatura que para solucionar a ocorrência desses fenômenos havia a necessidade de facilitar a expansão diametral do corpo-de-prova. Esse tipo de problema é contornado por diversos autores através de diferentes abordagens. Ainda com base na observação da literatura, uma lubrificação mais 
efetiva poderia trazer êxito para o presente ensaio, conforme observado em Boyce e Arruda (1990) que utilizaram folhas de teflon entre os aplicadores de carga e o CP.

Porém, no presente trabalho, chegou-se à conclusão da necessidade de se projetar outros aplicadores que permitissem o carregamento puramente uniaxial (ou bem próximo do uniaxial) na região de aquisição. Para este caso a solução foi obtida por meio do tratamento e do acabamento superficial dos aplicadores de carga, em conjunto com a lubrificação do contato entre estes e o $\mathrm{CP}$ durante o ensaio. Nesse sentido se tentou produzir nos aplicadores uma superfície com rugosidades específicas.

Para tal, o desenvolvimento desses aplicadores priorizou uma retificação que imprimisse uma superfície com rugosidade prescrita para que na realização do ensaio o lubrificante utilizado pudesse escoar do centro para a periferia do aplicador, o que teoricamente favoreceria a expansão diametral do CP.

Com a finalidade de facilitar ainda mais o deslocamento relativo entre o $\mathrm{CP}$ e os aplicadores, as superfícies eram lubrificadas com óleo Castrol Hyspin AWS 68 ou vaselina industrial Marcai ${ }^{\circledR}$.

Com a utilização da solução acima descrita, o CP que possuía o comportamento mostrado na Figura 4.17(a) passou a apresentar o desempenho mostrado na Figura 4.17(b), na qual é possível perceber que não houve flexão do $\mathrm{CP}$ durante o ensaio e o fenômeno do embarrilamento foi extremamente reduzido.

A partir da introdução dessa melhoria os ensaios com a utilização de strain gage passaram a ser realizados com esse tipo de configuração. 


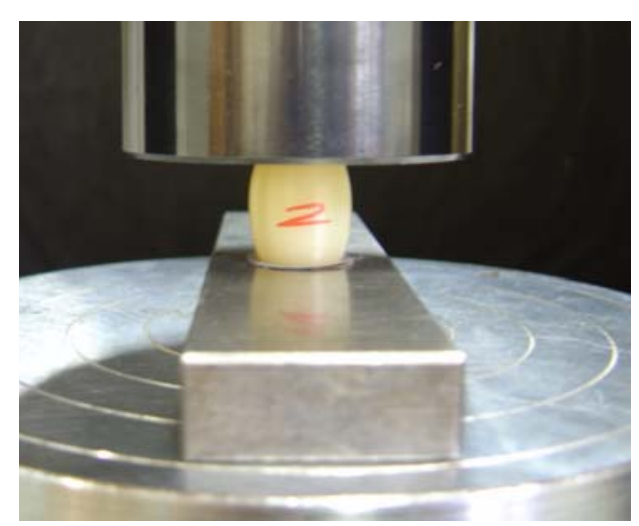

(a)

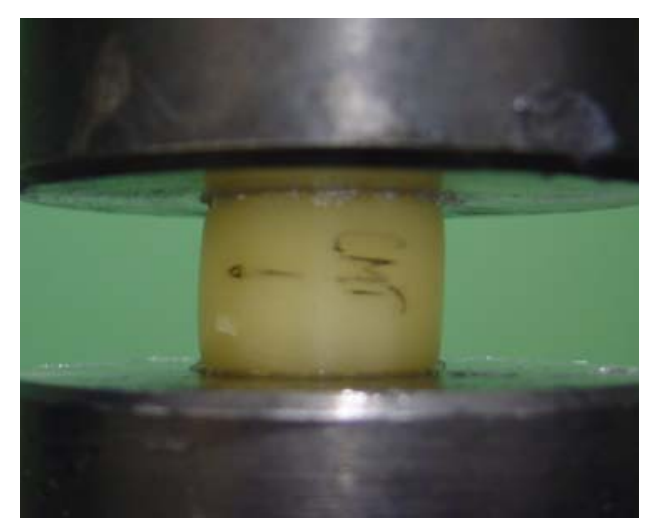

(b)

Figura 4.17 - O corpo-de-prova é mostrado numa comparação entre ensaios com:

(a) ocorrência do embarrilamento (b) comportamento esperado.

(ensaio monotônico de compressão sob $0,8 \mathrm{~mm} / \mathrm{min}$ ).

Dessa forma, a Figura 4.18 mostra a curva tensão-deformação, onde a deformação do CP no sentido axial é medida pelo strain-gage colado na direção longitudinal. Por outro lado, a tensão é obtida com o auxílio do strain-gage colado na direção transversal que é capaz de medir a deformação circunferencial. Conseqüentemente, pode-se calcular a variação da área da secção transversal do CP e obter a tensão instantânea atuante, que é dada pela razão entre a força aplicada e a área instantânea da secção transversal.

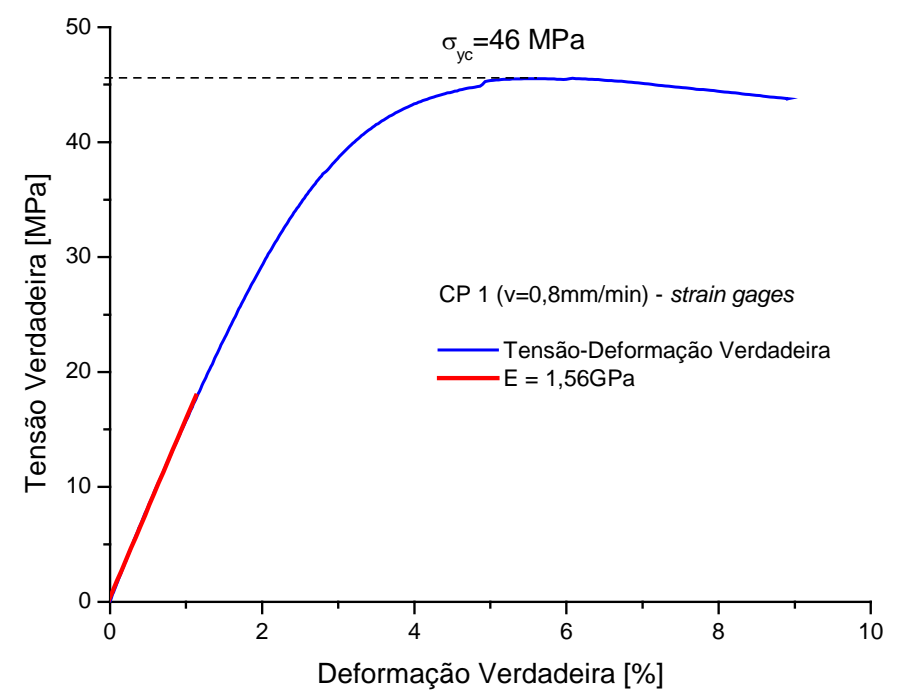

Figura 4.18 - Módulo de elasticidade e tensão de escoamento (strain-gage): ensaio monotônico de compressão sob $0,8 \mathrm{~mm} / \mathrm{min}$. 
Verifica-se inicialmente que a curva está isenta da não-linearidade entre $0 \%$ e $0,5 \%$ de deformação verdadeira, pois a mesma foi medida diretamente no CP. Além disso, o valor do módulo de elasticidade é superior, chegando a 1,56 GPa, o que evidencia a influência da rigidez da máquina nos ensaios anteriores. Por fim, deve-se destacar que o valor da tensão de escoamento foi reduzido devido ao cálculo do valor da tensão instantânea atuante.

\section{$\underline{\text { Ensaios de Compressão com Ciclos }}$}

Os resultados a seguir são de testes onde a amostra sofreu vários ciclos de carregamento, descarregamento e re-carregamento sob velocidade igual a $0,8 \mathrm{~mm} / \mathrm{min}$. Dessa forma, torna-se possível avaliar não apenas as curvas carga-deslocamento e tensãodeformação, mas também, as curvas tensão-tempo e deformação-tempo.

A Figura 4.19 mostra curvas carga-deslocamento com ciclos de carregamento, descarregamento e re-carregamento medidas com o auxílio do travessão da máquina. Nota-se que durante o descarregamento e o re-carregamento, a curva carga-deslocamento possui uma inclinação similar à inclinação inicial, após o período de acomodação do sistema (Figura 4.19). Sendo assim, caso o descarregamento fosse mantido, verificar-se-ia uma deformação permanente, o que caracteriza um comportamento elasto-plástico.

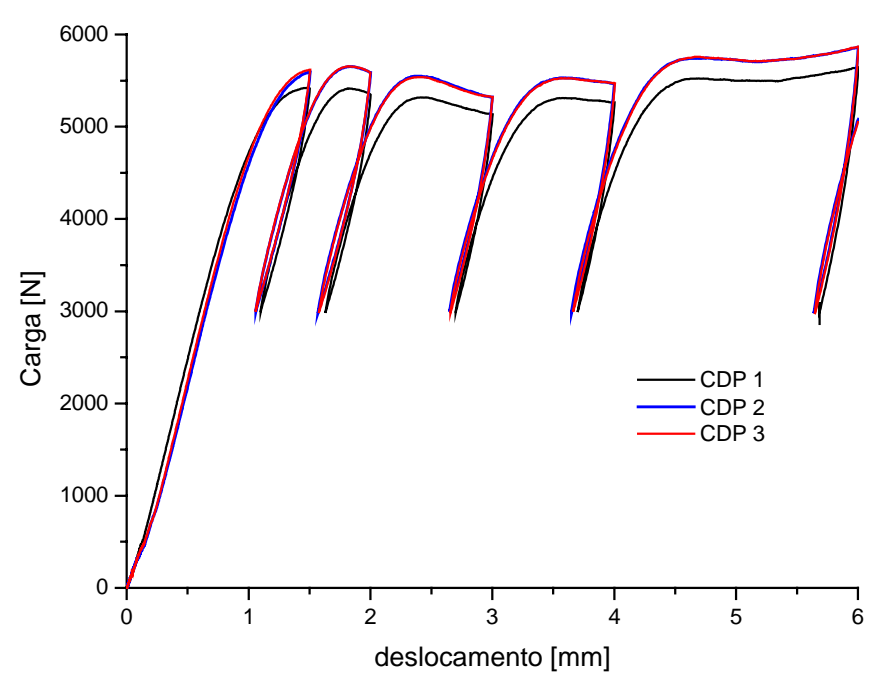

Figura 4.19 - Curvas carga-deslocamento com ciclos sob $0,8 \mathrm{~mm} / \mathrm{min}$ (ensaio de compressão). 
Além disso, forma-se um laço histerético caracterizando assim um comportamento viscoelasto-plástico (Figura 4.20). Dessa forma, com o intuito de uma investigação preliminar do fenômeno de relaxação ("relaxation"), fez-se um ensaio com controle de deslocamento onde a amostra foi submetida por um determinado tempo sob uma dada deformação, e verificou-se a queda de tensão ao longo desse tempo.

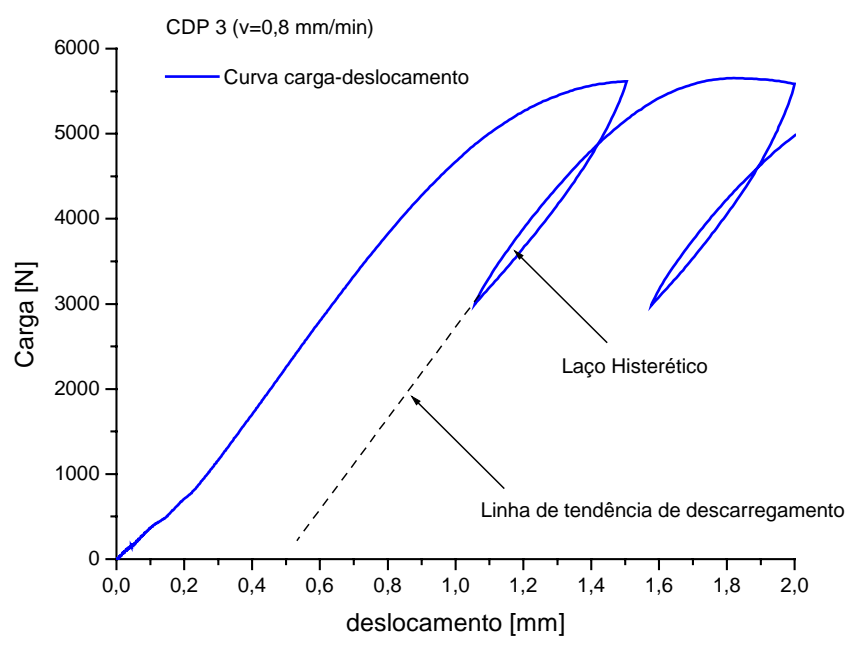

Figura 4.20 - Linhas de tendência de descarregamento e laço histerético sob compressão.

Portanto, a Figura 4.21 mostra uma curva tensão-deformação onde há dois ciclos de carregamento-descarregamento e re-carregamento. Sendo que antes de ocorrer o descarregamento, aguardou-se um tempo determinado para que o biopolímero relaxasse. Após esse tempo, a amostra foi descarregada até um nível zero de tensão, e então logo em seguida foi re-carregada. 


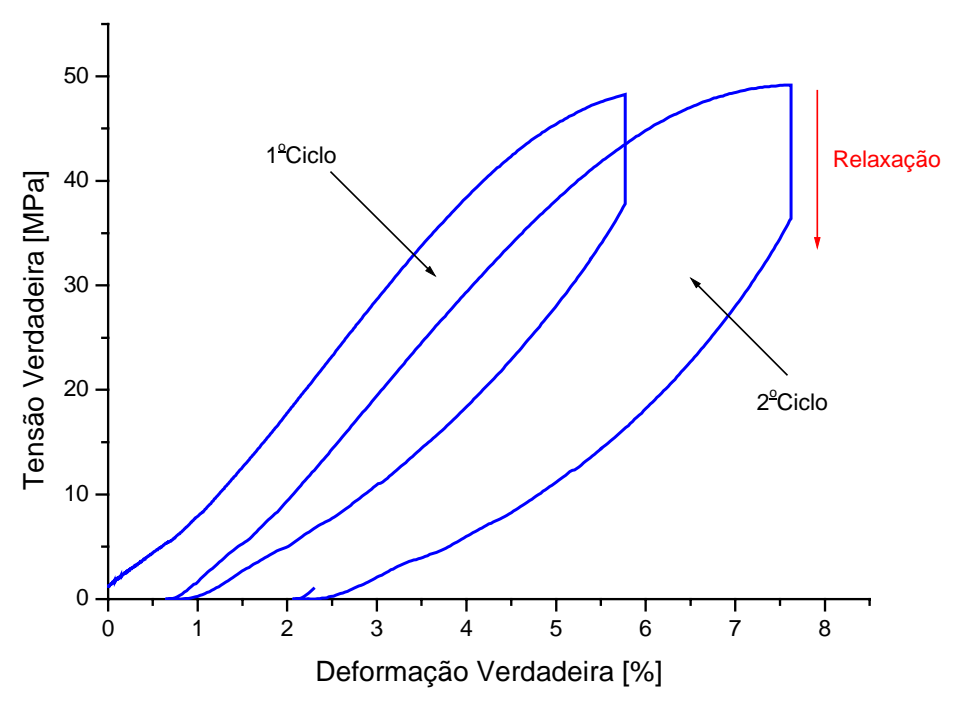

Figura 4.21 - Curva tensão-deformação para dois ciclos.

Para a curva da Figura 4.21 se pode notar que o $1^{\circ}$ ciclo inicia-se bem próximo à tensão de escoamento de compressão, ou seja, quando a amostra atinge 5,8\% de deformação verdadeira. Mesmo assim, já é possível notar a presença de uma pequena deformação residual (cerca de $0,5 \%$ ). Por outro lado, o $2^{\underline{0}}$ ciclo inicia-se com 7,6\% de deformação verdadeira (acima da tensão de escoamento), fazendo com que a deformação residual após o final do descarregamento seja bem maior (cerca de $2 \%$ ).

Como os fenômenos viscoelásticos (fluência e relaxação) são verificados em função do tempo, torna-se interessante mostrar as curvas tensão-tempo e deformação-tempo para os dois ciclos. Verifica-se assim, pela Figura 4.22 que o fenômeno da relaxação é bem acentuado na iminência do escoamento do material como durante a fase de plastificação. Contudo, tanto o fenômeno de relaxação como o de fluência serão investigados com maior profundidade na segunda fase desse projeto. 


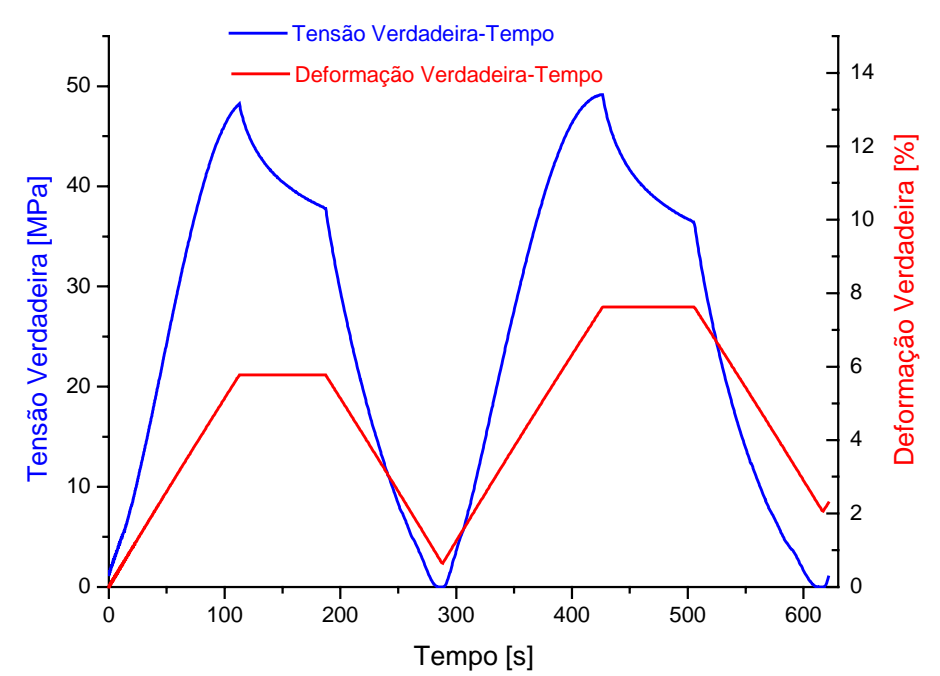

Figura 4.22 - Curvas tensão-tempo e deformação-tempo para dois ciclos

Por fim, foram realizados ensaios cíclicos com strain-gages para medir a evolução das deformações circunferenciais. A Figura 4.23 mostra a curva deformação circunferencialtempo medida com auxílio do strain-gage e a curva tensão-tempo, geradas por um ensaio com ciclos de carregamento-descarregamento e re-carregamento.

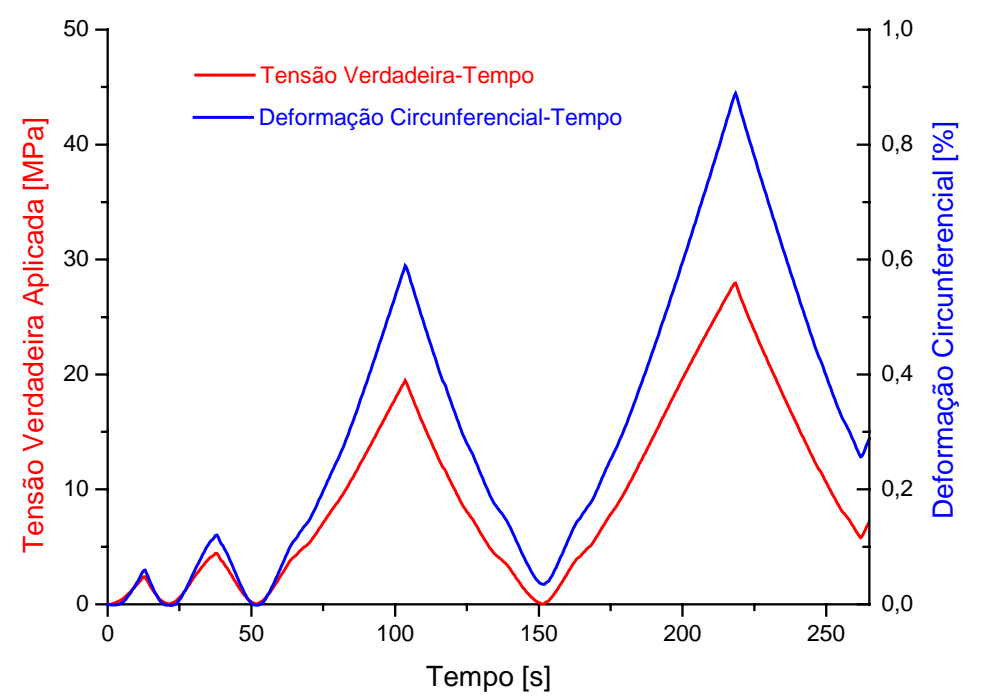

Figura 4.23 - Curvas tensão-tempo e deformação circunferencial-tempo (medida por strain-gage). 


\subsection{C) RESULTADOS DOS ENSAIOS DA PRÓTESE DE QUADRIL}

No ensaio experimental da prótese de implante de quadril foram seguidas as especificações da norma ISO 7206-3 que determina o desempenho de próteses de quadril submetidas a carregamentos cíclicos sem aplicação de torção. No entanto, no ensaio realizado, utilizou-se um carregamento quase-estático com deslocamento controlado sob a velocidade de $0,8 \mathrm{~mm} / \mathrm{min}$ e a prótese foi engastada a uma distância de $80 \mathrm{~mm}$, verticalmente abaixo do centro da esfera. Sendo que da mesma maneira como procedido com os ensaios de tração e compressão, os ensaios numa primeira etapa tiveram o intuito principal de avaliar o funcionamento do novo dispositivo utilizado, descrito no capítulo 3 - Materiais e métodos.

A Figura 4.24(a) mostra o início do ensaio da prótese de quadril segundo a norma ISO 7206-3, que exige a aplicação de uma força sempre normal em relação à esfera de alumina acoplada a ponta da prótese e uma linha de força sempre passando pelo centro da esfera. Verifica-se inicialmente que o acetábulo em contato com a esfera encontra-se alinhado com o centro da pista do rolamento. No entanto, com a evolução do ensaio, há aplicação do deslocamento vertical fazendo com que a prótese se deforme, empurrando o acetábulo que por sua vez empurra o rolamento acoplado a este. O rolamento desliza sobre a pista, mantendo a linha de força alinhada com o centro da esfera até o final do ensaio (Figura 4.24(b)). 


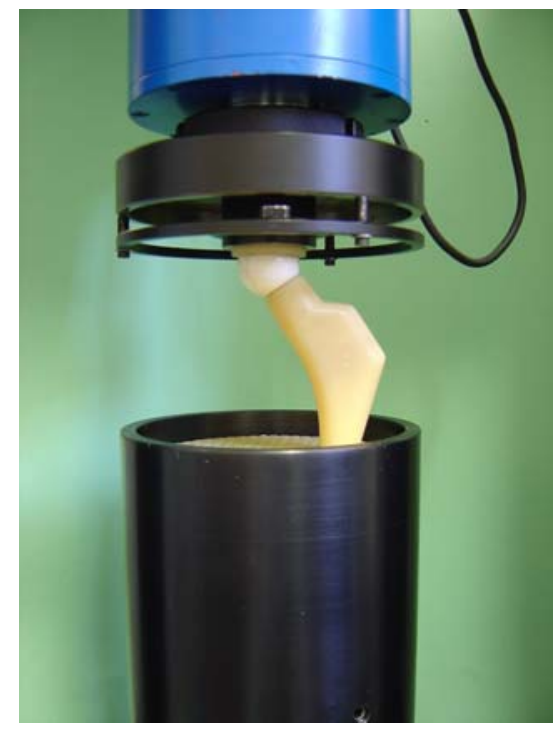

(a)

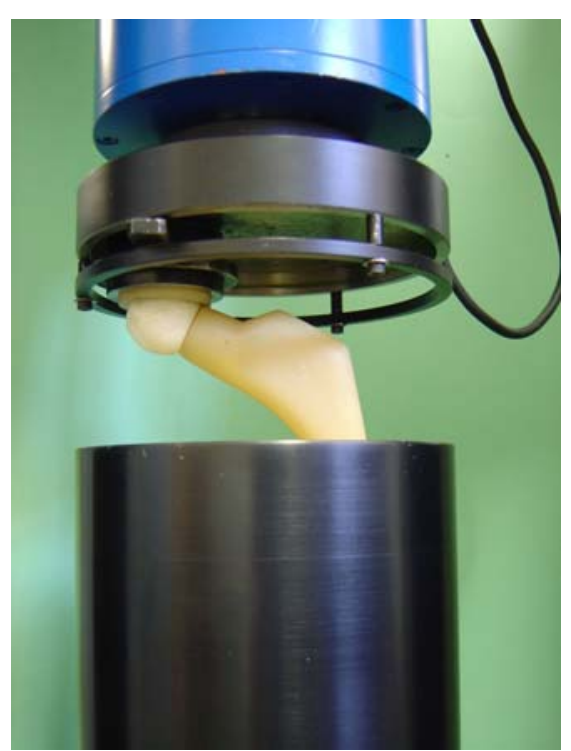

(b)

Figura 4.24 - Ensaio segundo a norma ISO 7206-3: posição do acetábulo no início do ensaio (a) bem como ao final do ensaio (b).

A Figura 4.25 mostra a curva carga-deslocamento obtida do ensaio realizado. Nota-se um comportamento ligeiramente linear apresentado pela prótese até que seja atingida a carga de 500 N. Acima deste valor, verifica-se um comportamento não-linear. Sendo que há um aumento do carregamento até aproximadamente $600 \mathrm{~N}$, e após este valor verifica-se uma perda considerável de rigidez. Além disso, nota-se por toda a extensão da curva algumas ligeiras quedas de carregamento, que são acentuadas na faixa entre $150 \mathrm{~N}$ e $200 \mathrm{~N}$.

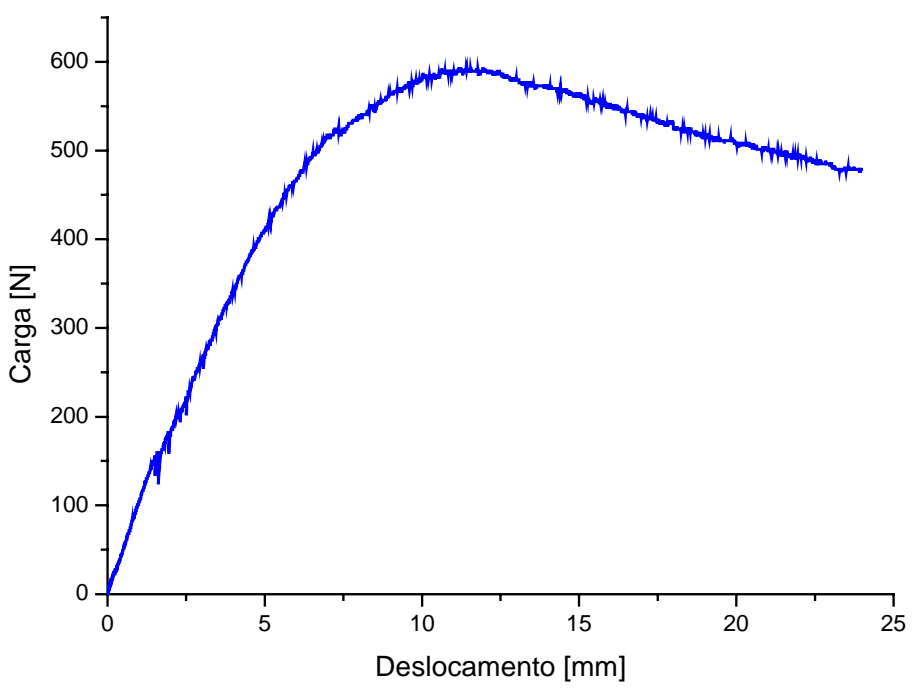

Figura 4.25 - Curva carga-deslocamento sob $0,8 \mathrm{~mm} / \mathrm{min}$ (ISO 7206-3). 
Isto provavelmente ocorre devido aos fenômenos de atrito-contato existente entre a esfera de alumina e o acetábulo, entre o rolamento e a pista do rolamento e finalmente entre a prótese e a sua fixação no cimento especial. A norma ISO 7206-3 recomenda que a fixação da prótese seja efetuada utilizando "cimento ósseo" (poli-metil-metacrilato), pois tal composto é empregado nas cirurgias de prótese de quadril metálica. No entanto, o custo deste "cimento" é elevado, inviabilizando o seu uso em grande quantidade. Dessa forma, optou-se por realizar os ensaios utilizando um "cimento" desenvolvido no Laboratório de Tribologia e Compósitos do Departamento de Engenharia Mecânica (EESC-USP). Este cimento é composto pela mistura de pequenas pedras de granito com resina epóxi, sendo assim chamado de "granito sintético". Atualmente, tem-se avaliado a qualidade da adesão do "granito sintético" ao biopolímero a fim de que a prótese venha ficar engastada durante todo o ensaio.

A Figura 4.26 apresenta o dispositivo já com a haste fixada do "granito sintético" porém em dispositivo bipartido. Foram feitos ensaios preliminares da fixação da haste de implante de quadril ao dispositivo através desse método quanto aderido a um bloco de granito maciço. Dessa forma, devido a obtenção de resultados semelhantes, optou-se pelo mecanismo mostrado na Figura 4.26 uma vez que essa configuração apresentou boa praticidade na realização dos ensaios assim como resultados satisfatórios.
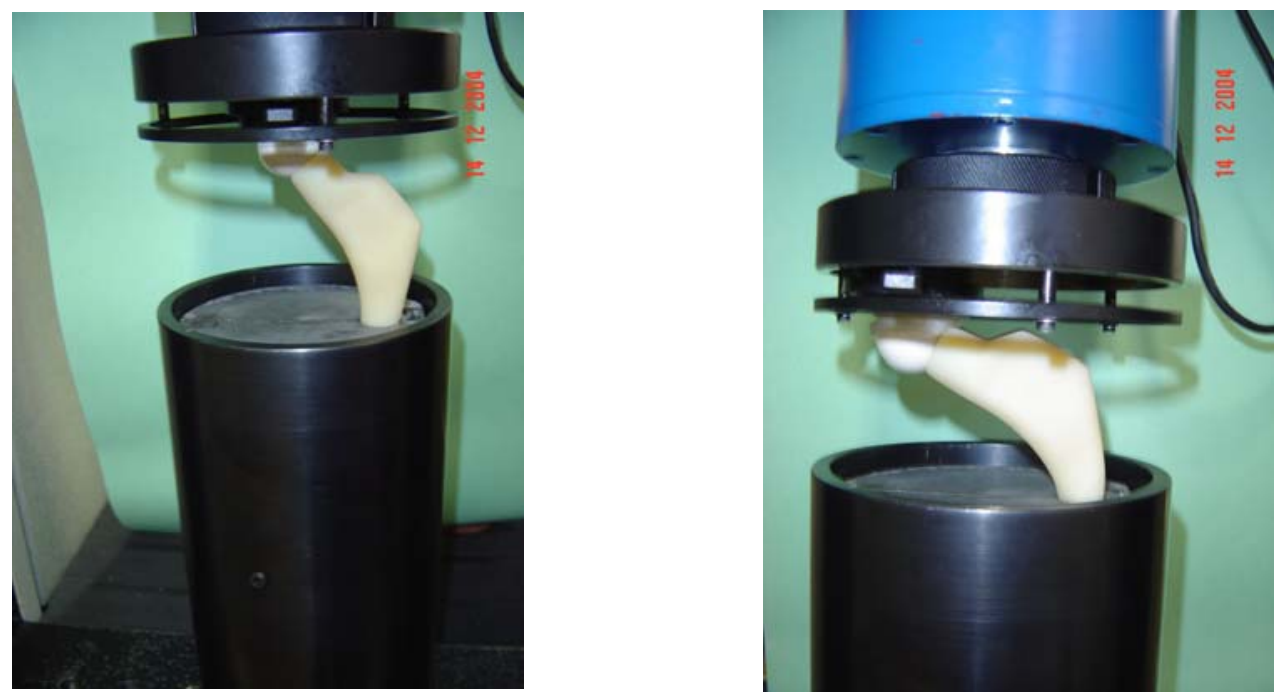

Figura 4.26 - Ensaio segundo a norma ISO 7206-3:

Utilização de bloco de granito sintético bipartido como suporte da haste de implante de quadril. 
A Figura 4.27 mostra a curva carga-deslocamento obtida a partir dos ensaios realizados com a nova configuração do dispositivo de ensaios, mostrada na Figura 4.26. Conforme observado anteriormente, nota-se também um comportamento ligeiramente linear apresentado pela prótese no inicio do ensaio, aproximadamente 400 a $500 \mathrm{~N}$, conforme esperado teoricamente e como resultado dos experimentos efetivados anteriormente. Acima deste valor, verifica-se um comportamento não-linear. Há um aumento do carregamento até aproximadamente $700 \mathrm{~N}$, e após este valor verifica-se uma perda considerável de rigidez.

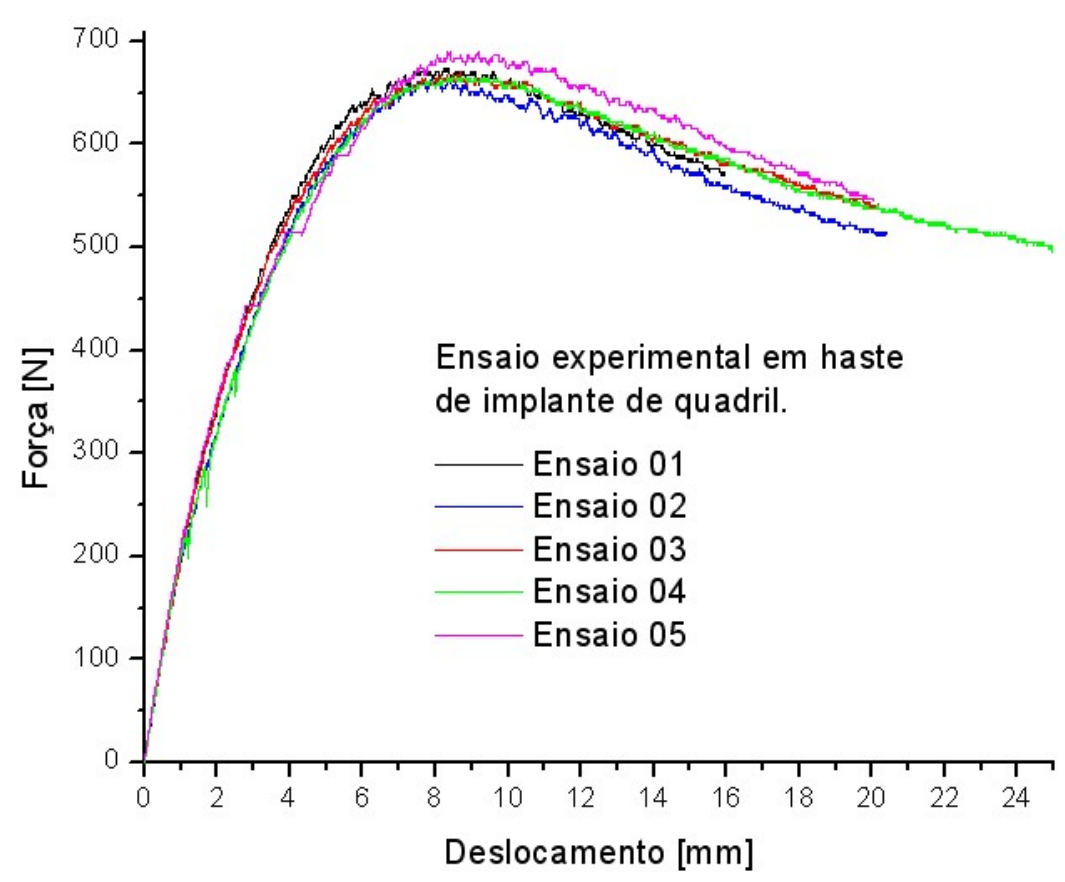

Figura 4.27 - Curva carga-deslocamento sob 0,8 mm/min (ISO 7206-3). 


\subsection{RESULTADOS COMPUTACIONAIS}

\subsection{A) MODELOS COMPUTACIONAIS DE TRAÇÃO}

\section{Modelo de Material}

Com base nos resultados dos ensaios experimentais sob velocidade de $0,8 \mathrm{~mm} / \mathrm{min}$, determinou-se os parâmetros associados ao modelo de Drucker-Prager apresentados no Capítulo 2.

Sendo que $\sigma_{\mathrm{c}}$ corresponde à resistência sob compressão e $\sigma_{\mathrm{t}}$ corresponde à resistência sob tração. Porém, para o presente trabalho $\sigma_{\mathrm{c}}$ corresponderá à tensão de escoamento sob compressão e $\sigma_{\mathrm{t}}$ corresponderá à tensão de escoamento sob tração, pois o biopolímero apresentou um comportamento dúctil tanto nos ensaios de tração como nos ensaios de compressão. Considerando que o biopolímero irá respeitar a regra da associatividade descrita no Capítulo 2, tem-se a igualdade dos valores para ângulo de dilatação $(\psi)$ e ângulo de atrito ( $\beta$ ) (associatividade: $\psi=\beta$ ) para os parâmetros de Drucker-Prager. O cálculo dos coeficientes foi feito tomando-se a média dos valores das tensões de tração e de compressão registradas nos ensaios. Os valores médios de tensão obtidos foram $\sigma_{\mathrm{t}}=31,422 \mathrm{MPa}$ para tração e $\sigma_{\mathrm{c}}=$ 42,54 MPa para compressão, sendo que as deformações médias para foram 10,47\% e 14,18\%, para tração e compressão, respectivamente. Através da utilização desses valores no cálculo dos coeficientes foram obtidos os valores de 36,14 para coesão e $24,28^{\circ}$ para ângulo de atrito (mostrados na Tabela 4.1). 
Tabela 4.1 - Valores dos parâmetros de Drucker-Prager:

\begin{tabular}{cc}
\hline Parâmetros & Valor \\
\hline Ângulo de Atrito $(\beta)$ & $24,28^{\circ}$ \\
\hline Coesão $(\mathrm{d})$ & $36,14 \mathrm{MPa}$ \\
\hline $\begin{array}{c}\text { Ângulo de Dilatação }(\psi) \\
\text { (Associatividade: } \psi=\beta \text { ) }\end{array}$ & $24,28^{\circ}$ \\
\hline
\end{tabular}

Para o modelo linear de Drucker-Prager, utilizado nas análises, ao mesmo tempo que se insere os valores de $\psi$ e $\beta$, é necessário se fixar um outro parâmetro $(\mathrm{K})$ chamado de taxa do fluxo de tensão (“flow stress ratio”). Segundo Hibbit et al (2000), esse parâmetro deve estar entre $0,778 \leq \mathrm{K} \leq 1,0$ para assegurar a convexidade da superfície de plastificação. Com a instituição de $\psi=\beta$ como também de $K=1$, retoma-se o modelo original de Drucker-Prager (Hibbit et al, 2000).

Além da determinação dos parâmetros de Drucker-Prager, torna-se necessário obter a curva tensão-deformação plástica (verdadeira) para expressar a evolução do encruamento, que será inserida na opção “Drucker Prager Hardening”. No entanto, como foi discutido anteriormente, a determinação da curva tensão-deformação após o "necking” não é uma tarefa simples, pois envolve um campo triaxial de tensões, portanto, a tensão na direção do carregamento necessita ser corrigida. Caso o CP de tração seja cilíndrico, pode-se utilizar o método de correção analítico proposto por Bridgman (1952), onde a tensão corrigida é função do raio de curvatura da estricção e do raio atual da secção transversal do CP. Todavia, o CP ensaiado tem formato prismático e as hipóteses utilizadas por Bridgman (1952) não são válidas neste caso (Ling, 1996).

Uma alternativa foi testar inicialmente uma curva considerando o material como sendo plástico perfeito, ou seja, não há incremento das tensões com a evolução das deformações plásticas. Assim, aplicou-se essa curva ao modelo mostrado na Figura 3.16 mostrado no capítulo 3 - Materiais e Métodos, comparando posteriormente os resultados numéricos carga- 
deformação de engenharia com os resultados experimentais pôde-se avaliar tal hipótese adotada.

Em seguida, com o intuito de determinar uma curva de encruamento mais realista, buscou-se na literatura metodologias para a obtenção da mesma. Deve-se ressaltar que a grande maioria dessas metodologias é do tipo numérico-experimental, ou seja, envolvem ensaios bem como modelagem computacional. Dentre os trabalhos pesquisados, destacam-se as metodologias propostas por: Ling (1996); Zhang et al (1999); Zhang et al (2001); Cabezas e Celentano (2004). No entanto, todas essas metodologias foram empregadas para materiais metálicos, utilizando-se assim do Modelo de Mises. No presente trabalho, adotou-se a metodologia proposta por Ling (1996), porém o modelo de material empregado foi o de Drucker-Prager, haja vista que os materiais poliméricos sofrem variação volumétrica durante a plastificação.

A metodologia proposta por Ling (1996) consiste em encontrar uma curva de encruamento isótropo através da ponderação de duas leis constitutivas: uma Lei de Potência e uma Lei Linear, dadas respectivamente por:

$$
\begin{aligned}
& \text { Lei de Potência: } \sigma_{\mathrm{v}}=\left(\frac{\sigma_{\mathrm{vu}}}{\varepsilon_{\mathrm{vu}}^{\varepsilon_{\mathrm{vu}}}}\right) \varepsilon_{\mathrm{v}}^{\varepsilon_{\mathrm{vu}}} \\
& \text { Lei Linear: } \sigma_{\mathrm{v}}=\sigma_{\mathrm{vu}}\left(1+\varepsilon_{\mathrm{v}}-\varepsilon_{\mathrm{vu}}\right)
\end{aligned}
$$

onde:

$$
\begin{aligned}
& \varepsilon_{\mathrm{vu}}=\text { deformação verdadeira no inicio do "necking" } \\
& \sigma_{\mathrm{vu}}=\text { tensão verdadeira no inicio do "necking" }
\end{aligned}
$$

Segundo Ling (1996), a Lei de Potência subestima a lei de encruamento real ao passo que a Lei Linear superestima. Conseqüentemente, a Lei de Potência pode ser considerada uma 
curva Limite Inferior (“lower bound”), e a Lei Linear pode ser considerada uma curva Limite Superior ("upper bound"), de tal forma que a lei de encruamento "quase-real” esteja entre essas curvas limites (Figura 4.28).

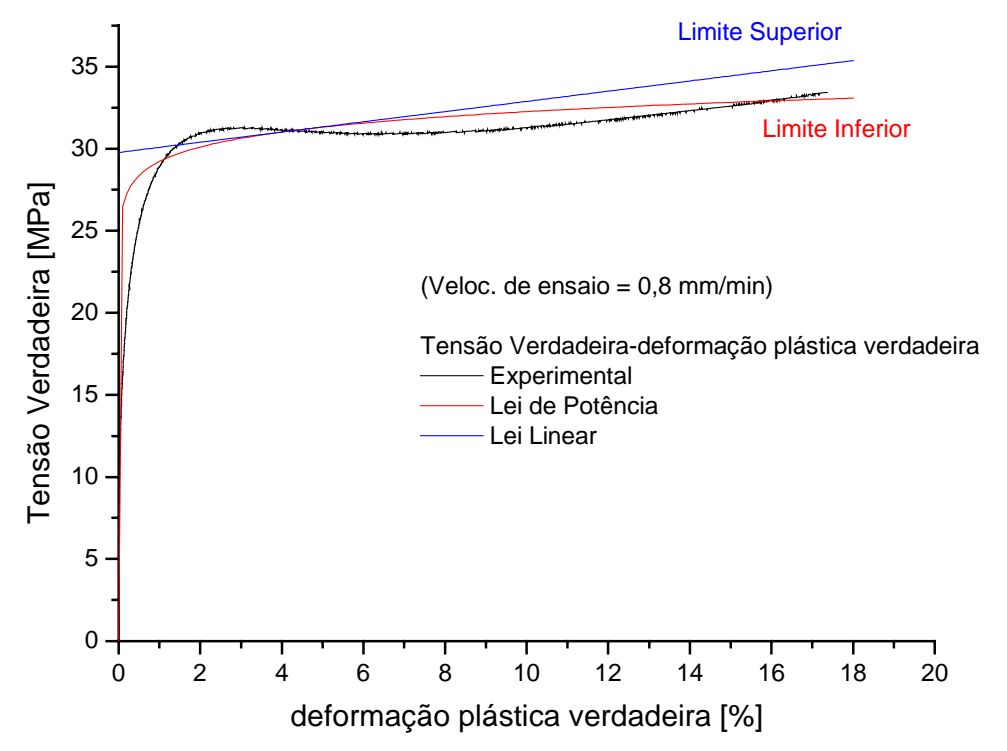

Figura 4.28 - Curvas Limite Superior e Limite Inferior para o biopolímero.

Portanto, uma lei de encruamento "quase-real" pode ser estimada pela ponderação dessas duas leis constitutivas:

$$
\sigma_{\mathrm{v}}=\sigma_{\mathrm{vu}}\left[\mathrm{w}\left(1+\varepsilon_{\mathrm{v}}-\varepsilon_{\mathrm{vu}}\right)+(1-\mathrm{w})\left(\frac{\varepsilon_{\mathrm{v}}^{\varepsilon_{\mathrm{vu}}}}{\varepsilon_{\mathrm{vu}}^{\varepsilon_{\mathrm{vu}}}}\right)\right]
$$

Onde w é o fator de ponderação, dado entre os limites zero e um: $0 \leq \mathrm{w} \leq 1$. Caso w seja igual a zero, a curva de encruamento será dada por uma Lei de Potência. Caso w seja igual a 1, a curva de encruamento será dada por uma Lei Linear, e finalmente, caso w esteja entre 0 e 1, a curva de encruamento será dada pela ponderação das duas leis. Sendo assim, o aspecto mais importante da metodologia é a determinação de w. Para tal, utiliza-se o modelo da Figura 4.27, o critério de plastificação de Drucker-Prager e emprega-se como estimativa 
inicial, a lei de encruamento dada pela equação (4.7), considerando w igual a 0,5 (Figura 4.29).

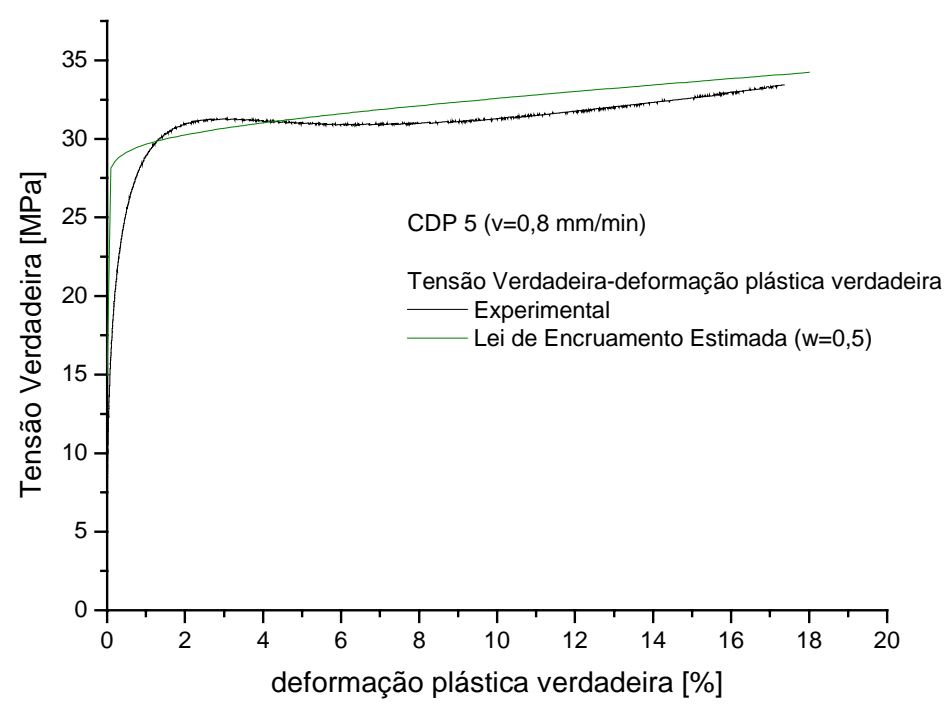

Figura 4.29 - Curva de encruamento de tração estimada para o biopolímero $(\mathrm{w}=0,5)$.

Compara-se assim a curva carga-deformação de engenharia numérica obtida com a curva experimental, a fim de verificar se o parâmetro w necessita ser ajustado. Caso isto seja necessário, deve-se alterar a lei de encruamento e simular novamente. Este procedimento iterativo ocorre até que a força calculada computacionalmente se aproxime da força medida. Em suma, a curva carga-deformação de engenharia é utilizada para calibrar o fator de ponderação w.

\section{Resultados Numéricos dos Modelos de Tração}

A Figura 4.30 mostra os resultados numéricos do modelo de tração comparado ao resultado experimental quando empregado um modelo Elástico Linear e o Modelo de Drucker-Prager com a curva de plasticidade perfeita. Verifica-se inicialmente que o modelo Linear Elástico demonstra perda de linearidade da curva experimental logo a partir de $800 \mathrm{~N}$. Isto ocorre devido à presença de não-linearidades provocadas por efeitos visco-elásticos que não são captados pelos modelos atuais. 
Por outro lado, o Modelo de Drucker-Prager com a curva de plasticidade perfeita mostra um resultado razoável até $11 \%$ de deformação. Porém, para valores de deformação acima de $11 \%$, o resultado numérico diverge do experimental, pois o biopolímero passa apresentar um certo encruamento, como foi evidenciado nas curvas tensão verdadeira por deformação plástica verdadeira.

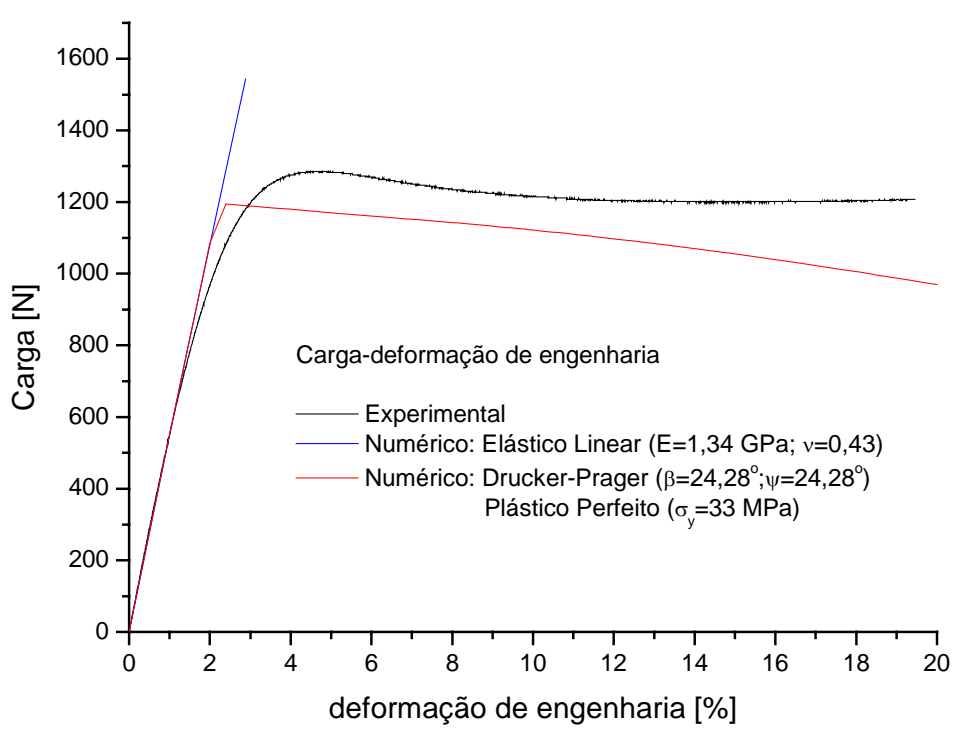

Figura 4.30 - Resultado numérico de carga-deformação de engenharia considerando o biopolímero plástico perfeito.

Apesar da Figura 4.31 demonstrar a coerência do modelo computacional em representar o fenômeno físico de "necking” difuso e localizado, é importante ressaltar que os modelos podem ser melhorados com emprego da metodologia numérico-experimental.

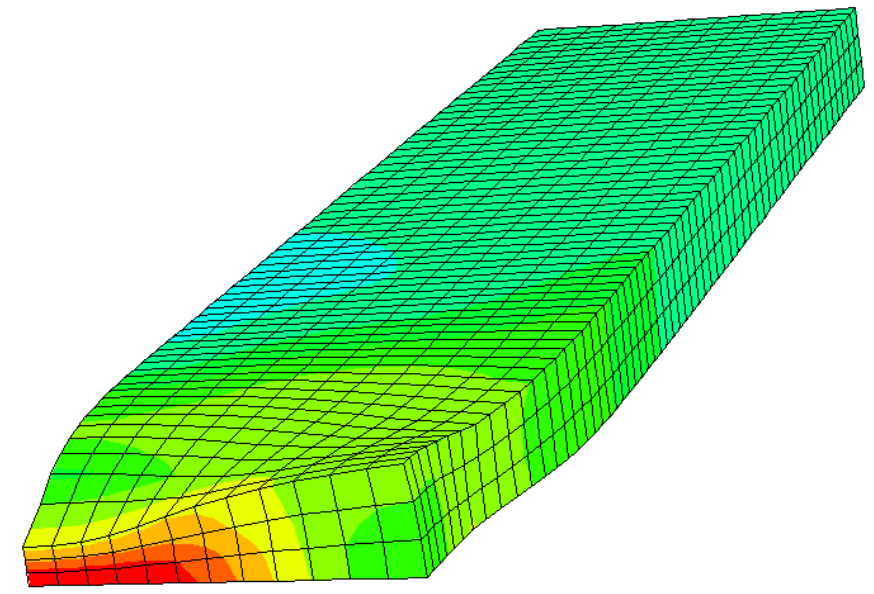

Figura 4.31 - Resultado numérico: "necking” difuso e "necking” localizado. 
A Figura 4.32 mostra os resultados numéricos do modelo de tração comparado ao resultado experimental quando empregada à curva da equação (4.7), adotando alguns valores para o fator de ponderação w.

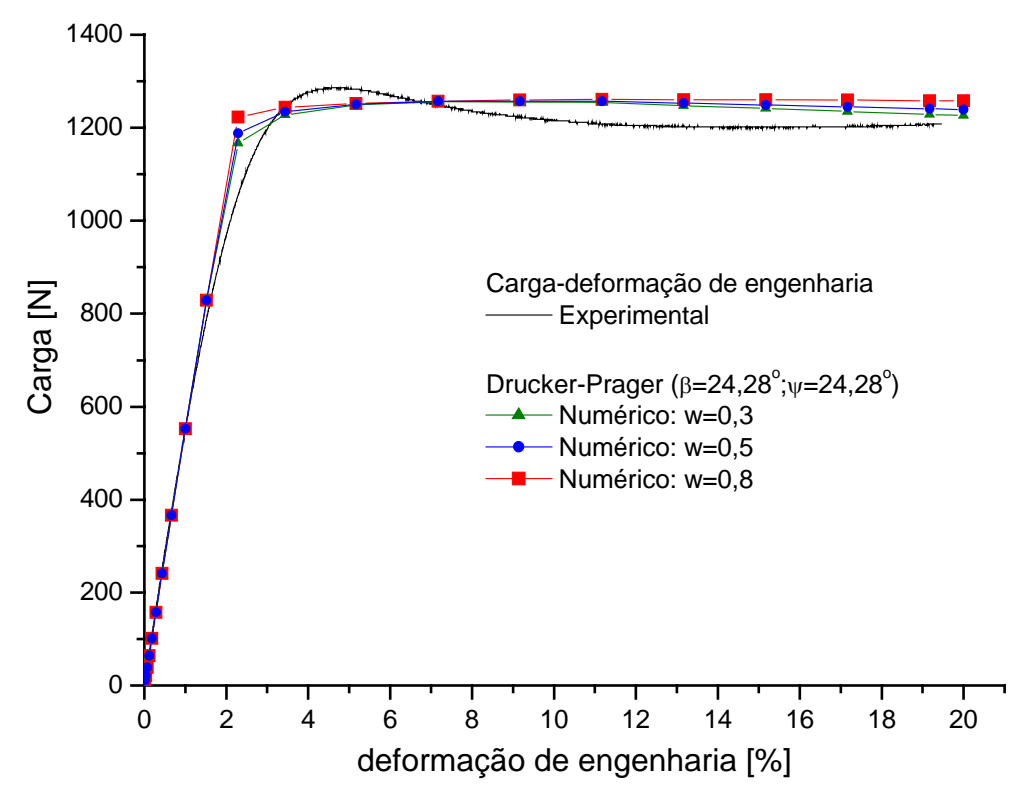

Figura 4.32 - Resultado numérico de carga-deformação de engenharia empregando a metodologia numérico-experimental.

Vale salientar que os resultados numéricos supra apresentados podem ser melhorados, alterando as equações (4.5) e (4.6) por equações que contemplem o fenômeno de softening bem como os efeitos viscoelásticos.

\subsection{B) MODELOS COMPUTACIONAIS DE COMPRESSÃO}

\section{Modelo de Material}

Com base nos resultados dos ensaios experimentais sob velocidade de $0,8 \mathrm{~mm} / \mathrm{min}$, determinou-se os parâmetros associados ao modelo de Drucker-Prager, mostrado no item 4.2A - Modelos Computacionais de Tração. Assim como nos ensaios de tração, os parâmetros estão evidenciados na Tabela 4.1 com a inserção do valor de $\mathrm{K}=1$. 
Da mesma forma como procedido para a simulação do ensaio de tração, além da determinação dos parâmetros de Drucker-Prager, torna-se necessário obter a curva tensãodeformação plástica (verdadeira) para expressar a evolução do encruamento em materiais poliméricos, que ocorre de forma diferente sob carregamentos de tração e de compressão. No entanto, como foi discutido anteriormente, a determinação da curva tensão-deformação após o conhecido Ponto A, não é uma tarefa simples, pois envolve um aumento considerável do diâmetro do CP, principalmente em níveis elevados de deformação. Todavia, com auxílio dos strain-gages longitudinal e transversal pode-se obter esta curva tensão-deformação com uma certa precisão. Dessa forma, tem-se na Figura 4.33 uma curva de encruamento estimada com base na curva obtida através dos strain-gages.

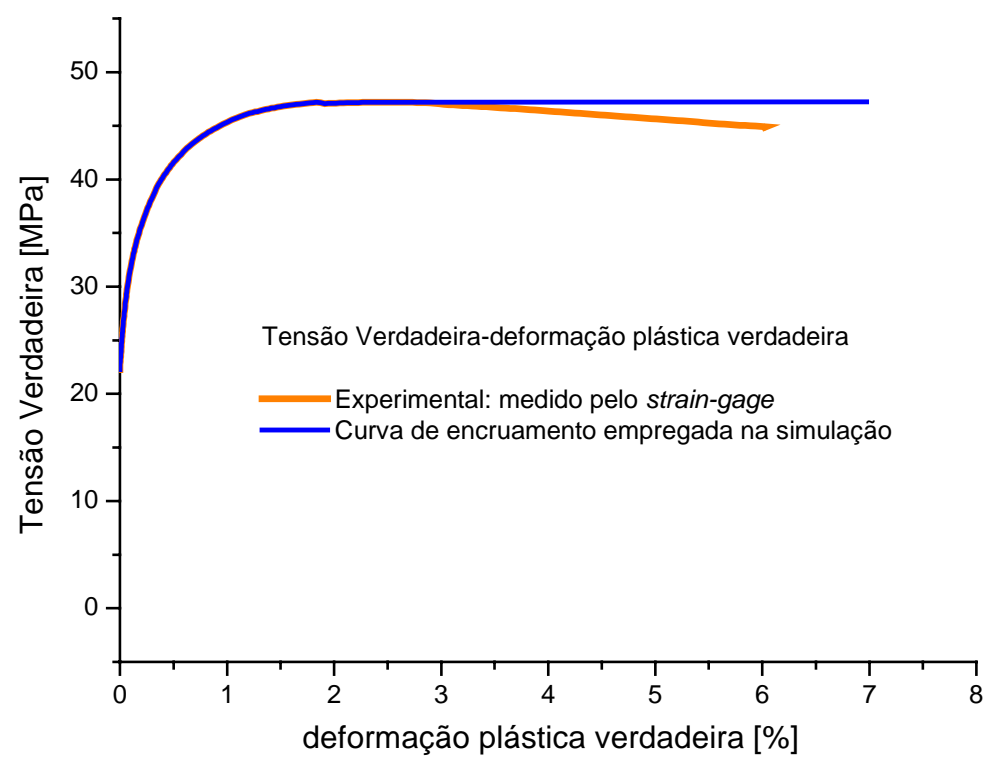

Figura 4.33 - Curva de encruamento de compressão estimada para o biopolímero.

Finalmente, aplica-se ao modelo da Figura 4.33, o Modelo de Drucker-Prager juntamente com curva de encruamento estimada e, compara-se assim, a curva cargadeformação numérica com a curva experimental, a fim de verificar se a curva de encruamento estimada é consistente fisicamente. 


\section{$\underline{\text { Resultados Numéricos dos Modelos de Compressão }}$}

A Figura 4.34 mostra os resultados numéricos do modelo de compressão comparado ao resultado experimental, quando empregado o Modelo Elástico Linear e o Modelo de Drucker-Prager com a curva de encruamento de compressão estimada.

Para o modelo Elástico Linear, adotou-se o módulo de elasticidade medido em ensaios experimentais de compressão (1,56 GPa) com auxílio de strain-gages e o coeficiente de Poisson medido nos ensaios de tração $(0,45)$. Verifica-se inicialmente que o modelo Elástico Linear demonstra perda de linearidade da curva experimental logo a partir de $2.000 \mathrm{~N}$. Isto pode ter ocorrido devido à presença de tensões de cisalhamento indesejadas durante os ensaios experimentais. Para evitar essas tensões de cisalhamento, Arruda e Boyce (1990) realizaram seus ensaios utilizando um dispositivo de compressão autocompensador.

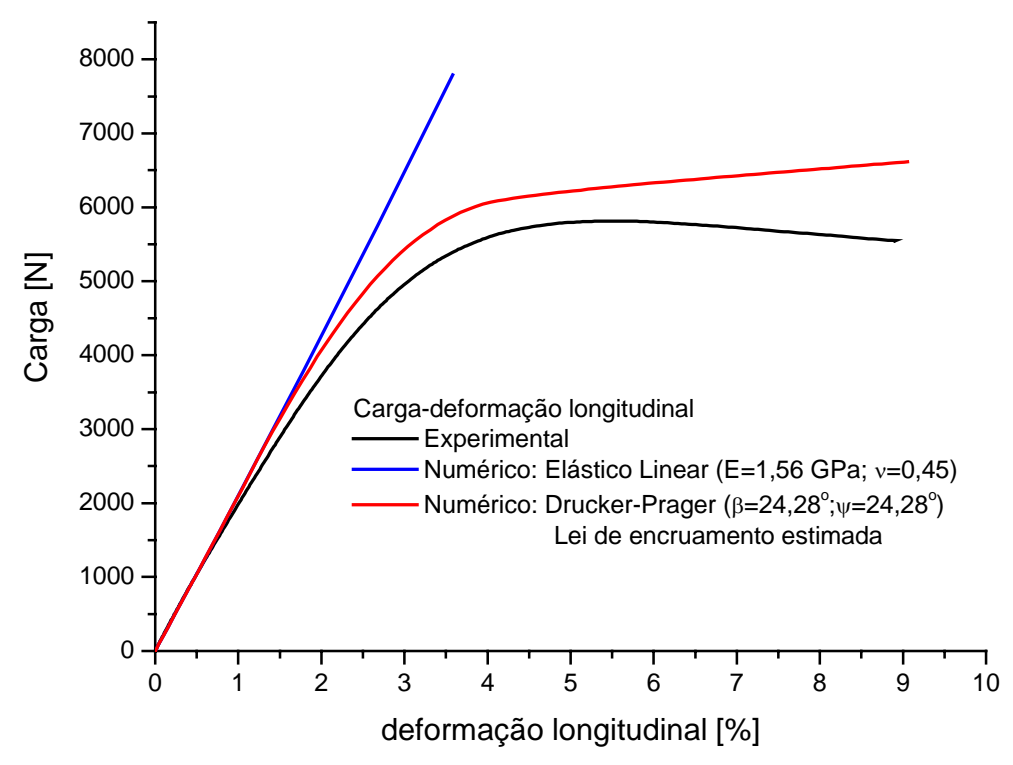

Figura 4.34 - Resultado numérico de carga-deformação (sob compressão).

Por outro lado, o Modelo de Drucker-Prager com a curva de encruamento estimada fornecem um resultado razoável até 5\% de deformação longitudinal. Após este valor de deformação, a curva experimental diverge da curva numérica. Constata-se, portanto, que a curva de encruamento estimada não é capaz de fornecer bons resultados para grandes deformações, em decorrência do fenômeno de softening. 


\subsection{C) MODELOS COMPUTACIONAIS DA PRÓTESE DE QUADRIL}

\section{Modelos de Material}

No modelamento do conjunto de implante de quadril, haste-esfera-acetábulo, tem-se que à esfera de alumina foram atribuídas a seguintes propriedades linear-elasticas: módulo de elasticidade igual a 366 GPa e coeficiente de Poisson igual a 0,22 (WREGGE, 2000).

A prótese de quadril e o acetábulo, ambos fabricados a partir do biopolímero, foram modelados com base nos resultados dos ensaios experimentais sob velocidade de $0,8 \mathrm{~mm} / \mathrm{min}$ para tração e compressão. Como o ensaio da haste de implante utilizado é norteado pela flexão, utilizou-se o módulo de flexão como informação de propriedade elástica $\left(\mathrm{E}_{1}{ }^{\mathrm{f}}\right)$ no abastecimento do programa CAE, baseado nos valores já citados.

De acordo com Carlsson \& Pipes (1987) para esse tipo de caso utiliza-se o módulo de flexão aparente. Da equação 4.8 é possível calcular o módulo de flexão aparente em função das propriedades de tração e compressão puras:

$$
E_{1}^{f}=\frac{2 E_{t}}{1+\sqrt{E_{t} / E_{c}}}
$$

Desta forma, como temos os valores de $E_{t}$ e $E_{c}$ para os módulos de tração e compressão, respectivamente, utilizando a equação 4.8 obteremos um valor de $\mathrm{E}_{1}^{\mathrm{f}}=1,375 \mathrm{GPa}$. Portanto, o valor calculado recomendado é intermediário em relação àqueles obtidos para tração e compressão. Este valor foi o utilizado para as análises computacionais do ensaio da haste.

Para complementar o modelo de material desses dois itens (haste e acetábulo) foram utilizados os parâmetros associados ao modelo de Drucker-Prager, mostrado no item 4.2A Modelos Computacionais de Tração. Assim como nos ensaios de tração, os parâmetros estão 
evidenciados na Tabela 4.1 com a inserção do valor de $K=1$. Da mesma forma como procedido para a simulação do ensaio de tração, além da determinação dos parâmetros de Drucker-Prager, torna-se necessário obter a curva tensão-deformação plástica verdadeira para expressar a evolução do encruamento em materiais poliméricos.

A curva de evolução é introduzida na característica "Drucker-Prager Hardening" do modelo de Drucker-Prager na forma de pares conforme apresentados na Tabela 4.2.

Tabela 4.2 - Valores de tensão-deformação plástica verdadeira:

\begin{tabular}{|c|c|}
\hline $\begin{array}{c}\text { Tensão } \\
\text { Verdadeira (MPa) }\end{array}$ & $\begin{array}{c}\text { Deformação plástica } \\
\text { verdadeira }\end{array}$ \\
\hline 28.94437 & 0.00 \\
\hline 29.37160 & 0.002 \\
\hline 29.82726 & 0.004 \\
\hline 30.11299 & 0.006 \\
\hline 30.32771 & 0.008 \\
\hline 30.50300 & 0.01 \\
\hline 31.11696 & 0.02 \\
\hline 31.90464 & 0.04 \\
\hline 33.02644 & 0.08 \\
\hline 34.80279 & 0.16 \\
\hline 35.60575 & 0.2 \\
\hline 49.62848 & 1.00 \\
\hline
\end{tabular}

\section{Resultados Numéricos do Modelo da Prótese}

Na modelagem do contato no conjunto esfera-acetábulo foram testadas as duas condições descritas no item D.3 do capítulo 3 - Materiais e Métodos: finite sliding e small sliding. A opção finite sliding foi aquela que alcançou melhor representação acerca das condições observadas no ensaio experimental. Pode-se notar que o deslocamento do acetábulo na direção vertical procedeu com o posicionamento adequado entre ambos elementos desde o inicio até o final da análise. Quanto à carga imposta devido ao deslocamento das partes, a direção de sua resultante passa pelo centro da esfera durante todo o ensaio. Com as considerações implementadas no modelo do presente trabalho, tais exigências foram atendidas como pode ser percebido pela Figura 4.35 que mostra o conjunto na posição indeformada 
(Figura 4.35(a)) e na posição deformada (Figura 4.35(b)), onde o acetábulo permanece sempre em posição normal em relação à esfera.

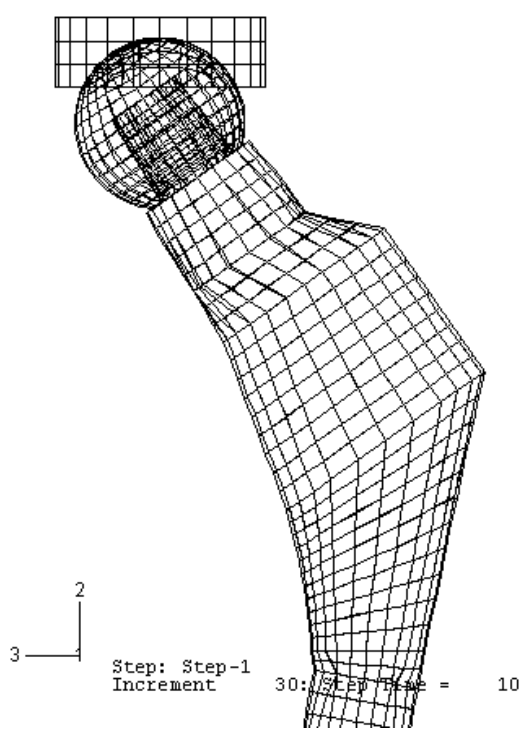

(a)

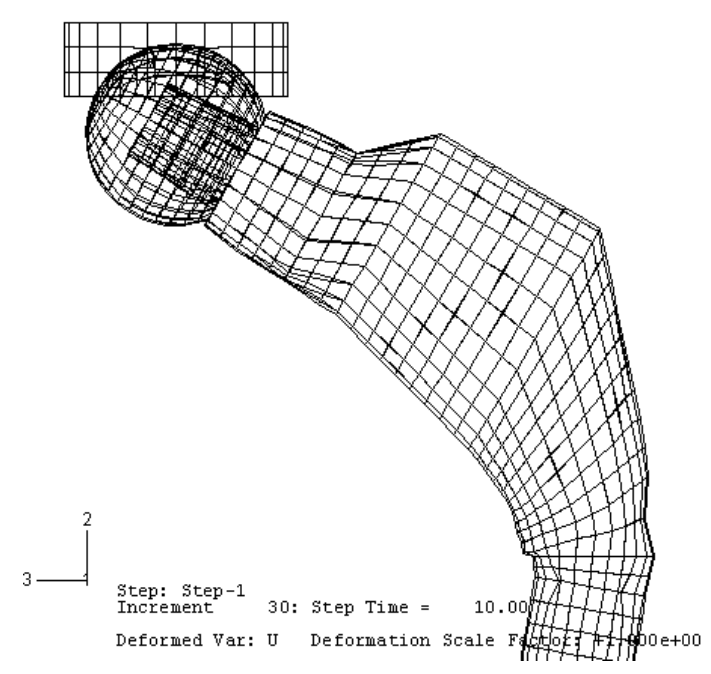

(b)

Figura 4.35 - Posição do implante (a) no inicio da análise, não deformada e (b) no final da análise, deformada.

Para a análise do implante de quadril foram testados três tipos de condições de contato ao conjunto acetábulo-esfera. Em um delas, denominada "Frictionless", a presença de atrito entre esses dois elementos é desconsiderada. Numa segunda opção, denominada "Penalty", admitiu-se a existência de atrito entre as duas peças, no qual foi assumido um coeficiente igual a 0,3 , que pode ser considerado elevado. No terceiro caso analisado, denominado “Static-Kinematic Exponential Decay" são estimados valores de 0,1 para o atrito estático, um de 0,015 para cinemático e uma taxa de redução de 0,001 entre eles. Na Figura 4.36 são apresentadas análises com variações das situações de atrito, sendo que em todas elas o contato entre as superfícies da esfera e acetábulo foi assumido como finite sliding. Dessa forma, pela Figura 4.36 é possível notar que as opções citadas possuem comportamento ligeiramente semelhante. 


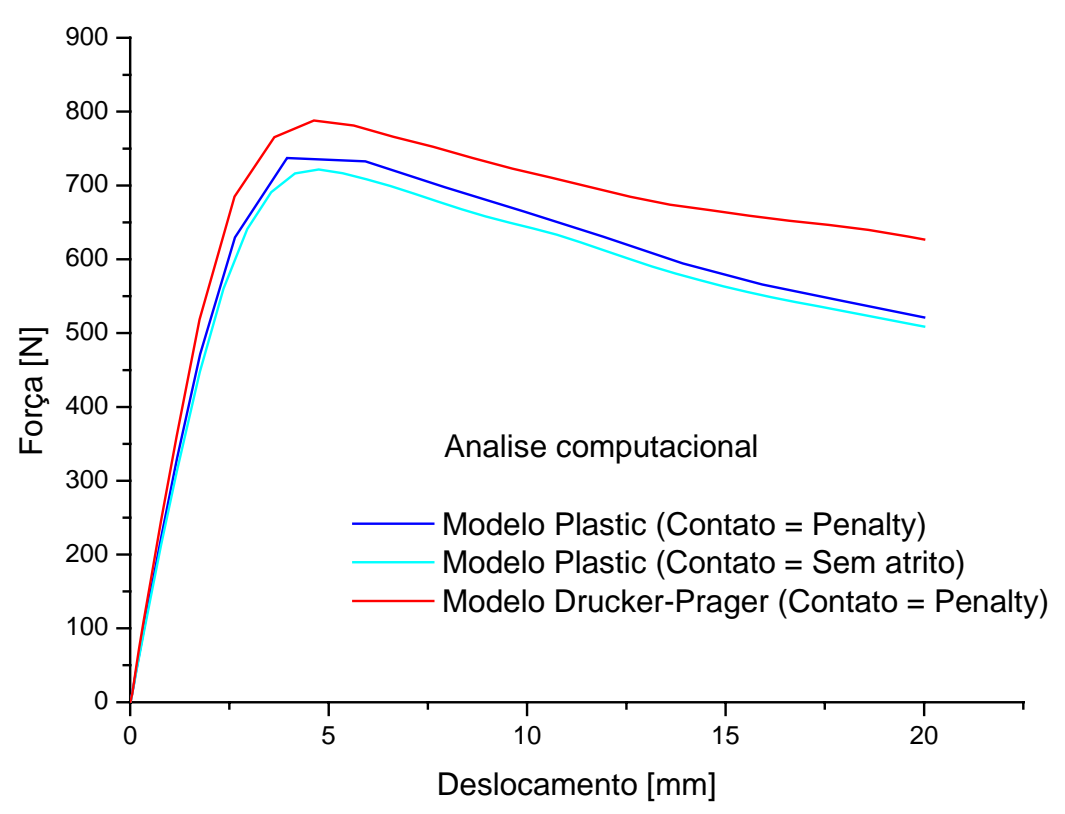

Figura 4.36 - Curva carga-deslocamento comparando: Modelo Plastic X Modelo de Drucker-Prager.

A opção small sliding também foi utiliza com cada uma das três situações de atrito não produzindo comportamento satisfatório do conjunto.

Na interação do tipo "tie" entre esfera e haste, mostrada na Figura 4.37, existe apenas a restrição de cada um dos nós sobre a superfície slave ter o mesmo valor de deslocamento, temperatura, pressão pura ou potencial elétrico que o ponto na superfície "master" com o qual ele está em contato. Assim existe apenas a restrição dos graus de liberdade de translação nas simulações. Os graus de liberdade rotacionais dos elementos estruturais envolvidos no par em contato não são restringidos (HIBBIT et al., 2000). Assim, de maneira simplificada, existe uma "transferência de valores" entre as superfícies, donde se pode concluir que esta iteração não exerce forte influência nos resultados. Mas possui sua parcela de contribuição para a convergência ou divergência dos resultados do modelo. 


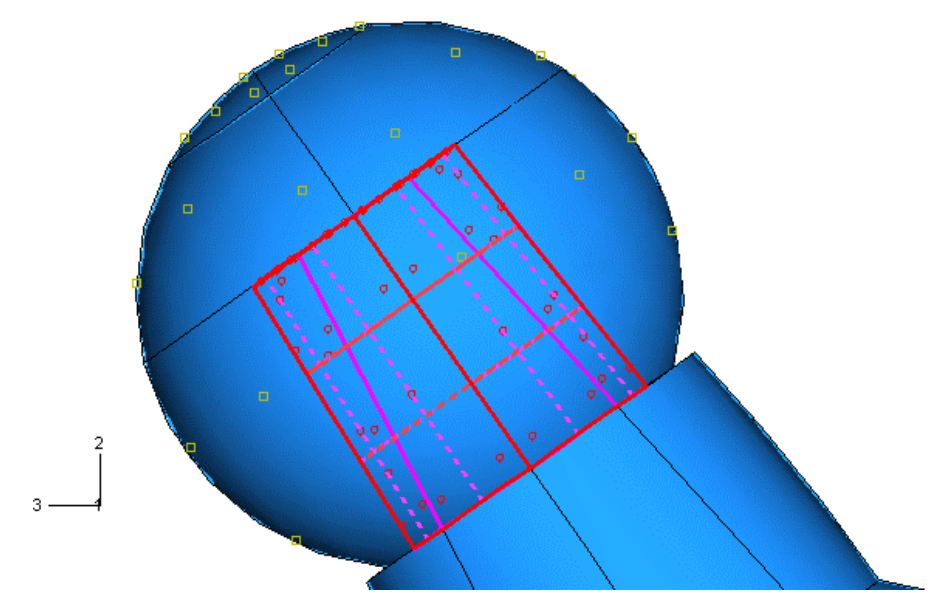

Figura 4.37 - Superfícies da interação do tipo "tie-contact" entre a esfera de alumina e a cabeça da prótese de quadril.

Sob o aspecto qualitativo, os resultados numéricos mostram que o modelo do conjunto prótese-dispositivo bem como as condições de contorno impostas ao mesmo, são razoáveis para simular os ensaios especificados pela norma ISO 7206-3 (Figura 4.38).

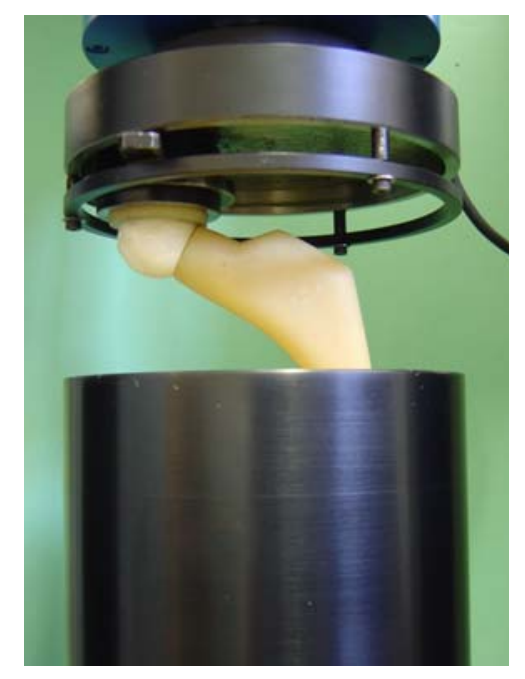

(a)

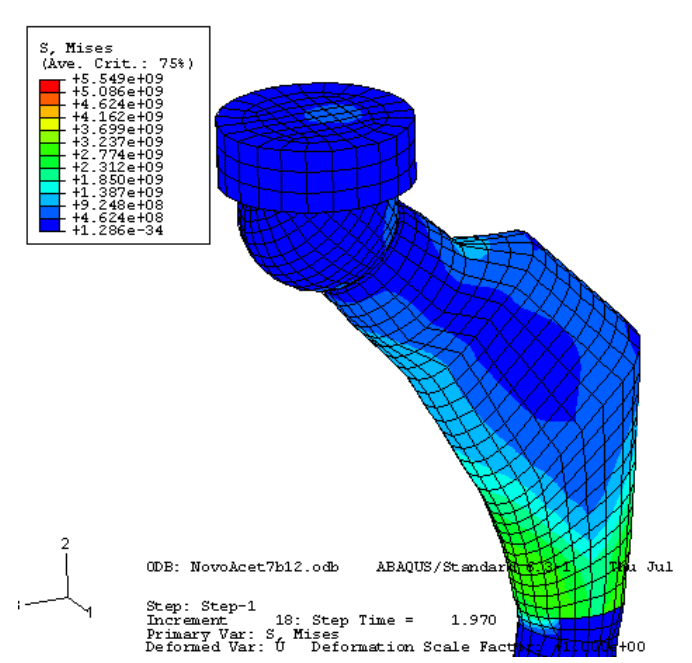

(b)

Figura 4.38 - Ensaio segundo a norma ISO 7206-3:

(a) Ensaio Experimental; (b) Análise computacional.

Porém através da Figura 4.39 é possível perceber que os resultados das simulações com a utilização do modelo de Drucker-Prager não exprimem explicitamente aqueles obtidos com o experimental. Pode-se notar que as curvas obtidas dos dados computacionais possuem representação do fenômeno de softening do biopolímero. 


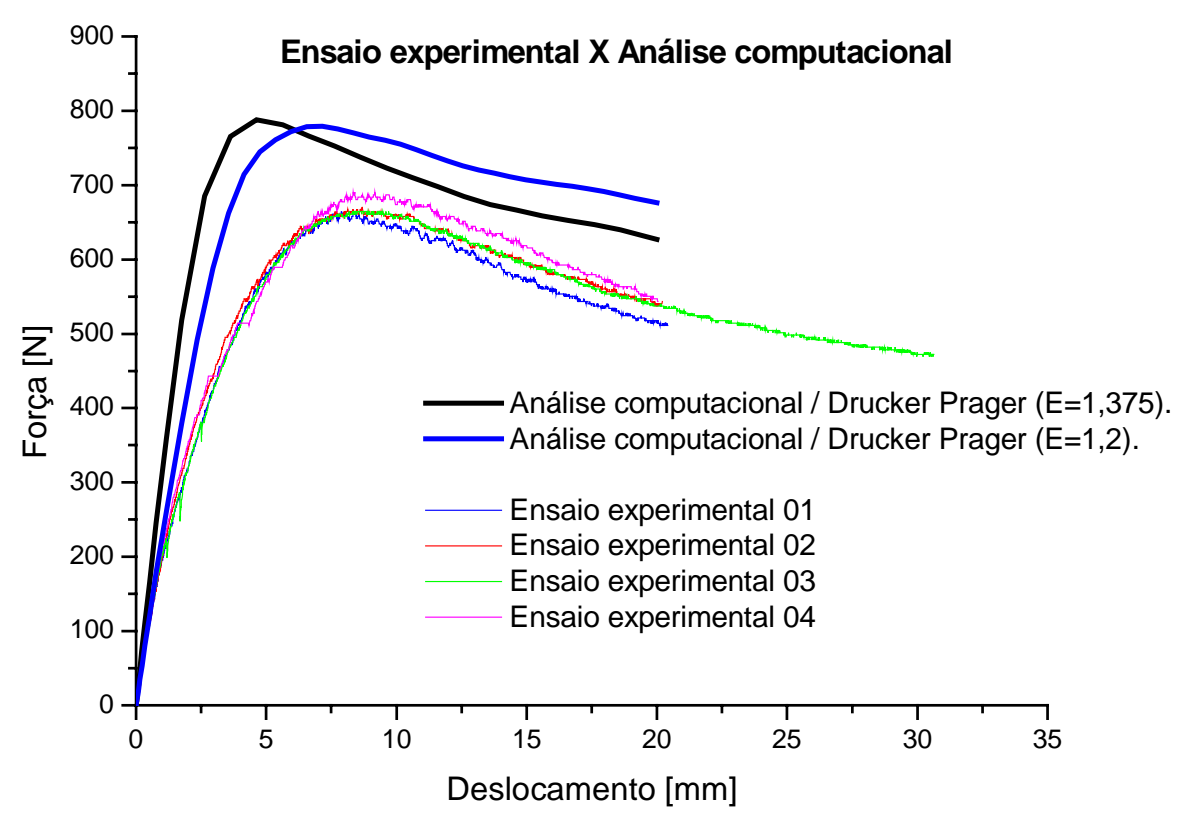

Figura 4.39 - Curva carga-deslocamento comparando: resultado experimental x resultado Drucker-Prager.

Efetuou-se um teste de redução do valor de módulo de elasticidade, de 1.375 para 1.2, para se analisar a sensibilidade do modelo a esse parâmetro. Notou-se que a curva numérica tendeu para as experimentais.

Assim, adicionalmente ao modelo de material para Drucker-Prager, foi testada a opção "Plastic" para inserção de modelos de material que utiliza o critério de von Mises (Hill). A inserção de dados consiste das propriedades elásticas do material, Módulo de elasticidade e coeficiente de Poison, adicionados da curva tensão-deformação plástica verdadeira para expressar a evolução do encruamento no biopolímero, apresentada na Tabela 4.2. A Figura 4.40 apresenta uma comparação entre a curva força versus deslocamento para Drucker-Prager, von Mises (com casos de contato diferentes) e ensaios experimentais. 


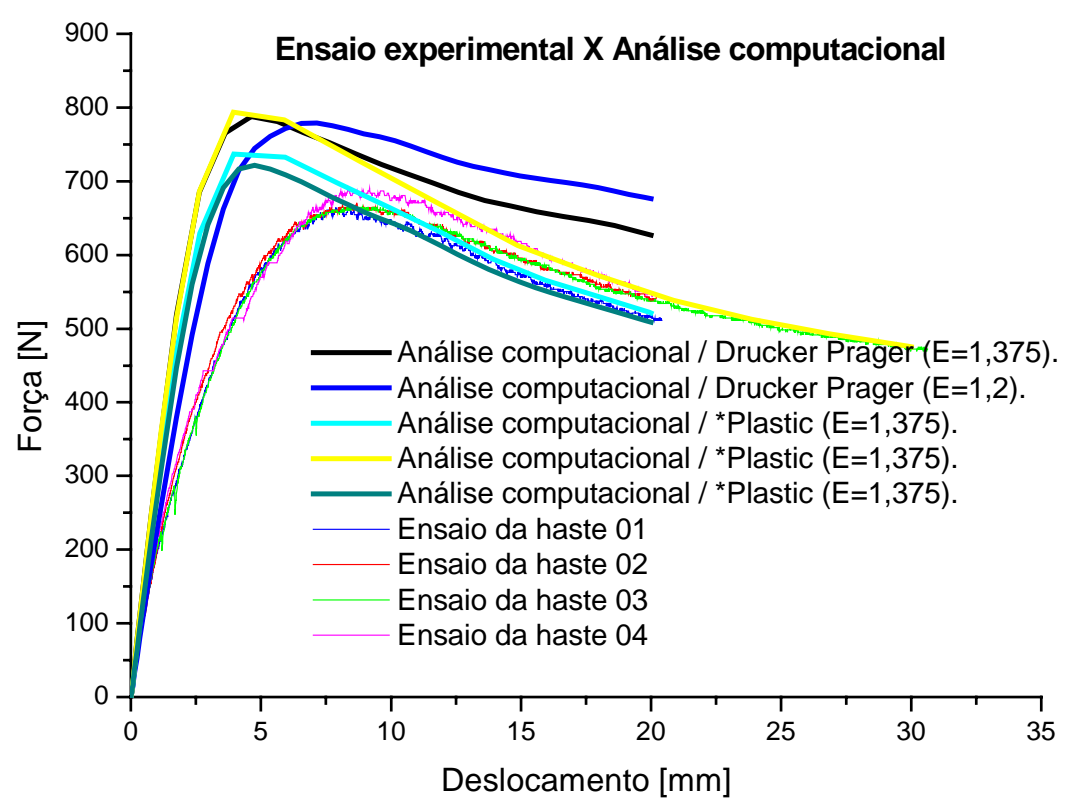

Figura 4.40 - Curva carga-deslocamento comparando: resultado experimental $\mathrm{x}$ resultado numérico.

A Figura 4.40 mostra que os resultados numéricos, sob o aspecto quantitativo, convergem ligeiramente para os resultados experimentais na fase elástica. No entanto, ao iniciar o processo de plastificação da prótese, os resultados tornam-se divergentes, demonstrando que o modelo apresenta uma rigidez maior do que o conjunto prótesedispositivo que foi ensaiado. Contudo, pode-se notar que as curvas obtidas dos dados computacionais possuem representação do fenômeno de softening do biopolímero. 


\section{Capítulo 5}

\section{CONCLUSÕES E SUGESTÕES}

\section{1 - CONCLUSÕES}

Os resultados dos ensaios monotônicos de tração demonstraram de uma maneira geral que o biopolímero possui grande ductilidade. Os gráficos tensão-deformação verdadeira foram analisados em duas velocidades diferentes de ensaio: $5 \mathrm{~mm} / \mathrm{min}$ e $0,8 \mathrm{~mm} / \mathrm{min}$. Verificou-se assim que o módulo de elasticidade praticamente não se alterou (1,34 GPa), ao contrário do valor da tensão de escoamento que foi cerca de $37 \mathrm{MPa}$ para $5 \mathrm{~mm} / \mathrm{min}$ e $33 \mathrm{MPa}$ para $0,8 \mathrm{~mm} / \mathrm{min}$. Além disso, para os ensaios com velocidade de $0,8 \mathrm{~mm} / \mathrm{min}$, a presença do "softening" é menos acentuada. Conclui-se, portanto, que o biopolímero é muito sensível à taxa de deformação. Por fim, os ensaios monotônicos de tração, tanto via extensômetros como via strain-gages, forneceram um coeficiente de Poisson que oscilou entre 0,44 e 0,45. Tendo essa investigação experimental de tração sido efetuada em equipamentos diferentes e de instituições distintas, pode-se considerar os valores confiáveis.

Os resultados dos ensaios monotônicos de compressão, feitos somente sob a velocidade de $0,8 \mathrm{~mm} / \mathrm{min}$, mostram que os níveis de deformação atingidos são bem superiores aos níveis de tração. Além disso, tanto o fenômeno de "softening" como de encruamento são mais acentuados do que nos testes de tração. As curvas tensão-deformação, obtidas com o auxílio do deslocamento do travessão da máquina, forneceram cerca de 1,1 GPa para o módulo de elasticidade e 49 MPa para tensão de escoamento. Posteriormente, a deformação do CP no sentido axial foi medida por um strain-gage colado na direção longitudinal e a tensão instantânea foi obtida com o auxílio de um strain-gage colado na 
direção transversal. $\mathrm{O}$ valor do módulo de elasticidade foi superior (1,56 GPa), o que evidenciou a influência da rigidez da máquina nas medidas realizadas através do travessão. Assim, destaca-se que o valor da tensão de escoamento, medido com o auxílio do strain-gage transversal, foi reduzido (46 MPa), devido ao cálculo do valor instantâneo da tensão atuante.

Tanto os resultados dos ensaios de tração como os de compressão com ciclos de carregamento-descarregamento e re-carregamento demonstraram que as linhas de tendência nos descarregamentos coincidem com a inclinação no regime elástico, além de apresentar laços histeréticos. Caso o descarregamento fosse mantido, verificar-se-ia uma deformação permanente, conclui-se assim que o biopolímero possui um comportamento visco-elastoplástico. Tal comportamento foi evidenciado pelos resultados obtidos dos ensaios com tempo de relaxação.

Os resultados dos ensaios monotônicos da prótese de quadril seguindo especificações da norma ISO 7206-3 demonstraram o sucesso do funcionamento do novo dispositivo utilizado. Mesmo assim, as curvas força versus deslocamento registradas pelo ensaio experimental com a haste apresentam uma forte não linearidade e acentuada perda de rigidez da estrutura no transcorrer do ensaio. Este comportamento pode ser explicado pelo fato de o ensaio da estrutura, segundo a norma ISO 7206-3, ainda apresentar indicações de que a estrutura se deforma na região de fixação durante o ensaio. Por outro lado, na simplificação adotada pela análise computacional na região de fixação entre a haste e o dispositivo, existe a imposição de restrições nodais do tipo "ENCASTRE", que não possibilita nenhum tipo de deformação nessa região. Assim, na comparação entre as duas curvas, ensaio experimental com análise computacional, nota-se a existência de um certo distanciamento entre as duas.

Antes do procedimento descrito acima, a fim de avaliar a consistência do modelo de material representar o comportamento do biopolímero, foram realizadas várias simulações computacionais acerca do comportamento do material a tração e compressão. Os resultados 
computacionais de tração mostram que o Modelo de Drucker-Prager com a curva de plasticidade perfeita foi capaz de representar de forma razoável o comportamento do biopolímero até $11 \%$ de deformação. Acima deste valor, o biopolímero apresentou um certo grau de encruamento juntamente com a presença do fenômeno de "necking", e portanto, adotou-se uma curva de encruamento estimada através de uma metodologia numéricoexperimental. Os resultados encontrados demonstraram que a metodologia aplicada é válida, porém pode ser melhorada com a inclusão de equações que venham contemplar o fenômeno de "softening" bem como os efeitos visco-elásticos.

Os resultados computacionais de compressão mostram que o Modelo de DruckerPrager com a curva de encruamento estimada, com base nos resultados obtidos via straingages, forneceram um resultado razoável até 5\% de deformação longitudinal. Após este valor de deformação, a curva experimental divergiu da curva numérica. Conclui-se, portanto, que a curva de encruamento estimada não foi capaz de fornecer bons resultados para grandes deformações.

\section{2 - SUGESTÕES PARA FUTUROS TRABALHOS}

\section{São propostas Sugestões para trabalhos futuros:}

- Desenvolver um modelo que leve em conta as características viscoelásticas do biopolímero;

- Investigar com maior profundidade tanto o fenômeno de relaxação como o de fluência para a caracterização da componente viscosa do material, necessários para a construção do modelo viscoelástico;

- Utilizar os ensaios de fluência e relaxação de tensões para investigar onde a curva perde a linearidade para uma melhor definição do ponto de escoamento e assim efetuar um estudo de sensibilidade deste parâmetro no comportamento do material na prótese estudada. 
- Realizar estudo de otimização estrutural da prótese, incorporando aos resultados apresentados neste trabalho outros possíveis modelos de material que incorporem as características viscoelásticas do biopolímero;

- Desenvolver estudos de análise do comportamento da prótese quanto à fadiga, eventualmente incorporando conceitos de mecânica da fratura. 


\section{Capítulo 6}

\section{REFERÊNCIAS}

ALEXANDER, J. W. (1985). Leonard's orthopedic surgery of the dog and cat. Philadelphia:

Saunders. p43-48.

AMENDOLA, G. F.; ILHA, M.; BERGER, R.; STEDILE, R.; SCHOSSLER, J. E. (2003). Correção de defeito ósseo femural em cães utilizando implante cortical homólogo conservado em mel. Acta Cirurgica Brasileira. v.18, n.4. São Paulo, Julho/Agosto.

AN, Y. G., VEGTER, H. (2005). Analytical and experimental study of frictional behavior in through-thickness compression test. Journal of Materials Processing Technology. n160.

Pp148-155.

ASTM D638 - 96 (1996). Standard test method for tensile properties of plastics. West

Conshohocken.

ASTM D695 - 96 (1996). Standard test method for compressive properties of rigid plastics.

West Conshohocken.

ASTM D790-96a(1996). Standard test method for flexural properties of unreinforced and reinforced plastics and electrical insulating materials. West Conshohocken.

AZEVEDO, C. R. F.; HIPPERT JR, E. (2002). Failure analysis of surgical implants in Brazil. Engineering Failure Analysis. v9. Pp621- 633

BONINI, S. (1999). Avaliação da resposta inflamatória à poliuretana derivada do óleo de mamona: estudo experimental em camundongos. Ribeirão Preto, 125p. Dissertação (Mestrado). FORP - Faculdade de Odontologia de Ribeirão Preto/USP.

BONINI, S. (2004). Estudo comparativo da resistência transversal, resistência à compressão, dureza superficial e comportamento visco-elástico da resina poliuretana em relação à resina acrílica usada para prótese dental. Ribeirão Preto, 127p. Tese (Doutorado). FORP Faculdade de Odontologia de Ribeirão Preto/USP.

BOYCE, M. C.; ARRUDA, E. M. (1990). An experimental and analytical investigation of the large strain compressive and tensile response of glassy polymers. Polymer Engineering and Science. October. v30. n10.

BRIDGMAN, P.W. (1952). Studies in large plastic flow and fracture. McGraw-Hill: New York. 
BURGESS, E. M.; FORSGREN, S. M. (1982). In: VERMON, N. Orthopedic Rehabilitation. Edinburg. Churchill Livingstone. Cap1, pp. 1-15.

CABEZAS, E.E. \& CELENTANO, D.J. (2004). Experimental and numerical analysis of tensile test using sheet specimens. Finite Elements in Analysis and Design, v.40, p.555-575.

CALIXTO, R. F. E. (2001). Implante de um floculado de resina derivada do óleo de mamona (Ricinus communis) em alvéolo de rato imediatamente após a extração dental. Avaliações histológica e histométrica da biocompatibilidade e da cronologia do reparo ósseo. Ribeirão Preto, 90p. Dissertação (Mestrado). FORP - Faculdade de Odontologia de Ribeirão Preto/USP.

CANN, P. M.; WILLIANSON, B. P.; COY, R. C.; SPIKES, H. A. (1992). The behaviour of greases in elastohydrodynamic contacts. Journal of Physics, D: Applied Physics. V25. N 1 A. pp A124 - A132.

CANTO, R. B. (2001). Projeto e fabricação de moldes para prensagem hidrostática isostática utilizando tecnologias CAD/CAE e prototipagem rápida. São Carlos, 74p. Dissertação (Mestrado) - Escola de Engenharia de São Carlos, Universidade de São Paulo.

CARLSSON, L. A.; PIPES, R. B. (1987). Experimental characterization of advanced composite materials. PRENTICE-HALL, INC. Englewood Cliffs, New Jersey, USA.

CARVALHO, T. L.; ARAÚJO, C.; TEÓFILO, J. M.; BRENTEGANI, L. G. (1997). Histologic and histometric evaluation of rat alveolar wound healing around polyurethane resin implants. International Journal of Oral Maxillofacial Surgery. v26. n2. p149-152.

CHEN, W.; LU, F.; CHENG, M. (2002). Tension and compression tests of two polymers under quasi-static and dynamic loading. Polymer Testing, Volume 21, Issue 2, P113-121.

CHRISTENSEN, G. J. (1996). Ridge preservation: why not? Journal of American Dentist Association. v127. n5. Pp669-670.

CLARO NETO, S. (1997). Caracterizações físico-química de um poliuretano derivado de óleo de mamona utilizado para implantes ósseos. São Carlos, 127p. Tese (Doutorado) Instituto de Química de São Carlos, Universidade de São Paulo.

DOWSON, D.; JIN, Z. M. (1992). Micro elastohydrodynamic lubrification of low-elasticmodulus solids on rigid substrates. In: Frontiers of Tribology. Proceedings of the International Conference on Frontiers of Tribology. Stratford-upon-Avon, UK. Pp. A116A123.

DU PONT INSTRUMENTS (1986). 983 Dynamic Mechanical Analyzer (da Du Pont Instruments): Notas do Manual do Operador. Feito por E.I. du Pont de Nemours \& Co. (Inc.). Concord Plaza - Quillen Building Wilmington, DE. PN983006.001 Rev.B.

EGM - 200 (1969). Diamond tool precision lathe: Operator's manual. Pp. A311-03-2 e A31103-3. Número de série: 156 
ERENO, D. (2003) Polímero derivado de óleo vegetal, sintetizado por químico de São Carlos, ganha mercado internacional. Pesquisa Fapesp. Edição 91. Setembro.

ETCHEBEHERE, E. C. S. C. (1998). Recentes Avanços em Densitometria Óssea. Jornal do Médico. Pp. 7.

FERNEDA, A. B. (1999). Integração Metrologia, CAD e CAM: Uma contribuição ao estudo de Engenharia Reversa. São Carlos. 102p. Dissertação (Mestrado) - Escola de Engenharia de São Carlos, Universidade de São Paulo

FRACHON, A. (2002). Modélisation et Simulation Numérique de la Compression en Matrice de Poudres Métalliques. Grenoble. 252p. Thèse (Doctorat). Institut National Polytechnique de Grenoble.

FRASCINO, L. F. (1998). Implante de resina poliuretana vegetal em cranioplastia: Estudo experimental em coelhos. São José do Rio Preto. 108p. Dissertação (Mestrado). Faculdade de Medicina de São José do Rio Preto.

GARCIA, A.; SPIM, J. A.; SANTOS, C. A. (2000). Ensaios dos materiais. LTC - Livros Técnicos e Científicos Editora S. A.

G'SELL, C.; HIVER, J.M.; DAHOUN, A. (2002). Experimental characterization damage in solid polymers under tension, and its enterrelation with necking. International Journal of Solids and Structures, v.39, p.3857-3872.

HBM (2002). MGCplus: Sistema de aquisição de dados HBM com AB22A / AB32. Manual código B31.MGC PAB22.100en.

HIBBIT, KARLSSON \& SORENSEN (2000). ABAQUS Theory Manual. v2. Version 6.1.

HULSE, D.; HYMAN, D. (1993). Fracture biology and biomechanics: In: Slatter D. Textbook of small animal surgery. Philadelphia: Saunders. p2035-2049.

IGNÁCIO, H. (1995). Utilização do cimento derivado do polímero da mamona no preeenchimento de falha óssea: Estudo experimental em coelhos. Ribeirão Preto, 96p. Dissertação (Mestrado) - Faculdade de Medicina de Ribeirão Preto, Universidade de São Paulo.

IGNÁCIO, H. (1999). Avaliação da poliuretana da mamona nas formas compacta e porosa no preenchimento de falha óssea. Estudo experimental em cães. Ribeirão Preto, 92p. Tese (Doutorado) - Faculdade de Medicina de Ribeirão Preto, Universidade de São Paulo.

JESUS, J. M. H.; CALIL JÚNIOR, C.; CHIERICE, G. O. (1998). Adesivo a base de óleo de mamona para madeiras. Curitiba. p.2063-2971. Congresso Brasileiro de Engenharia e Ciência dos Materiais, 13. Anais Curitiba.

KATTI, K. S. (2004). Biomaterials in total joint replacement. Colloids and Surfaces B: Biointerfaces. n39. Pp.133-142.

KFOURI JR, M. (1999). Comparação entre pinos absorvíveis de poliparadioxanona e de poliuretana da mamona na fixação de segmentos osteocondrais do fêmur distral de coelhos. 
Ribeirão Preto, 108p. Tese (Doutorado) - Faculdade de Medicina de Ribeirão Preto, Universidade de São Paulo.

KHAN, A.; ZHANG, H. (2001). Finite deformation of a polymer: experiments and modeling. International Journal of Plasticity, v.17, p.1167-1188.

KHARMANDAYAN, P. (1997). Estudo da interface de contato entre osso e implantes de poliuretano com e sem carbonato de cálcio, empregando microscopia de luz e eletrônica de varredura em coelhos. São Paulo, 175p. Tese (Doutorado) - Escola Paulista de Medicina, Universidade de São Paulo.

KUHNEN, R. B. (2001). Avaliação do comportamento citológico in vitro do polímero poliuretano de mamona (Ricinus communis). São Paulo, 103p. Dissertação (Mestrado) Faculdade de Medicina, Universidade de São Paulo.

KYOWA (2004a). Strain gages: A complete lineup of high performance strain gages and acessories (catálogo). Código: Cat. No. 101E-U1. Kyowa Electronic Instuments Co., Ltd. Tokyo, Japão.

KYOWA (2004b). Adesivo CC-36 - Manual de instruções. Código: IM-G-052b '99.10. Kyowa Electronic Instuments Co., Ltd. Tokyo, Japão.

LATHAM, B.; GOSWAMI, T. (2004). Effect of geometric parameters in the design of hip implants paper IV. Materials and Design. n25. Pp715-722.

LI, C.; GRANGER, C.; Del SCHUTTE Jr., H.; BIGGERS Jr., S.B.; KENNEDY, J.M.; LATOUR Jr., R.A. (2002). Progressive failure analysis of laminated composite femoral prostheses for total hip asthroplasty. Biomaterials, v.23, p.4249-4262.

LING, Y. (1996). Uniaxial true stress-strain after necking. AMP Journal of Technology, v.5, p.37-48.

MALAYAPPAN, S.; NARAYANASAMY, R. (2003). Observations of barrelling in aluminium solid cylinders during cold upsetting using different lubricants. Materials Science and Technology. v110. p1705-1708.

MALVERN, L.E. (1969). Introduction to the mechanics of a continuous medium. PrenticeHall, Inc: New Jersey.

McCRUM, N. G.; BUCKLEY, C. P.; BUCKNALL, C. B. (1992). Principles of polymer engineering. Oxford Science Publications. Oxford University Press, INC. New York, USA.

MORALES, A. (1999). Emprego experimental da poliuretana derivada do óleo de mamona (Ricinus communis) em implantes lamelares, interlamelares e penetrantes na córnea de coelhos (Oryctolagus cuniculus). São Paulo, 72p. Tese (Doutorado) - Faculdade de Medicina Veterinária e Zootecnia, Universidade de São Paulo.

MURAKAMI, C. R. (2002). Aplicações das resinas poliuretanas derivadas do óleo de mamona, como materiais isolantes elétricos. São Carlos. 123p. Tese (Doutorado) - Escola de Engenharia de São Carlos, Universidade de São Paulo. 
NAGARAJAN, P.; YAO, D. (2004). Forging behavior of nylon. Proceedings da ANTEC, Annual Technical Conference. Chicago, IL., United States. v3. p2892-2896.

NARAYANASAMY, R.; RAO, M. N.; PANDY, K. S. (1993). Mathematical treatment of barreling in porous solid cylinders under axial compression. Transactions of the PMAI. v20. p33-40.

ODOM, E. M.; ADAMS, D. F. (1994). Development of an improved compression specimen geometry for unreinforced polymers. Journal of Testing \& Evaluation. v22. n2. Pp104-110.

OHARA, G. H.; KOJIMA, K. E.; ROSSI J. C.; TELLES, M.; SOARES, T. V. C.; SALOMÃO, C.; SANDA, M. (1995). Estudo experimental da biocompatibilidade do polímero da mamona implantada inta-óssea e intra-articular em coelhos. Acta Ortopédica Brasileira. v3. n2. Pp62-68.

PASCON, E. A. (1999). Projeto biocompatibilidade dos materiais endodônticos:

Biocompatibilidade da resina poliuretana derivada da mamona. Ribeirão Preto, $167 \mathrm{p}$. Tese (Doutorado) - Faculdade de Odontologia de Ribeirão Preto, Universidade de São Paulo.

PLEPIS, A. M. S. (1991). Caracterização térmica e viscoelástica de resinas poliuretanas derivadas de óleo de mamona. São Carlos, 155p. Tese (Doutorado) - Instituto de Química de São Carlos, Universidade de São Paulo.

RAVI-CHANDAR, K.; MA, Z. (2000). Inelastic Deformation in Polymers under Multiaxial Compression. Mechanics of Time-Dependent Materials. v4. n4. Pp333-357.

ROMERO, T. (2005). Tratamento econômico. Agência Fapesp. http://www.agencia.fapesp.br/boletim dentro.php?data[id materia boletim] $=3666$.

SCHAPERY, R.A. (2000). Nonlinear viscoelastic solids. International Journal of Solids and Structures. n37. Pp 359-366.

SHACKELFORD, J.F. (1996). Introduction to materials science for engineers, $4^{\text {th }}$ edition. Prentice-Hall, Inc: New Jersey.

SILVA, I. J. (1996). Contribuição ao estudo da utilização da resina poliuretana a base de óleo de mamona na construção civil. São Carlos. 163p. Dissertação (Mestrado) - Escola de Engenharia de São Carlos, Universidade de São Paulo.

SILVA, R. V. (2003). Compósito de resina poliuretano derivado de óleo de mamona e fibras vegetais. São Carlos. 139p. Tese (Doutorado) - Escola de Engenharia de São Carlos, Universidade de São Paulo.

SILVESTRE FILHO, G. D. (2001). Comportamento mecânico do poliuretano derivado de óleo de mamona reforçado por fibra de carbono: contribuição para o projeto de hastes de implante de quadril. Dissertação, Mestrado. Escola de Engenharia de São Carlos Universidade de São Paulo. 155p. 
SIMÕES, J. A.; MARQUES, A. T.; JERONIMIDIS, G. (2000). Design of a controlledstiffness composite proximal femural prosthesis. Composite Science and Technology, v.60, p.559-567.

SIMÕES, J. A.; MARQUES, A. T. (2001). Determination of sttifness properties of braided composites for the design of a hip prosthesis. Composites: Part A, v.32, p.655-662.

VIANNA, D. L. (1997). Estudo comparativo da resistência mecânica da poliuretana derivada de óleo vegetal submetida à ensaios de tração. Ribeirão Preto e São Carlos, 67p. Dissertação (Mestrado) - Faculdade de Medicina de Ribeirão Preto e Escola de Engenharia de São Carlos, Universidade de São Paulo.

VINSON J. R. and SIERAKOWSKI R. L. (1986). Behavior of Structures Composed of Composite Materials. Dordrecht, The Netherlands, Martinus Nijhoff.

VITALI, M. (1986). Amputations and Prostheses. 2ed. London. Editora Ballieri Tendall. pp. $1-10,28-40$.

WILSON JR., A. B. (1981). History of amputation sugery and prosthetics. In: American Academy of Orthopaedics Surgeons. Atlas of limb prosthese - surgical and prosthetic principles. The Mosby Company. St Louis. Cap. 1, p. 1-13.

WILLIAMS, J. G. (1973). Stress analysis of polymers. Longman Group Limited: London.

WILLIAMS, D. F. (1987). Definitions in biomaterials. Elsevier. New York.

WEIGEL, P. J. (1993). Bone grafting: In: Bojrab JM. Disease mechanisms in small animal surgery. 2ed. Philadelphia: Lea \& Febiger. p678-685.

WREGGE, P. A. S. (2000). Metodologia para obtenção de esferas de cerâmica para próteses de quadril. São Carlos, 186p. Tese (Doutorado). Escola de Engenharia de São Carlos Universidade de São Paulo.

WU, J. Z.; DONG, R. G.; SCHOPPER, A. W. (2004). Analysis of effects of friction on the deformation behavior of soft tissues in unconfined compression tests. Journal of Biomechanics. v37. Pp147-155.

YILDIZ, H.; HA, S-K; CHANG, F-K. (1998). Composite hip prosthesis design. J. Biomed. Mater. Res., v.39, p.92-101.

YOUNG, R.J. \& LOVELL, P.A. (1991). Introduction to polymers. Second edition. Chapman \& Hall: London.

ZHANG, Z.L.; HAUGE, M.; ODEGARD, J.; THAULOW, C. (1999). Determining material true stress-strain curve from tensile specimens with rectangular cross-section. International Journal of Solids and Structures, v.36, p.3497-3516.

ZHANG, Z.L.; ODEGARD, J.; SOVIK, O.P. (2001). Determining true stress-strain curve for isotropic and anisotropic materials with rectangular tensile bars: method and verifications. Computational Materials Science, v.20, p.77-85. 
